\title{
Estudo e avaliação de Educação à Distância utilizando a tecnologia WWW
}

Mônica Giacomassi de Menezes de Magalhães

Dissertação apresentada ao Instituto de Física de São Carlos, da Universidade de São Paulo, para obtenção do título de mestre em Ciências: Física Aplicada opção Física Computacional.

Orientador: Prof. Dr. Dietrich Schiel

SÃO CARLOS 
Magalhães, Mônica Giacomassi de Menezes de

Estudo e avaliação de Educação à Distância utilizando a tecnologia WWW / Mônica Giacomassi de Menezes de Magalhães. São Carlos, 1997.

$154 \mathrm{p}$.

Dissertação (Mestrado) - Instituto de Física de São Carlos, 1997.

Orientador: Prof. Dr. Dietrich Schiel

1. Educação à Distância. 2. Internet. 3. WWW. 4. Ensino de Física 
Ao meu marido, Luís Eduardo, pelo amor, apoio e compreensão; aos meus pais, Eunice e Francisco, pelo amor, incentivo e oportunidades e à minha querida irmã, Maria Fernanda, por todo carinho, amor e apoio. 


\section{Agradecimentos}

Ao Prof. Dr. Dietrich Schiel, pela orientação, confiança e amizade elementos estes fundamentais que possibilitaram a realização deste trabalho.

Ao Prof. Dr. Álvaro Garcia Neto, pela atenção à pesquisa realizada.

Ao Prof. Dr. Januário Sylvio Pezzotti, pela valiosa atenção e revisão.

À Profa. Íria Müller Guerrini, por todo o apoio, incentivo e amizade.

Às secretárias do CDCC/USP, Edna R. O. Ferreira e Renata Grilli, pela ajuda, dedicação e amizade.

À Célia Gobbo, assistente técnico-pedagógica da Delegacia de Ensino de Americana, e à Profa. Wallesandra Araújo Silva da E. E. P. S. G. João XXIII de Americana, pelo auxílio prestado durante a realização do teste piloto.

À bibliotecária do CDCC/USP, Silvelene, por toda a sua atenção.

Aos funcionários do CDCC/USP, entre eles, Silvia, Sônia, Miriam, Godoy, Otávio, S. João e D. Maria, e ao amigo Rafael.

À Wladerez A. G. Caiado, por sua dedicação e atenção aos alunos da PósGraduação.

Às funcionárias da Biblioteca do IFSC/USP, pela valiosa assistência.

Ao amigo e companheiro de trabalho, analista de sistemas Sérgio Luis Antonello, pela amizade sincera e pelo apoio nos momentos mais difíceis.

Ao ex-supervisor do CEAPLA/UNESP Prof. Dr. Gilberto José Garcia e à atual supervisora Profa. Dra. Juraci Zani dos Santos, pelo apoio prestado e pela amizade.

Aos funcionários do CEAPLA/UNESP: Lucila, Lucimari, Claudio, Juliene, Carlo e Niuro, e aos funcionários e professores do Depto. de Cartografia da UNESPRio Claro, pela amizade.

À minha tia, Leni Giacomassi, pelo constante incentivo e pela torcida.

À todos os meus familiares, por todo o apoio recebido.

Obrigada Senhor, pelas oportunidades, pela minha família e por todos os amigos que encontrei ao longo de mais uma caminhada.

Obrigada Nossa Senhora, por me guiar e orientar os meus passos. 


\title{
Sumário
}

\author{
Lista de Figuras
}

Lista de Tabelas

Lista de Abreviaturas

Resumo

Abstract

1. Introdução .............................................................................................. 1

2. Educação à Distância (EAD) ............................................................. 3

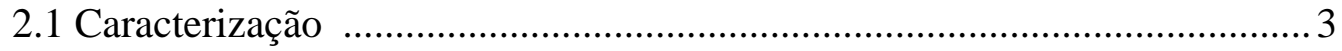

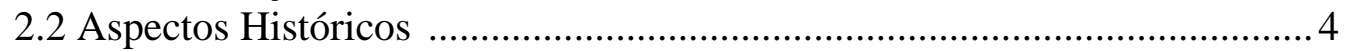

2.2.1 Cursos por Correspondência ......................................................... 7

2.2.2 Open Universities ......................................................................... 7

2.2.3 Transmissão Via Rádio, Via TV e a Teleconferência ........................ 8

2.2.4 Multimídia e Redes de Computadores ..........................................10

2.2.5 Situação Atual ...........................................................................11

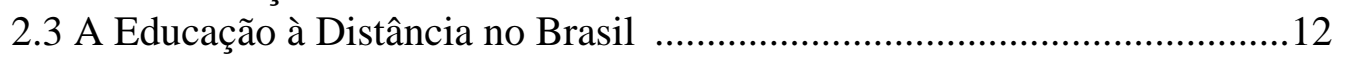

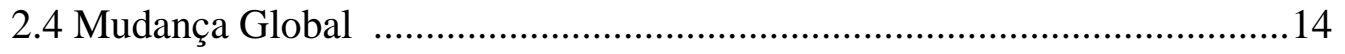

3. Estrutura de um Sistema de Educação à Distância ........................16

3.1 Considerações Gerais ..........................................................................16

3.2 Aspectos Operacionais de um Sistema de Educação à Distância................18

3.2.1 O Aluno da Educação à Distância ................................................19

3.2.2 O Professor da Educação à Distância ..............................................20

3.3 A Qualidade da Educação à Distância ....................................................21

3.4 Fases de um Sistema de Educação à Distância .........................................22

3.4.1 Planejamento e Projeto ..................................................................25

3.4.2 Desenvolvimento e Implementação ................................................25

3.4.3 Avaliação .................................................................................25

3.4.3.1 Tipos de Avaliação ........................................................28

a) Avaliação Formativa ..................................................28

b) Avaliação Somativa ......................................................28

3.4.3.2 Métodos de Coleta de Dados ............................................29

4. Uso da Internet na Educação ....................................................... 31

4.1 Evolução das Tecnologias Educacionais ...................................................31

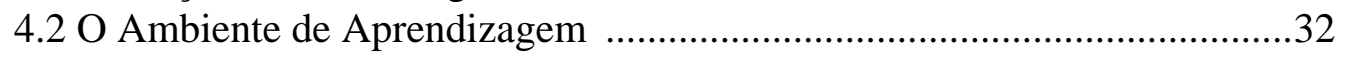

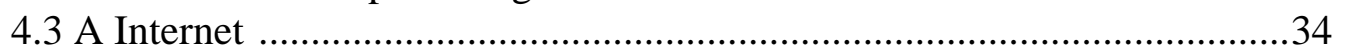




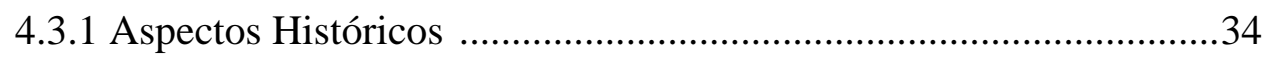

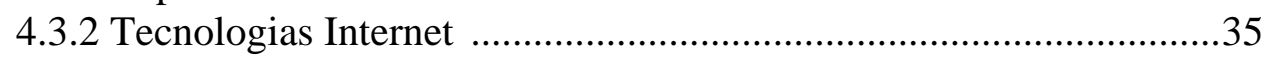

5. A World-Wide Web (WWW) .......................................................... 38

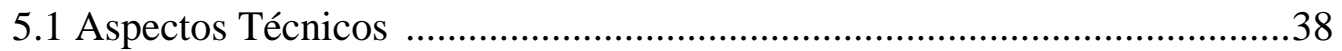

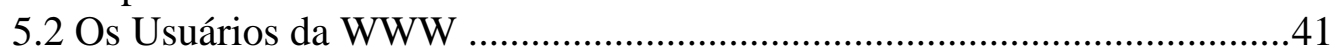

5.3 Características da Linguagem HTML ..................................................41

6. Aspectos Educacionais da WWW ..................................................... 48

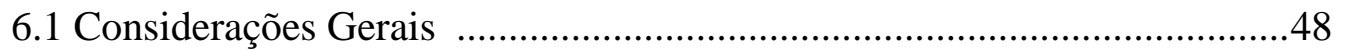

6.2 Características Educacionais da WWW ................................................49

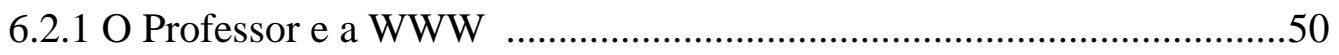

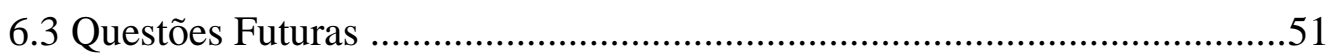

6.4 Educação à Distância Usando a Tecnologia WWW ..................................52

6.4.1 Projeto de Documentos WWW ........................................................54

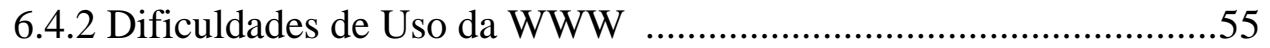

6.4.3 Custos dos Cursos Via WWW ........................................................55

7. Avaliação de Programas de Educação à Distância ........................ 57

7.1 Considerações Gerais .............................................................................57

7.2 Projeto New Directions in Distance Learning (NDDL) ..........................57

7.3 Commonwealth Graduate Engineering Program ...................................59

7.4 English as a Second Language Course (ESL) ........................................61

8. Programa Educ@r ..........................................................................63

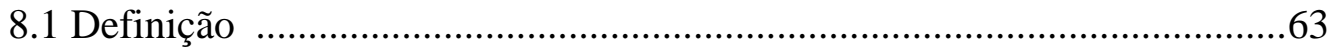

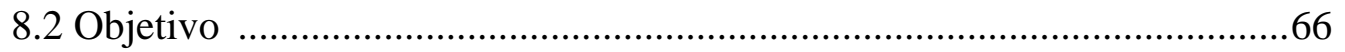

8.3 O Curso de Mecânica Gráfica .............................................................66

9. Metodologia de Avaliação do Programa Educ@r ...........................68

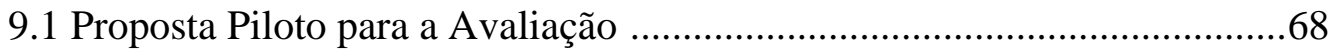

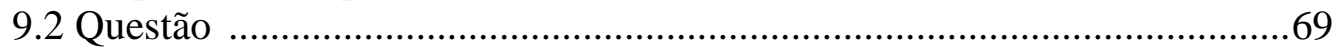

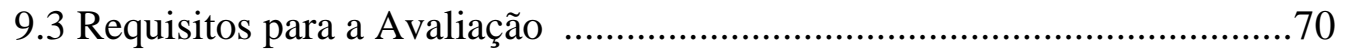

9.4 Desenvolvimento dos Mecanismos de Avaliação ......................................70

9.5 Descrição das Atividades Avaliadas .........................................................71

9.5.1 Curso em Americana - Nov./Dez. 1996 .............................................71

9.5.2 Curso em Americana - Abril/Maio 1997 ..........................................73

9.5.3 Treinamento de Professores - Jan. 1997 ........................................74

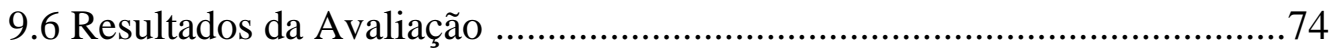

9.6.1 Cursos com Alunos ......................................................................75

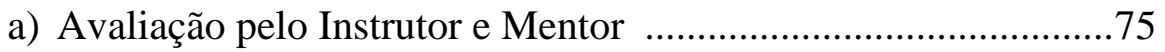

b) Avaliação pelos Alunos ............................................................77

9.6.2 Curso com Professores ...................................................................83

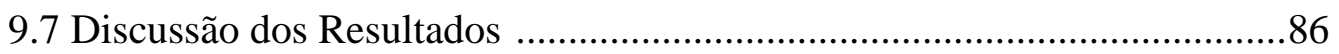

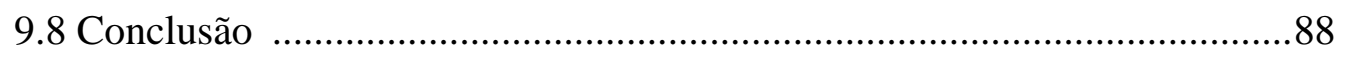

9.8.1 Importância deste Trabalho ............................................................88

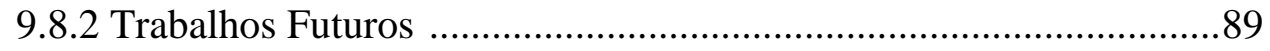




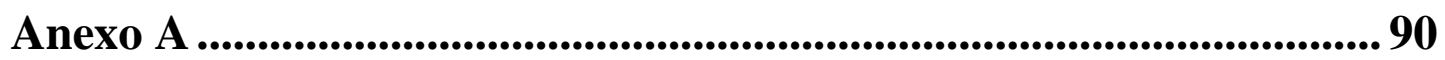

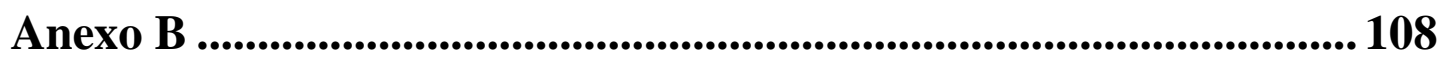

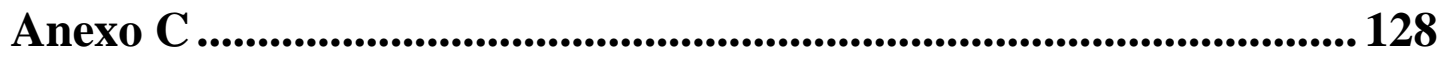

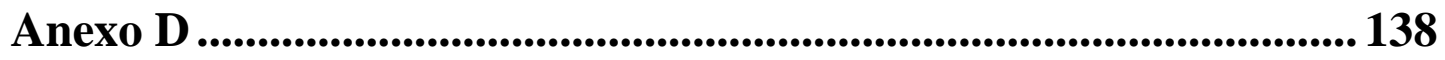

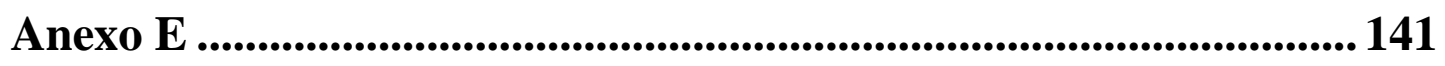

Referências Bibliográficas .......................................................................... 144

Bibliografia Complementar ...................................................................... 152

Apêndice

Glossário 


\section{Lista de Figuras}

Figura 1 - Um modelo de interação no Programa Educ@r. ......................................18

Figura 2 - Processo de desenvolvimento instrucional............................................23

Figura 3 - Fases de um sistema de Educação à Distância. .........................................24

Figura 4 - Um exemplo de escala Likert de 7 níveis. ...............................................30

Figura 5 - Configuração Cliente-Servidor da WWW. ..............................................40

Figura 6 - Exemplo de uma tabela na WWW. ......................................................43

Figura 7 - Exemplo de um documento HTML. ..............................................44 e 45

Figura 8 - Apresentação de um documento HTML pelo browser Explorer. .............46

Figura 9 - Cena da interação entre o aluno e um software instrucional via WWW. .54

Figura 10 - Resultados obtidos na avaliação 1994/95, relativos às tecnologias utilizadas no Projeto NDDL. ................................................................58

Figura 11 - Exemplo de uma tabela interativa do curso de Mecânica Gráfica. ........64

Figura 12 - Exemplo de uma tabela interativa preenchida. .65

Figura 13 - Esquema simplificado de uma conexão à Internet do Projeto de Física do Programa Educ@r. .........................................................................67

Figura 14 - Fases para o desenvolvimento de um sistema de avaliação inicial. 69

Figura 15 - Evolução do nº de alunos participantes nos cursos de Mecânica Gráfica em 1996/97.

Figura 16 - Avaliação formativa pelo instrutor e pelo mentor durante o $2^{\circ}$ semestre de 1996.

Figura 17 - Avaliação pelos alunos do $1^{\circ}$ Colegial noturno da E. E. P. S. G. João XXIII. .78

Figura 18 - Avaliação formativa pelos alunos do $2^{\circ}$ Colegial noturno da E. E. P. S. G. João XXIII no $2^{\circ}$ semestre de 1996.

Figura 19 - Avaliação formativa pelos alunos do $1^{\circ}$ Colegial noturno da E. E. P. S. G. João XXIII no $1^{\circ}$ semestre de 1997.

Figura 20 - Avaliação do curso de treinamento de instrutores em Jan. 1997. .86

Figura 21 - Comparação das avaliações pelos alunos no período de 1996 a 1997. ..87 


\section{Lista de Tabelas}

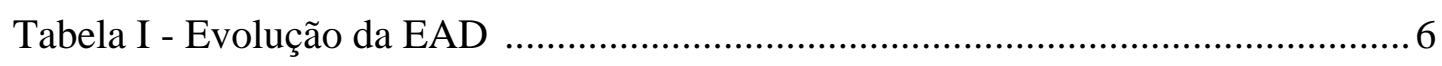

Tabela II - Resultados obtidos através de questionários usando a escala Likert. .....60

Tabela III - Resultados obtidos através de feedback escrito pelos alunos. ................60

Tabela IV - Resultados preliminares da avaliação. .....................................................62

Tabela V - Resultados da avaliação final em 1996. ……………………………….....79

Tabela VI - Resultados da avaliação final em 1996. ..................................................79 


\title{
Lista de Abreviaturas
}

\author{
ABED - Associação Brasileira de Educação à Distância \\ ARPA - American Department of Defense Advanced Research Projects Agency \\ ARPAnet - Advanced Research Projects Agency Network \\ BBS - Bulletin Board System \\ CDCC - Centro de Divulgação Científica e Cultural \\ EAD - Educação à Distância \\ E-mail - Electronic Mail ou correio eletrônico \\ ESL - English as a Second Language \\ ETV - Educational TV \\ FIESP - Federação de Indústrias do Estado de São Paulo \\ FRM - Fundação Roberto Marinho \\ FTP - File Transfer Protocol \\ HTML - HypeText Mark-up Language \\ HTTP - HyperText Transfer Protocol \\ IP - Internet Protocol \\ ITV - Interactive TV \\ NDDL - New Directions in Distance Learning \\ PC - Personal Computer ou Computador pessoal \\ TCP/IP - Transmission Control Protocol/Internet Protocol \\ URL - Uniform Resource Locator \\ UUCP - Unix-to-Unix Copy \\ VRML - Virtual Reality Modelling Language \\ WAIS - Wide Area Information Service \\ WWW - World-Wide Web
}




\section{Resumo}

O presente trabalho tem como finalidade o estudo e a aplicação de mecanismos de avaliação para controlar a qualidade dos cursos à distância via WWW, de forma que possam ser aprimorados. São pesquisados ainda, os aspectos históricos da Educação à Distância (EAD), usando diversas tecnologias; a estrutura de um sistema de EAD; a utilização da Internet nesta área; a tecnologia WWW e seus aspectos educacionais e as avaliações de programas de EAD em instituições internacionais. Mecanismos de avaliação são adaptados e aplicados em teste piloto de um programa de EAD - o Programa Educ@r, - através do curso de Física realizado numa escola estadual da cidade de Americana, Estado de São Paulo. Métodos de avaliação do curso à distância e análise dos dados, são sugeridos e aplicados durante o período. São realizadas avaliações formativas e finais através de questionários respondidos por alunos, professor presente e professor distante, cujos resultados estão, na escala Likert entre "Bom” e "Muito Bom”, para os alunos e “Médio” e “Muito Bom” para os professores. Também são apresentados os resultados de uma avaliação do curso de treinamento de instrutores, realizado no Centro de Divulgação Científica e Cultural da USP - São Carlos. Estes resultados estão na escala Likert, entre “Bom” e “Muito Bom”. 


\section{Abstract}

The purpose of the present work is the study and the application of evaluation mechanisms to highlight distance course strengths and weaknesses, allowing to control its quality and to accomplish improvements. They are also studied, the historical aspects of Distance Education (EAD), using several technologies; the structure of a system of EAD; the use of the Internet in this area; the technology WWW and its educational aspects and the evaluations of programs of $\mathrm{EAD}$ in international institutions. Evaluation mechanisms are adapted and applied in pilot test of a program of EAD - the "Programa Educ@r”, - through Physics course offered in a public high school in Americana, State of São Paulo. Evaluation methods of distance course and data analysis, are suggested and applied during the period. Formative and final evaluations are administered through questionnaires answered by students, onsite teacher and distance teacher, whose results are, in the Likert scale between "Good” and "Very Good", for the students and "Average” and "Very Good" for the teachers. The results of an evaluation of the instructors' training course are also presented, conducted in the Center of Scientific and Cultural Divulgation in São Carlos, University of São Paulo. These results are in the Likert scale, between “Good” and "Very Good”. 


\section{Introdução}

Com o avanço das tecnologias de comunicação aplicadas ao ensino, cada vez mais a Educação à Distância (EAD) se apresenta como uma das maneiras para se resolver o problema da concentração das potencialidades em alguns centros de excelência. É um meio eficaz para se levar estas potencialidades a locais que não possuem tanta tecnologia e estão geograficamente distantes de centros mais desenvolvidos. Os programas de EAD vêm se intensificando e se tornando uma das tendências mais marcantes dos últimos tempos, inovando totalmente a forma de aprendizagem e possibilitando vários tipos de interação entre alunos e professores.

O desenvolvimento de material para a EAD utilizando a tecnologia World-Wide Web (WWW) em São Carlos mostrou, devido à novidade desta tecnologia, a dificuldade em se encontrar um referencial técnico para o assunto em si e a questão importante da avaliação da EAD neste contexto. O objetivo deste trabalho é preencher essa lacuna, de utilidade aos grupos que se lançam hoje à tarefa de contribuir com propostas práticas para a consolidação desta tecnologia. Para isto, foi realizada uma avaliação de um curso à distância, na fase de sua implantação, com destaque para as opiniões de alunos e professores participantes, mostrando métodos de coleta e análise de dados e a necessidade de haver um sistema de avaliação continuada do programa de EAD. Portanto, para atingir o objetivo deste trabalho, avaliou-se apenas o processo em relação à tecnologia utilizada, à interação aluno/instrutor/mentor, ao suporte técnico, ao material do curso e ao feedback. Não foi avaliado o conhecimento do aluno e também não foi avaliado se a EAD, utilizando a tecnologia WWW, fornece aprendizagem. 
Procuramos redigir um texto que, além de se constituir num relato de pesquisa, fosse uma leitura interessante tanto para um não especialista em computação quanto em educação. Desta forma, estão inseridas revisões dos temas técnicos mais correntes. Dada a novidade do tema e as dificuldades em encontrar referências bibliográficas, procuramos apresentar a bibliografia mais extensa possível. 


\section{Educação à Distância (EAD)}

\subsection{Caracterização}

O termo Educação à Distância, segundo Geber (1991), apareceu primeiramente impresso em 1892 no catálogo de cursos da University of Wisconsin Madison, sendo também popularizado em outros países como Alemanha, França e Austrália.

A EAD é caracterizada:

- pela separação do professor e do aluno no espaço e/ou tempo (Keegan, 1986; Perraton, 1988; McIsaac \& Gunawardena, 1997);

- o controle da aprendizagem é realizado mais intensamente pelo aluno do que pelo professor instrutor (Jonassen, 1992);

- a interação entre alunos e professores é mediada por alguma forma de tecnologia (Keegan, 1986; Garrison \& Shale, 1990; Kearsley, 1995).

“A Educação à Distância é uma aprendizagem planejada que normalmente ocorre em um local diferente do tradicional e como resultado requer projeto de curso e técnicas instrucionais especiais, métodos especiais de comunicação eletrônica e outra tecnologia, bem como sistemas organizacionais e administrativos especiais” (Moore \& Kearsley, 1996).

As tecnologias utilizadas para fornecer informação na EAD tem o objetivo de promover interação entre professor/aluno e fornecer o feedback 
necessário para o aluno à distância (McIsaac \& Gunawardena, 1997). Por isso, o emprego da informática em um sistema de EAD pode viabilizar melhorias na qualidade de ensino, em larga escala e a custos reduzidos. A interatividade pode ser incorporada neste processo através da hipermídia interativa, a qual integra textos, imagem, vídeo, fotos, som e animação, proporcionando um ambiente de ensino atraente, envolvente e multissensorial (Salvador, 1995). A autora conclui que "a hipermídia interativa é uma tecnologia chave para a educação nos anos 90 ...”. Podese usufruir dos benefícios da hipermídia na EAD utilizando a tecnologia mais recente e que mais cresceu nos últimos tempos, a Internet, que através dos recursos WorldWide Web (WWW) pode-se “navegar” e interagir com hiperdocumentos.

Tecnologias anteriores de EAD como correio, TV e vídeo, têm tendências para um ensino com pouca interação. Ao contrário da WWW, por exemplo, que é uma ferramenta descentralizada e cria o potencial para novas formas de interação entre alunos, reativando a crença de que "a tecnologia aumenta a educação” (Dillenbourg \& Schneider, 1995).

\subsection{Aspectos Históricos}

A EAD é uma atividade que existe há muito tempo através dos cursos por correspondência, via rádio, pela TV como os Telecursos e, mais recentemente, cursos via Internet utilizando os recursos da tecnologia WWW (Magalhães \& Schiel, 1996). Durante os últimos 30 anos, o ambiente de EAD tem mudado rápida e constantemente. Tem se tornado um veículo viável para o fornecimento de novos e avançados cursos a alunos de todas as idades (Barbrow, et al., 1996) e de qualquer localização geográfica. Muitas das mudanças que têm ocorrido na EAD se devem às aplicações de novas tecnologias para melhorar os aspectos do processo de ensinoaprendizagem (Oliver, /199 /; McIsaac \& Gunawardena, 1997).

Durante a pesquisa realizada pode-se perceber que houve mais do que um caminho histórico para a EAD e sua evolução não foi fácil (Jeffries, 1995). Primeiro o correio, depois o rádio e a televisão foram usados para alcançar alunos isolados, até em áreas rurais. Hoje, o vídeo, o áudio e tecnologias de rede são 
adaptadas não somente para diminuir as distâncias entre alunos e professores ou para compensar lacunas educacionais, mas também para fornecer novas experiências educacionais (Grimaldi, 1995). Quatro estágios da evolução da EAD serão descritos historicamente: cursos por correspondência; Open Universities; transmissão via rádio, via TV e teleconferência; multimídia e redes de computadores. 
Tabela I - Evolução da EAD

\begin{tabular}{|c|c|c|c|}
\hline Início & Estágios da EAD & Tecnologias Utilizadas & Ensino-aprendizagem \\
\hline $\begin{array}{l}\text { aproximadamente } \\
\text { em } 1840\end{array}$ & Cursos por Correspondência & $\begin{array}{l}\text { no início o correio, atualmente } \\
\text { também utiliza-se o telefone, fax e o } \\
\text { e-mail. }\end{array}$ & $\begin{array}{l}\text { - alunos trabalham sozinhos; } \\
\text { - interação limitada; } \\
\text { - ênfase nos exames e testes. }\end{array}$ \\
\hline 1950 & Open Universities & rádio, TV e outros meios. & $\begin{array}{l}\text { - uso de grupos de desenvolvimento de } \\
\text { curso; } \\
\text { - uso de tutores; } \\
\text { - centros de estudos regionais; } \\
\text { - inclusão de áudio e vídeo. }\end{array}$ \\
\hline Década de 70 & Teleconferência & TV via Satélite & $\begin{array}{l}\text { - grupos de alunos juntos em cada site; } \\
\text { - interação em tempo real entre alunos e } \\
\text { instrutor. }\end{array}$ \\
\hline Década de 80 & $\begin{array}{l}\text { Multimídia e } \\
\text { Redes de Computadores }\end{array}$ & $\begin{array}{l}\text { uso do computador com recursos de } \\
\text { multimídia e redes. }\end{array}$ & $\begin{array}{l}\text { Representa caminhos para: } \\
\text { - apresentar a informação; } \\
\text { - fornecer mais interação entre alunos e } \\
\text { instrutores do que as tecnologias } \\
\text { anteriores. }\end{array}$ \\
\hline Década de 90 & $\begin{array}{l}\text { o meio mais evidente continua } \\
\text { sendo o computador, através de } \\
\text { softwares educativos e da Internet. }\end{array}$ & Multimídia e Internet. & \\
\hline
\end{tabular}




\subsubsection{Cursos por Correspondência}

Os cursos por correspondência foram a primeira forma de EAD e tiveram seu início na Europa (Sherry, 1996). Em 1840, na Grã Bretanha, Isaac Pitman começou a ensinar taquigrafia por correspondência. Em 1856, um francês, Charles Toussaint, e um alemão Gustav Langenscheidt começaram a ensinar línguas por correspondência. Nos Estados Unidos, a respeitabilidade acadêmica do curso por correspondência foi reconhecida formalmente em 1883, quando Chautauqua Institute foi autorizado pelo Estado de New York a fornecer diploma através deste método (Moore \& Kearsley, 1996). Os países da América Latina e Espanha começaram a demonstrar interesse pela EAD na década de 60, sendo o curso por correspondência primeiramente utilizado por empresas privadas para treinamento de funcionários (Roberts, 1996).

Muitas universidades, desde 1890 até os dias atuais, oferecem cursos por correspondência para alunos que não podem freqüentar as aulas normalmente (White \& Thomas, 1995; Moore \& Kearsley, 1996; Sherry, 1996). Esta forma de EAD utiliza materiais impressos distribuídos pelo correio e ainda é empregada nos dias de hoje, também utilizando áudio, vídeo ou até softwares de computadores, como materiais do curso. A princípio, a interação entre aluno e instrutor nos cursos por correspondência era via correio, porém atualmente também são utilizadas novas tecnologias, como o telefone, o fax e o correio eletrônico (e-mail ou electronic mail).

De uma perspectiva ensino-aprendizagem, o que é significante nesta forma de EAD é que os alunos trabalham sozinhos e têm pouca interação com o instrutor. Uma das questões mais importantes no curso por correspondência é verificar se o aluno tem completado os requisitos de aprendizagem; por isto, é dada uma ênfase maior aos exames e testes (Moore \& Kearsley, 1996).

\subsubsection{Open Universities}

A partir de 1950, as instituições de ensino primário, secundário e superior à distância, começaram a fornecer diplomas próprios reconhecidos e a 
usufruir da tecnologia via rádio, TV e outros meios como veículos de ensino à distância (White \& Thomas, 1995; Sherry, 1996) dando um avanço para o desenvolvimento das Open Universities. A idéia foi que, usando essas mídias e eliminando os pré-requisitos para os cursos, estes poderiam ser oferecidos por um preço mais acessível para muitas pessoas. A primeira Instituição a usar esta forma de EAD foi a British Open University estabelecida em 1969, sendo que hoje há várias Open Universities pelo mundo (Moore \& Kearsley, 1996; McIsaac \& Gunawardena, 1997).

Quanto ao processo de ensino-aprendizagem, esta forma de EAD introduziu alguns elementos novos, como o uso de grupos de desenvolvimento de cursos, o uso de tutores, centros de estudos regionais e a inclusão de áudio e vídeo (Moore \& Kearsley, 1996).

\subsubsection{Transmissão Via Rádio, Via TV e a Teleconferência}

A transmissão educacional via rádio, nos Estados Unidos, é praticada desde a década de 20, quando em 1923, o rádio foi primeiramente usado por educadores na New York High School (Barron, 1996). A primeira licença do rádio educacional foi emitida pelo Governo Federal dos Estados Unidos, em 1921, para $a$ Latter Day Saints University da cidade de Salt Lake e, em 1922, as University of Wisconsin e University of Minnesota também receberam licenças para estabelecer estações de rádio educacional (Saba, 1996).

A TV foi usada pela University of Iowa, em 1933, antes de se tornar um meio comercial (Barron, 1996). E em 1945, esta mesma Universidade começou a transmitir programas educacionais, tornando-se a primeira transmissora ETV Educational TV - do mundo (Saba, 1996). Desde então, a TV foi um componente dos cursos à distância e com o advento da TV a cabo, em 1972 a Federal Communications Commission (FCC) requisitou todos os sistemas a cabo para fornecer um canal educacional (Moore \& Kearsley, 1996). No meio desta década, os satélites começaram a ser usados para transmissão via TV e a idéia de teleconferência começou a surgir. Atualmente a teleconferência possui quatro tipos: 
Audioconferência, Audiographics, Videoconferência e Conferência por computador (Moore \& Kearsley, 1996):

a) Na Audioconferência, a transmissão de uma aula é feita por telefone, usando linhas públicas. Necessita-se de um locutor, de microfones e de diferentes grupos de alunos à distância.

b) Sistemas Audiographics: envolvem o uso de computadores ou FAX para transmitir imagens visuais e a interação é feita através de linhas telefônicas.

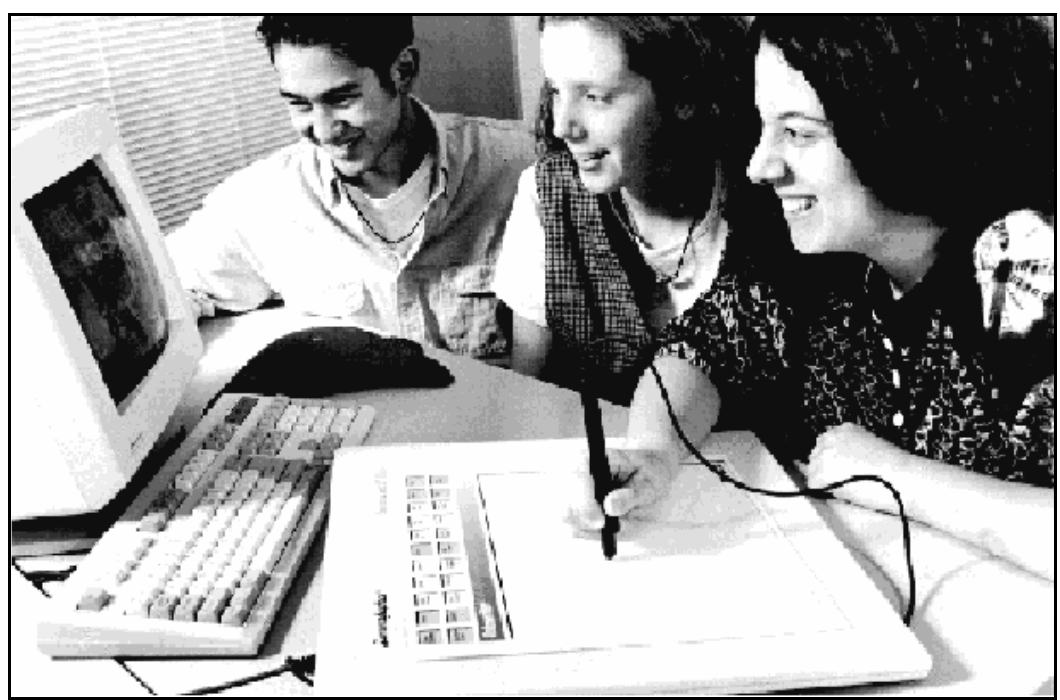

Alunos usando uma mesa digitalizadora, caneta óptica, microfone e computador, em uma sessão Audiographics, com um professor distante. Fonte: Porter, et al. (1995).

c) Videoconferência Two-way: permite uma interação face a face entre alunos e instrutor, fornecendo comunicações de vídeo e áudio. Pode ser transmitida via satélite, cabo, por vídeo comprimido (transmissão de 10 a 15 frames/s. e necessita de uma linha telefônica especial que é muito cara) ou vídeo "slow-scan" (transmite de 20 a 30 frames/s. e usa linha telefônica comum, tendo o mesmo custo da Audioconferência e Audiographics).

d) Conferência por computador: permite uma interação entre alunos e instrutor, via rede de computadores. Pode-se enviar mensagens por email e transmitir arquivos de dados uns aos outros. O computador é conectado a uma rede, por uma linha telefônica, através de um modem.

No final da década de 70, a EAD via rádio declinou, e o uso da TV 
aumentou, introduzindo-se séries educativas de televisão projetadas para os alunos, e que ainda são consideradas importantes complementos para a sala de aula (White \& Thomas, 1995; Sherry, 1996). A teleconferência adicionou duas importantes dimensões para a EAD: grupos de alunos juntos em cada local e interação em temporeal entre alunos e instrutor (Moore \& Kearsley, 1996).

\subsubsection{Multimídia e Redes de Computadores}

Com a difusão dos computadores pessoais (PC’s), duas novas tecnologias começaram a viabilizar propósitos de EAD: a multimídia e as redes de computadores (como a Internet). Estas tecnologias estão disponíveis desde o início da década de 80 até o presente momento (Moore \& Kearsley, 1996; Saba, 1996). Com a multimídia pode-se usufruir dos recursos de áudio, vídeo, animação e hipertextos ${ }^{1}$, enriquecendo os materiais do curso, e pode-se armazenar grande volume de dados em CD-ROM, facilitando a distribuição do material aos alunos com baixo custo. Com as redes de computadores pode-se usufruir de e-mail, troca de arquivos, conferência por computador, entre outros.

Nos anos 90, o meio de comunicação mais evidente utilizado na educação está sendo o computador, através de softwares educativos utilizando tecnologias de multimídia, e através da Internet, utilizando os recursos de hipermídia da tecnologia WWW.

Quanto ao processo de ensino-aprendizagem, estes desenvolvimentos representam caminhos para apresentar a informação e fornecer mais interação entre alunos e instrutores do que as tecnologias anteriores, tornando a EAD mais plausível e poderosa (Moore \& Kearsley, 1996). No futuro, as redes de EAD precisarão ser projetadas para aumentar a comunicação e o processo de aprendizagem na sala de aula (Comeaux, 1995).

\subsubsection{Situação Atual}

De um modo geral, os equipamentos e infra-estrutura para a EAD estão 
se tornando mais baratos, mais confiáveis, mais disponíveis e mais acessíveis ao usuário. Nos últimos dez anos pode-se perceber uma grande expansão deste tipo de educação, tornando-a muito popular. Isto se deve à algumas razões (White \& Thomas, 1995):

1. A EAD pode ampliar as oportunidades educacionais em países onde há escassez de recursos;

2. Oferece respostas flexíveis em uma época em que as pessoas estão exigindo tipos de educação e treinamentos diversificados, não podendo ser encontrados em escolas tradicionais;

3. Oferece meios rápidos de atualização do conhecimento técnico, mesmo em países onde se encontra pouca ou nenhuma modernização.

Atualmente há grandes interesses políticos e públicos na EAD, em especial, onde a população é largamente distribuída. Cada região desenvolveu sua própria forma de EAD com recursos locais, público alvo e filosofia das organizações que fornecem a instrução (Sherry, 1996). Em todo o mundo, várias instituições públicas e privadas estão oferecendo cursos de graduação, mestrado e até doutorado à distância. Cada vez mais alunos estão se graduando nestas instituições também chamadas de Universidades Virtuais. O aluno não precisa sair de sua casa para estudar, só é necessário um computador conectado à Universidade Virtual que está oferecendo o curso e se inscrever no mesmo (Carroll, 1996). Alguns cursos são grátis, mas a maioria tem um custo. Os alunos fazem seu próprio trabalho com materiais fornecidos pelo curso, materiais impressos e comunicação postal, alguma forma de teleconferência e/ou rede eletrônica, e possuem suporte dos professores presentes (instrutores) e professores distantes (mentores) via telefone ou e-mail (Sherry, 1996).

A EAD é frequentemente relacionada com colégios e universidades, porém é muito utilizada em locais de trabalho para treinamento de funcionários (Geber, 1991). "Eric Boehm - presidente do International School of Information Management em Denver e contribuinte do Oryx Guide to Distance Learning sempre disse que as pessoas não deveriam ir a escola para aprender; a sala de aula é que deveria ir até elas. Esta é a era da informação” (Carroll, 1996).

\footnotetext{
${ }^{1}$ Hipertexto foi idealizado primeiramente por Vannevar Bush, ver Bush (1945).
} 


\subsection{A Educação à Distância no Brasil}

No Brasil, não há registros precisos da criação da EAD. Segundo Alves (1996), tem-se um marco histórico em 1904, quando foram implantadas as "Escolas Internacionais” representando as organizações norte-americanas. Porém, o referido autor salienta que, já em 1891, na $1^{\text {a }}$ edição do “Jornal do Brasil” havia um anúncio oferecendo curso de profissionalização por correspondência, o que ocasiona dúvidas quanto ao início exato da EAD no Brasil. Nessa época, já se notava crise na educação nacional e devido a esse momento conturbado, à pouca importância que se dava à EAD e às muitas vezes alegadas dificuldades nos correios, o ensino por correspondência recebeu pouco incentivo por parte das autoridades educacionais e órgãos governamentais (Alves, 1996).

O Brasil está muito atrasado comparando-o com outros países, porém, este quadro está mudando. Após a hegemonia dos programas educativos transmitidos em rede aberta pela televisão durante os últimos trinta anos, o Ministério da Educação e as universidades vêm tentando ocupar o espaço da produção e veiculação do conhecimento à distância. Desta forma, a perspectiva é de ampliação acelerada da oferta e procura de cursos à distância nas mais variadas formas e conteúdos (Santos, 1996).

Pode-se perceber a atual preocupação com a EAD no Brasil, pois em 20 de dezembro de 1996 foi decretada e sancionada a Lei $n^{\circ}$ 9.394/96, que estabelece as diretrizes e bases da educação nacional - a LDB. Esta Lei possui artigos onde a EAD é incentivada pelo Poder Público, a saber:

- “o ensino fundamental será presencial, sendo o ensino à distância utilizado como complementação ou em situações emergenciais” (Art. 32 $\left.\$ 4^{\circ}\right)$

- “é obrigatória a freqüência dos alunos e professores, salvo nos programas de educação à distância” (Art. 47 \$3 );

- “Art. 80 - O Poder Público incentivará o desenvolvimento e a veiculação de programas de ensino à distância, em todos os níveis e modalidades de ensino, e de educação continuada. 
$\$ 1^{\circ}$. A educação à distância, organizada com abertura e regime especiais, será oferecida por instituições especificamente credenciadas pela União. $\$ 2^{\circ}$. A União regulamentará os requisitos para a realização de exames e registro de diploma relativos a cursos de educação à distância.

$\$ 3^{\circ}$. As normas para produção, controle e avaliação de programas de educação à distância e a autorização para sua implementação, caberão aos respectivos sistemas de ensino, podendo haver cooperação e integração entre os diferentes sistemas.

\$ $4^{\circ}$. A educação à distância gozará de tratamento diferenciado, que incluirá:

I - custos de transmissão reduzidos em canais comerciais de radiodifusão sonora e de sons e imagens;

II - concessão de canais com finalidades exclusivamente educativas;

III - reserva de tempo mínimo, sem ônus para o Poder Público, pelos concessionários de canais comerciais.”

Hoje, devido ao grande avanço da EAD no Brasil ocorrido no final da década de 80 e início de 90, há inumeráveis cursos oferecidos por meio de vídeos, fitas cassetes e de instruções por computador (Alves, 1996). Cursos via TV também são fornecidos pelo setor privado, através do Telecurso 2000 para $1^{\circ}$ e $2^{\circ}$ graus, que está no ar desde 1995. É a mais nova iniciativa educacional da Fundação Roberto Marinho (FRM) a qual possui 15 anos de experiência em telecursos e outros programas educacionais. O Telecurso 2000 é financiado pela própria FRM e pela Federação de Indústrias do Estado de São Paulo (FIESP), com apoio do SENAI. Apesar de ser ainda um programa novo, possui um número de participantes expandindo-se rapidamente, com tele-salas em centenas de empresas, centros de treinamentos industriais e penitenciárias federais. Atualmente, com o apoio do Instituto Aqua, este programa está explorando os recursos interativos da Internet, como fornecimento de materiais de treinamento atualizados, testes de padronização e muitos outros serviços (Knight, 1996). 


\subsection{Mudança Global}

Em um mundo onde o conhecimento é poder, levar o conhecimento certo, para a pessoa certa, no lugar certo, num tempo certo, é uma necessidade operacional (Picard, 1996). O mundo está se tornando rapidamente uma aldeia global. A rede existente para trocas de informações oferece desafios especiais nas comunicações técnicas, fornece aos negociantes a oportunidade de procurar cursos e Workshops. Educadores e treinadores enfrentam o desafio de concentrar suas habilidades nas necessidades específicas dos sites e alunos distantes (Connors, 1995).

A EAD como conceito e como uma prática educacional, tem sido utilizada com, pelo menos, dois propósitos (Saba, 1996):

- para trazer mudança;

- para responder à mudança social.

Os educadores distantes, como agentes de mudanças, têm usufruído deste conceito para levar mudanças a organizações rígidas e estagnadas. Não somente houve uma mudança social, mas também uma mudança global, e esta mudança na civilização marcou a educação. As tecnologias da era da informação têm o potencial de contribuir para a pessoa ter mais responsabilidade para com sua aprendizagem independente. Num ambiente baseado em tecnologia, a educação tenderá a ser mais (Saba, 1996):

- centralizada no aluno do que no professor;

- baseada em caso do que em conteúdo;

- contextualizada do que abstrata;

- democrática do que ética.

A necessidade de novas habilidades flexíveis de aprendizagem e sistemas de distribuição mudará o caminho no qual o professor trabalha, requer uma reestruturação de instituições educacionais e desenvolvimento de novos modelos de currículos para servir uma extensa gama de alunos (Kinnaman, 1996; Payne, 1996). A EAD apresenta uma grande oportunidade para esta reestruturação. Restringí-la apenas à estrutura de uma sala de aula tradicional condicionaria a liberação de instrução e não o engajamento intelectual, a participação ou o progresso dos alunos 
individualmente. É preciso reconhecer que a capacidade da tecnologia atual para superar restrições de tempo e lugar, invalida o modelo tradicional de instrução (Kinnaman, 1996). Por isso é necessário repensar os parâmetros da sala de aula tradicional e recriar um currículo. O futuro será uma colaboração entre professores e tecnologia que supere as restrições de tempo e espaço, habilitando os alunos a aprender mais, em menos tempo e com menos despesas (Kinnaman, 1995).

Quatro tendências futuras são destacadas por Roberts (1996):

1. o crescimento projetado da atividade de EAD;

2. uma tendência para tecnologias digitais e de redes;

3. o aumento do uso de computadores como o meio mais comum;

4. o impacto econômico e custos da EAD. 


\section{Estrutura de um Sistema de Educação à Distância}

\subsection{Considerações Gerais}

O sistema de EAD é composto por uma variedade de componentes organizacionais, administrativos, instrucionais e tecnológicos (Harrison, 1991). A característica principal deste sistema é que todos os componentes estão interrelacionados, portanto se um componente for alterado irá afetar outros componentes. Por exemplo, se uma mídia de comunicação for adicionada aos sistemas, isto afetará o projeto instrucional, a interação e o ambiente de aprendizagem. Sendo assim, ao se projetar ou implementar um projeto de EAD, é necessário levar em consideração a característica acima citada, senão o sistema provavelmente falhará ou será inativo (Harrison, 1991; Moore \& Kearsley, 1996).

A EAD faz parte do sistema educacional como um todo, o qual inclui escolas, departamento de treinamento, etc. Portanto, quando um programa de EAD é implementado afeta todo o sistema educacional, de alguma maneira. Por exemplo, quando um curso oferecido anteriormente em sala de aula tradicional, começa a ser oferecido à distância, elimina a necessidade do espaço físico para a sua realização e elimina o capital necessário para mantê-lo, entre outros (Moore \& Kearsley, 1996).

Pesquisas indicam que a EAD pode ser tão eficaz quanto o ensino em sala de aula tradicional, quando os métodos e tecnologias usados são apropriados para tarefas instrucionais, quando há interação entre alunos e quando há feedback do 
professor para com o aluno em tempo oportuno (Moore \& Thompson, 1990; Verduin \& Clark, 1991).

O êxito da EAD depende, além de sistemas e programas bem definidos, de recursos humanos capacitados, de material didático adequado e, principalmente, de meios apropriados para fornecer instrução aos alunos. Este conjunto de ferramentas permite resultados altamente positivos. Adicionam-se ainda, como elementos antecedentes ao trabalho, um completo diagnóstico das necessidades do potencial do aluno e da região onde se encontra, e avaliações durante e após o curso à distância (Alves, 1996). Segundo o referido autor, poucos são os trabalhos desenvolvidos no Brasil que consideram esses fatores, acentuando-se as evasões nos cursos à distância. Representam desta forma, desperdício de recursos e contribuem para o descrédito da EAD. Seu custo é elevado, porém extremamente pequeno se for considerado que a EAD auxilia o resgate da imensa dívida social notada no território brasileiro.

A criação de um curso ou programas de EAD requer vários tipos de experiências, sendo necessário um grupo de profissionais para elaborá-los. Este grupo seria composto por projetistas instrucionais, editores, produtores, escritores, especialistas ou técnicos em mídia e pessoal administrativo (Moore \& Kearsley, 1996). Aplicações de EAD deveriam começar com o conhecimento do perfil do aluno, bem como das necessidades educacionais e dos objetivos da organização (Yoakam, 1995)

A EAD requer mais tempo de preparo (Keegan, 1993) do que os cursos tradicionais em sala de aula (Ward \& Lee, 1995; Willis, et al., 1995d; Moore \& Kearsley, 1996; Owston, 1997) e há tipos diferentes de interações possíveis no contexto da aprendizagem à distância, sendo que bons ensinos à distância incorporam todas as formas de interação (Moore \& Kearsley, 1996).

\subsection{Aspectos Operacionais de um Sistema de Educação à Distância}

Os aspectos operacionais envolvem o planejamento, a administração, o 
gerenciamento e a economia, todos cruciais para o sucesso do programa de EAD. Devemos considerar a relação aluno/instrutor/mentor, treinamento dos professores e da equipe do programa, implementação e adoção de nova tecnologia, e questões como facilidades, custos e programação (Sherry, 1996).

Como um curso à distância difere consideravelmente do curso em sala de aula tradicional, sua administração e gerência também diferem significativamente, estando as principais diferenças (Moore \& Kearsley, 1996):

1. no desenvolvimento de materiais com relação ao tempo e ao orçamento;

2. no tipo de pessoal envolvido (ex.: projetistas, instrutores, técnicos, etc.);

3. na política para professor e pessoal de trabalho;

4. na importância das decisões relacionadas à tecnologia e mídia;

5. nos procedimentos de inscrição dos alunos no curso, nivelamento e suporte.

A figura 1 mostra um modelo de interação entre alunos, instrutor e mentora (Prof ${ }^{a}$ Iria Müller Guerrini) no Programa Educ@r.

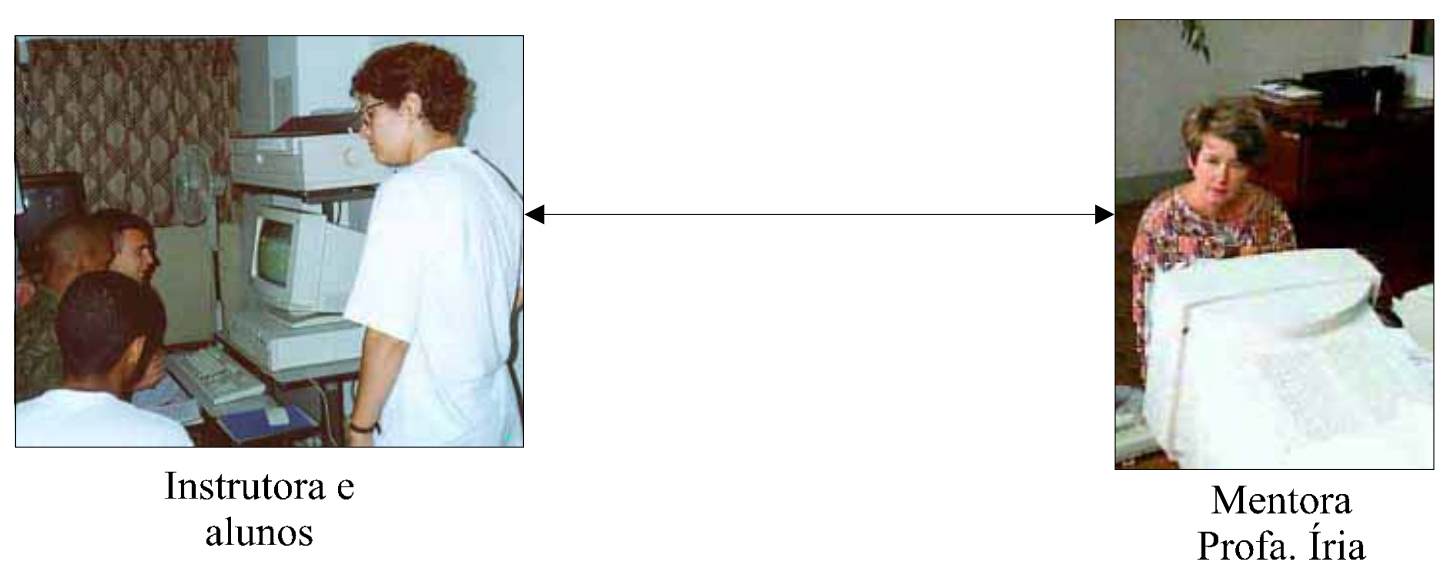

Figura 1 - Um modelo de interação no Programa Educ@r.

\subsubsection{O Aluno da Educação à Distância}

Encontrar as necessidades instrucionais dos alunos é a base de todo programa eficaz de EAD (Willis et al. 1995a). Geralmente, os alunos têm escolhido este método de estudo devido à flexibilidade que ele oferece (Eaton, 1996). Até 
recentemente a maioria dos alunos eram adultos, porém atualmente há muitos jovens usufruindo dos recursos da EAD e este número continua crescendo (Spodick, 1995). Os adultos possuem certas razões para fazer um curso à distância, como a falta de tempo, a distância, negócios, oportunidade de fazer cursos, aprimoramento e reciclagem no trabalho, contato com outras pessoas de diferentes classes sociais, culturais e econômicas, troca de experiências. (Willis, 1993). Como conseqüência disto, adquirem conhecimento e habilidades sociais como a comunicação e colaboração com colegas (Sherry, 1996). Os alunos adultos são mais entusiasmados e estruturados para a EAD do que os mais jovens, talvez pela sua maturidade e reconhecimento do valor da conveniência das oportunidades de um curso à distância (Reid, 1995). Em outro estudo, realizado por Sorensen (1995), os alunos acima de 25 anos sentiram um maior envolvimento na aula do que os mais jovens, e em outros itens como instrução, aspectos técnicos, gerenciamento do curso e satisfação com o curso, não foi encontrada diferença significativa.

A EAD oferece ao aluno a opção de estudar e aprender de uma forma mais autônoma e em locais mais convenientes, por seus próprios passos (Care, 1996). A instrução, que antes era centralizada no professor, passa a ser centralizada no aluno, dando mais responsabilidades a ele. Como resultado disto, o aluno deve estar ativamente engajado na formação do conhecimento pessoal que pode ser passado para novas e diferentes situações (Parker, 1997). Os alunos são questionados para examinar os processos de raciocínio e aprendizagem, coletar, arquivar e analisar dados, formular e testar hipóteses, refletir os entendimentos anteriores, e construir seus próprios pensamentos (Crotty, /199 / ).

Moore \& Kearsley (1996) identificam certos fatores que influenciam no sucesso dos alunos na EAD:

1. grau de formação do aluno e experiência anterior com EAD;

2. estilo de aprendizagem do aluno ou sua personalidade;

3. apoio que o aluno recebe da família e do pessoal de trabalho;

4. nível de importância do conteúdo do curso para os interesses pessoais e/ou profissionais;

5. quantidade e natureza de interação do aluno com instrutores e/ou com outros alunos; 
6. quantidade e natureza do feedback recebido no curso.

Conclui-se que, conhecendo as informações suficientes sobre o aluno e sobre o curso, é possível predizer o provável sucesso do aluno com a EAD.

\subsubsection{O Professor da Educação à Distância}

No ambiente de EAD, para fornecer uma instrução de qualidade para o aluno distante, o professor precisará mudar seu papel de transmissor de informação para orientador da aprendizagem. Suas responsabilidades são de planejar e implementar as atividades educacionais (Care, 1996). De um modo geral, o professor põe-se a disposição do aluno, auxiliando-o na construção do seu próprio caminho do conhecimento, orientando-o na aprendizagem, ajudando-o a esclarecer dúvidas, identificando suas dificuldades, sugerindo novas leituras e atividades, organizando suas atividades de estudo em grupo, supervisionando a prática de laboratório, entre outros (Gonçalves, 1996). A EAD não substitui o professor, mas, segundo Todorov (1994): a) abre novos horizontes; b) valoriza suas capacidades; c) motiva-o a trabalhar de uma maneira cooperada com outras habilidades e especializações; d) amplia seus magistérios, fornecendo milhares de experiências para serem compartilhadas.

Pelo fato da instrução ser centralizada no aluno, os educadores à distância ou mentores devem investigar como o aluno, o instrutor e a tecnologia colaboram para produzir o conhecimento (McIsaac \& Gunawardena, 1997). Os mentores precisam prestar mais atenção para com a motivação do aluno e seus sentimentos do que na sala de aula tradicional e sua eficácia está extremamente ligada aos seus conhecimentos da tecnologia/mídia envolvida (Moore \& Kearsley, 1996). Além disso, para os professores serem mentores devem adquirir habilidades de (Schlosser \& Anderson, 1994):

- entender a natureza e a filosofia da EAD;

- identificar as características do aluno nos sites distantes;

- projetar e desenvolver cursos interativos para adaptar cada tecnologia nova;

- adaptar estratégias de ensino para fornecer instruções à distância; 
- organizar recursos instrucionais de uma maneira apropriada para o estudo independente (Beaudoin, 1990);

- treinar e praticar o uso das tecnologias a serem utilizadas (Sherry \& Morse, 1995);

- envolver-se na organização, no planejamento colaborativo e nas tomadas de decisões;

- avaliar as realizações, atitudes e percepções do aluno nos sites distantes;

- lidar com questões de direitos autorais.

No sistema de EAD além dos mentores há os instrutores locais. O instrutor é uma extensão do professor distante, porém não precisa ser necessariamente um professor. As responsabilidades dos instrutores são: a) motivar e apoiar seus alunos; b) manter o entusiasmo dos alunos; c) preservar a disciplina durante a aula. Como suas atividades são similares às do mentor, necessitará de um treinamento também similar (Sherry, 1996).

\subsection{A Qualidade da Educação à Distância}

A falta de um controle de qualidade nos sistemas presenciais e à distância, é uma das grandes falhas do processo educacional. Não existe nada no Brasil, no âmbito da EAD, nem mesmo um cadastro nacional das entidades que utilizam esta metodologia, sendo assim muito difícil de controlar a qualidade (Alves, 1996). Este quadro está mudando, pois a Associação Brasileira de Educação à Distância (ABED) está elaborando um cadastro de instituições que utilizam a EAD, com previsão de lançamento para o $2^{\circ}$ semestre de 1997.

O sistema de avaliação precisa ser espontâneo, mas é imprescindível que se façam campanhas conscientizando as organizações quanto à necessidade de possuírem mecanismos capazes de evitar o desgaste do sistema devido a falta de credibilidade (Alves, 1996). O referido autor destaca que é de suma importância o intercâmbio com organizações internacionais, com o objetivo de orientar corretamente os melhores meios para que haja um real controle qualitativo da EAD. 
Portanto, para controlar a qualidade é necessária uma avaliação dos programas de EAD (Vaughan, 1996), permitindo a realimentação do projeto a partir da prática de sua execução.

Um exemplo de uma experiência educacional de qualidade inclui os seguintes elementos: a) qualidade dos materiais de aprendizagem; b) disponibilidade dos materiais; c) suporte para alunos através de uma equipe bem treinada; d) mecanismos de monitoramento; e) feedback para a melhoria do sistema (Seligman, 1992). A elaboração de questionários de avaliação de um curso, a coleta e a análise dos dados, são tarefas realizadas para destacar os pontos fortes e críticos do curso, a qualidade dos materiais de ensino e o feedback dos alunos para continuamente melhorar a qualidade do programa de EAD (Peck \& Wallace, 1993). Biner, et al. (1994) concluem que é de suma importância a constante implementação e manutenção da avaliação continuada da satisfação dos alunos com relação ao instrutor, mentor, tecnologia, material do curso, serviços de suporte, interação aluno/instrutor/mentor.

\subsection{Fases de um Sistema de Educação à Distância}

O desenvolvimento instrucional é essencial para a EAD. Fornece um processo e ambiente de trabalho para planejamento, desenvolvimento e adaptação da instrução, baseado nas necessidades do aluno e nos requisitos do conteúdo. Este processo consiste de algumas etapas básicas de Projeto, Desenvolvimento, Avaliação e Revisão (Willis, 1992). Pesquisas indicam que a qualidade e a quantidade de aprendizagem são influenciadas pelo projeto instrucional em conjunto com a mídia utilizada no sistema (Oliver, /199 /). Seguir os princípios do desenvolvimento instrucional, exibidos na figura 2, não superará todos os obstáculos encontrados no desenvolvimento de programa eficazes de EAD, afirma Willis (1992), entretanto, fornecerá procedimentos para direcionar as mudanças instrucionais que certamente ocorrerão. 


\section{PROJETO}

- Determinar as necessidades

- Analisar o público-alvo

- Estabelecer as metas

\section{REVISÃO}

- Desenvolver e implementar o Plano de revisão

\section{DESENVOLVIMENTO}

- Criar esboço do conteúdo

- Revisar materiais existentes

- Organizar e desenvolver o conteúdo

- Selecionar/desenvolver materiais e métodos de fornecimento do curso

Figura 2 - Processo de desenvolvimento instrucional. Fonte: Willis (1992).

Na figura 3, sugerimos as fases de um sistema de EAD, baseado no desenvolvimento atual do Programa Educ@r, apresentado mais à frente. Estas fases foram adaptadas do Projeto de Esther Giraudo, da Universidade Nacional de Córdoba - Argentina, citado por Alves (1996). 


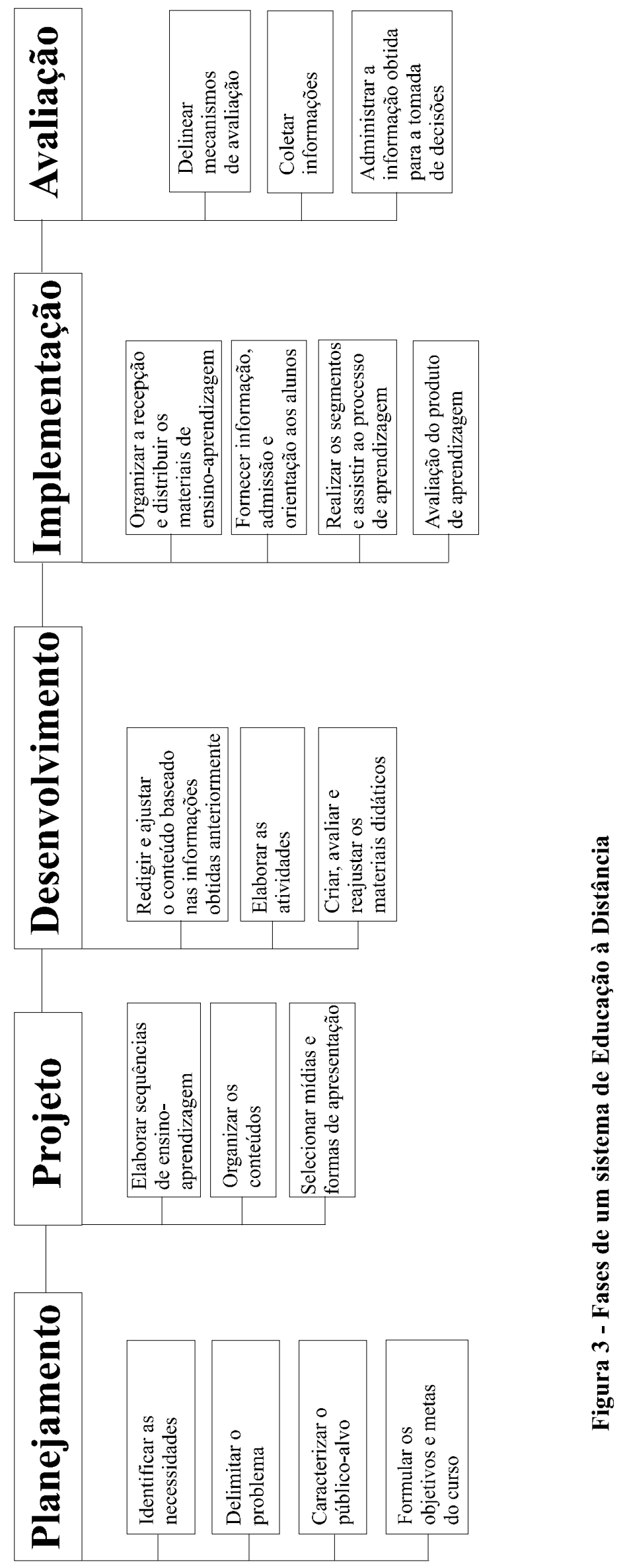




\subsubsection{Planejamento e Projeto}

Os procedimentos do Planejamento são: a) definir o problema e as necessidades; b) caracterizar o público-alvo; c) formular os objetivos e metas instrucionais, sendo que estes são estabelecidos com base na natureza do problema, bem como nas necessidades e características dos alunos (Willis, 1992).

Os procedimentos do Projeto são: a) elaborar seqüências de ensinoaprendizagem; b) organizar o conteúdo dos materiais; c) selecionar mídias e formas de apresentação do material.

\subsubsection{Desenvolvimento e Implementação}

Os procedimentos do Desenvolvimento são: a) redigir e ajustar o conteúdo baseado nas informações obtidas na etapa anterior; b) elaborar as atividades do curso; c) criar, avaliar e reajustar os materiais didáticos.

Os procedimentos para a Implementação são: a) organizar a recepção e distribuir os materiais de ensino-aprendizagem; b) fornecer informação, admissão e orientação aos alunos; c) realizar os segmentos e assistir ao processo de aprendizagem; d) avaliar o produto de aprendizagem.

Pesquisas indicam que a fase de Implementação, descrita acima, e a fase de Avaliação, descrita a seguir, são questões significantes na EAD (Roberts, 1996), assim como a fase de Projeto, pois podem afetar a comunicação e o processo de aprendizagem na sala de aula (Comeaux, 1995).

\subsubsection{Avaliação}

A avaliação deve ser praticada continuamente nos ciclos de projeto, desenvolvimento e implementação, para garantir que tudo saia de acordo com o projetado e planejado (Moore \& Kearsley, 1996). É um processo através do qual não somente a qualidade pode ser melhorada, mas podem ser iniciados novos desenvolvimentos (Thorpe, 1993). Um sistema de avaliação é uma tarefa importante no processo de identificação e modificação dos componentes de um programa, os 
quais resultaram num feedback negativo do aluno e na sua insatisfação (Biner, et al., 1994). Segundo Melton (1995), o sistema de avaliação deve ser um processo continuado ajudando a encontrar os pontos fortes e críticos de um programa de EAD.

Portanto, o processo de avaliação é fundamental para a EAD, pois mantém o controle da qualidade do curso, facilitando a identificação das falhas no sistema instrucional e orientando quanto às mudanças necessárias para melhorar os resultados obtidos com o programa de EAD. O objetivo desta fase é fornecer informações para a equipe do programa tomar decisões necessárias a fim de que os propósitos do projeto sejam atingidos. Os passos são: a) delinear mecanismos de avaliação; b) obter informações; c) administrar a informação obtida para a tomada de decisões.

A avaliação de um projeto é realizada para estimular o aluno em relação à tecnologia utilizada a fim de fornecer instrução à distância, conveniência de tarefas, clareza do conteúdo do curso, boa utilização do tempo, eficácia do ensino e formas de melhorá-lo (Willis, et al., 1995b). As áreas a serem avaliadas na EAD, segundo os referidos autores, são as seguintes:

uso da tecnologia - familiaridade, conceitos, problemas, aspectos positivos e atitude com relação à tecnologia (Johnson, 1996);

formas de aula - eficácia do assunto, discussão, pergunta e resposta, qualidade das questões ou problemas levantados em sala de aula e incentivo aos alunos para se expressarem;

ambiente da aula - contribuição para a aprendizagem do aluno;

quantidade e qualidade de interação com outros alunos e instrutor;

conteúdo do curso - pertinência, estrutura do conhecimento, organização;

tarefas - utilidade, grau de dificuldade e tempo requisitado; tempo de feedback; nível de leitura de materiais impressos;

testes - freqüência, pertinência, revisão suficiente, dificuldade, feedback; serviços de suporte - instrutor, tecnologia, serviços de biblioteca, disponibilidade do mentor;

realização do aluno - suficiência, conveniência, tempo, envolvimento do aluno; 
atitude do aluno - assistência, tarefas submetidas, participação na aula; mentor - contribuição como guia na discussão; eficácia, organização, preparação, entusiasmo, abertura para visão do aluno.

Recomendações para a avaliação, segundo Willis, et al. (1995b):

1. checar e adaptar questionários já publicados: não há necessidade de "reinventar a roda";

2. desenhar e revisar questões; mudar se necessário;

3. usar as seguintes tentativas:

- alternar entre instrução e interação;

- sequenciar questões para melhor efeito - solicitar sugestões para melhorias ao invés de perguntar o que está bom;

- colocar questões abertas depois de questões fechadas. Isto dá tempo aos alunos para construir o raciocínio;

- na avaliação somativa, assegurar anonimato;

- ressaltar respostas relevantes;

- adaptar o aluno em grau de formalidade;

- usar a avaliação como um método para ensino e aprendizagem;

- tentar conseguir ambos feedback positivo e negativo. É possível não somente conhecer o que não está trabalhando, mas também o que está.

Após a avaliação, a revisão baseada no feedback dos instrutores, do especialista do conteúdo e dos alunos é um processo contínuo. Estudos devem ser feitos para atualizar continuamente os cursos, os quais dependem de informação renovada para manter o assunto atualizado e relevante (Porter, et al, 1994). É essencial que todas as instituições participantes em um programa de EAD participem do esforço da avaliação (Gilcher, 1995).

\subsubsection{Tipos de Avaliação}

\section{a) Avaliação Formativa}


A avaliação formativa é uma avaliação sistemática do processo de construção do currículo, da fase de desenvolvimento do ensino e da aprendizagem, com a finalidade de aperfeiçoar qualquer um deles (Bloom, et al., 1971). É um processo contínuo realizado durante todo o desenvolvimento do processo instrucional; ajuda a garantir ao curso atingir metas determinadas (Draper, 1996; Flagg, 1990); habilita o mentor a melhorar o curso; facilita a adaptação do seu conteúdo; identifica lacunas maiores no plano instrucional ou a necessidade de ajustes menores (Willis, et al., 1995b).

A avaliação formativa pode ser usada para tornar o processo da aprendizagem mais efetivo, muito antes da avaliação somativa (Santarosa, 1982). Sua finalidade é fornecer um feedback contínuo tanto para o aluno quanto para o professor a respeito dos sucessos e dos pontos críticos. O feedback para o aluno identifica os erros específicos de aprendizagem que deverão ser corrigidos e fornece um reforço da aprendizagem bem sucedida. Para o professor o feedback fornece informações para proceder modificações na instrução (Gronlund, 1981).

\section{b) Avaliação Somativa}

A avaliação somativa tem a função de julgar o aluno, professor ou currículo, com o objetivo de determinar a efetividade da aprendizagem ou instrução (Bloom, et al., 1971). É realizada no final do curso, fornece uma base de dados para a revisão do mesmo e planos futuros e é usada para determinar o total de sua eficácia (Willis, 1992). Seu principal objetivo é a atribuição de conceitos ou testar o nível de rendimento alcançado pelo aluno. Também fornece informações para fazer um julgamento da adequação dos objetivos propostos no curso e a eficiência da instrução (Gronlund, 1981).

\subsubsection{Métodos de Coleta de Dados}

Os dados podem ser coletados através de métodos quantitativos ou qualitativos, descritos a seguir:

Os métodos quantitativos envolvem a elaboração de perguntas que 
podem ser estatisticamente tabuladas e analisadas, freqüentemente usando uma escala, checklist ou respostas “sim” ou “não” (Willis, et al, 1995b). Os autores ensinam que estes métodos necessitam de uma grande amostra para análise estatística relevante. Um exemplo são os questionários com questões fechadas. Segundo os autores Della-Piana (1994) estes métodos são usados para entender porque o aluno teve ou não uma boa performance no ambiente de EAD

Métodos qualitativos são mais subjetivos, envolvem a obtenção de um amplo e profundo campo de informação, são mais difíceis de tabular em categorias, são menos afetados pelo tamanho típico de classes pequenas, são métodos mais flexíveis e dinâmicos, não são limitados para assunto pré-formulado, e levam em conta a produção dos alunos nos tópicos do curso (Willis, et al, 1995b). São usados para fornecer indicadores de qualidade (Vaughan, 1996). Exemplos de métodos qualitativos são: análise do conteúdo, questionários com questões abertas, observação dos participantes e não participantes, e entrevistas (Guba, 1978).

A observação dos participantes é o método mais fácil para determinar como se procede a instrução. Se os alunos estão mostrando interesse ou parecem confusos em certas partes do programa, indicam que um problema potencial precisa de atenção (Moore \& Kearsley, 1996). A observação pode ser completamente informal, podendo ser registrada por exemplo, através de anotações de interesse, de gravações em vídeo ou áudio (Preece, 1994), entre outros. O professor distante pode observar o comportamento e a dinâmica de grupo enquanto participa da aula como um observador, fazendo perguntas ocasionais e procurando critérios com relação ao processo de EAD (Willis, et al, 1995b).

As entrevistas juntamente com a observação dos participantes, segundo Lüdke \& Menga (1986), representam um dos instrumentos básicos para a coleta de dados dentro de uma perspectiva qualitativa. As entrevistas devem ser preparadas cuidadosamente, para que a linha de questionamento que se deseja seguir seja relevante às questões que estão sendo investigadas. As entrevistas podem ser estruturadas, não estruturadas e semi-estruturadas; em grupos pequenos ou individuais. A entrevista estruturada tem questões predeterminadas, as quais são perguntadas em uma certa seqüência e não há exploração das atitudes dos indivíduos. As entrevistas não estruturadas ou flexíveis, geralmente possuem tópicos, mas 
nenhuma seqüência estabelecida e o entrevistador é livre para seguir as respostas dos entrevistados e avaliar suas atitudes pessoais. Na entrevista semi-estruturada o entrevistador freqüentemente tem uma lista de questões para dirigir a entrevista caso o entrevistado discordar ou não falar muito (Thorpe, 1993; Preece, 1994).

Para preparar questionários é necessário tempo dedicado do avaliador, tempo para envio e retorno dos mesmos e tempo para analisá-los. A aparência e projeto de um questionário é tão importante quanto elaborar as questões e codificálas. Portanto, é necessário torná-lo tão atrativo e fácil de completá-lo quanto possível (Thorpe, 1993). As questões devem ser claras e não ambíguas, uma vez que o avaliador pode não estar presente durante a fase de aplicação do questionário. Há dois tipos possíveis de estruturas de questões: a) questões fechadas - método quantitativo de coleta de dados, - onde o entrevistado pode selecionar uma resposta de um conjunto de alternativas; b) questões abertas - método qualitativo, - onde o entrevistado é livre para dar sua resposta (Preece, 1994). Segundo a autora, as questões fechadas possuem algum tipo de escala associada. As escalas mais simples consistem de checklists, como escala de três pontos "sim”, "não” e "não sei”, e as escalas mais complexas aumentam o número de pontos, formando uma escala multiponto. Uma variação da escala multi-ponto é a escala Likert (Preece, 1994).

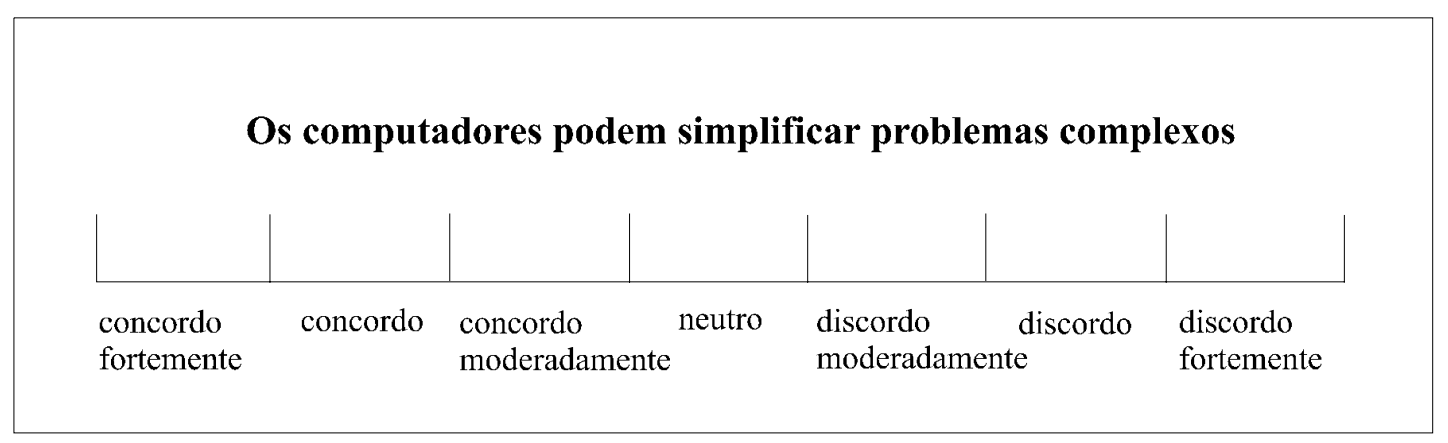

Figura 4 - Um exemplo de escala Likert de 7 níveis. Fonte: Preece (1994) 


\section{Uso da Internet na Educação}

\subsection{Evolução das Tecnologias Educacionais}

As novas tecnologias são liberadas como uma “chuva” de estímulos, mas freqüentemente terminam em desapontamento se reprovadas quanto à melhoria na aprendizagem pelos estudos de avaliação (Alexander, 1995). Um exemplo disto, foi a introdução do rádio na década de 20, cujo poder de influenciar comportamentos foi exagerado por muitos. As primeiras tentativas de educação através do rádio também provocaram expectativas maiores que os resultados obtidos. Com relação à TV, verificou-se o sucesso das Open Universities e os bons resultados de estudos e pesquisas em todo o mundo, desmentindo as suspeitas de que a TV "não pode ensinar” (White \& Thomas, 1995).

A introdução dos computadores na aprendizagem foi mais uma tecnologia utilizada. Nos anos 50, com a conclusão do primeiro computador comercial, anunciou-se uma onda de novas aplicações para os computadores e os educadores perceberam rapidamente o seu potencial para a educação (Alexander, 1995). O sonho dessa época foi que as salas de aula seriam conectadas por computadores, os quais serviriam como tutores pacientes, examinadores rigorosos e programadores incessantes de instruções. Além disso, os alunos teriam como benefício a liberdade para seguir seus próprios passos na aprendizagem em um tempo conveniente a eles, com materiais mais ricos para trabalhar e com medidas automáticas de seus progressos. Eles teriam acesso não somente aos computadores, 
mas também, aos professores que seriam capazes de trabalhar individualmente com alunos, pois teriam menos trabalhos "pesados" e repetitivos, e um acesso a documentação mais exata do progresso do aluno (Kulik, et al., 1983).

Com o surgimento das tecnologias interativas sofisticadas, os educadores passaram a utilizar ferramentas como e-mail, BBS (Bulletin Board System) e Internet (as quais são mais populares), audioconferência e videoconferência via rádio, cabo, telefone, fibra óptica, satélite, microondas, circuito fechado ou televisão (Sherry, 1996).

No futuro, a implementação de programas eficazes de EAD usufruirá de vantagens da tecnologia de computadores limitadas apenas por nossa imaginação (Fulton, 1992). Isto já está ocorrendo, com a mais nova tecnologia de comunicação, a WWW - descrita no próximo capítulo, - onde aprendeu-se com as falhas das tecnologias anteriores na educação, tendo a oportunidade de desenvolver novas experiências. Estas falhas ocorreram devido à transferência do ensino e aprendizagem da sala de aula tradicional para os computadores, sem ao menos redefiní-las (Alexander, 1995). É inadequado transportar o que ocorre na sala de aula tradicional para uma situação que difere situações de tempo, lugar e aprendizagem (Ringsted, 1992; Picard, 1996). Para isto é preciso que os educadores evitem as convenções da sala de aula tradicional e explorem as novas possibilidades fornecidas pela tecnologia de aprendizagem e pelas novas técnicas de comunicação (Kinnaman, 1995).

Embora a tecnologia seja parte fundamental da EAD, qualquer programa de sucesso deve focalizar mais as necessidades instrucionais dos alunos do que a própria tecnologia. Por exemplo, deve-se considerar suas idades, sua base cultural e sócio-econômica, interesses e experiências, níveis de educação e familiaridades com métodos de EAD (Schamber, 1988).

\subsection{O Ambiente de Aprendizagem}

O ambiente de aprendizagem, segundo Schneider \& Block (1995), refere-se a uma categoria de softwares educacionais onde o aluno é colocado para 
resolver problemas, sendo totalmente diferente do curso em sala de aula tradicional, o qual é baseado em uma seqüência de questões, respostas e feedback. Os mesmos autores citam como melhor exemplo de um ambiente de aprendizagem o simulador de vôo, pois o aluno não responde a perguntas sobre como pilotar, ele aprende a proceder como um piloto real. A experiência com ambiente de aprendizagem (como o LOGO) mostrou que estes sistemas ganham eficiência se o aluno receber alguma assistência. O “ambiente de aprendizagem inteligente” é aquele que inclui (Schneider \& Block, 1995):

- situação de resolução de problemas;

- arquitetura reflexiva que mostra aos alunos o que estão fazendo ou ainda os ajuda a estruturar ativamente suas atividades cognitivas;

- monitor(es) que assista(m) aos alunos em suas tarefas e monitore(m) sua aprendizagem.

É difícil de implementar um ambiente de aprendizagem no computador e ainda mais em rede, porém, projetos educacionais podem ser construídos com estes princípios em mente. Os componentes de um ambiente de aprendizagem rico tecnologicamente, são (Schneider \& Block, 1995):

- Professor - agente humano presente ou distante;

- Monitor;

- Aluno;

- Material de aprendizagem;

- Fontes de informações externas;

- Ferramentas - tudo o que pode ajudar no processo de aprendizagem;

- Escola.

O curso de Mecânica Gráfica do Programa Educ@r via WWW- descrito a seguir (item 8.3), - se encaixa nas características descritas anteriormente, pois possui os componentes de um ambiente de aprendizagem rico tecnologicamente, tais como:

- Mentor;

- Instrutor;

- Aluno;

- Material de aprendizagem: hipertextos na Internet; 
- Fontes de informações externas: Bibliotecas, apostilas;

- Ferramentas: computador conectado à Internet, exercícios interativos;

- Escola.

Também possui as características de um “ambiente de aprendizagem inteligente”, descritas anteriormente, pois neste curso existe uma situação de resolução de problemas através dos exercícios interativos elaborados em hipertextos com tabelas; uma arquitetura reflexiva que mostra aos alunos o que estão fazendo ou os ajuda a estruturar suas atividades cognitivas através do feedback do mentor aos alunos; e monitor(es) que assista(m) aos alunos em suas tarefas e monitore(m) sua aprendizagem. Porém, o desafio dos desenvolvedores educacionais é o uso do conhecimento da aprendizagem em conjunto com as características da WWW, para projetar experiências e promover um caminho de aprendizagem. Desta forma, os alunos aprendem a entender profundamente o conteúdo, a habilidade para analisar e sintetizar dados e informação, o desenvolvimento do pensamento crítico e de uma boa comunicação (Alexander, 1995).

\subsection{A Internet}

\subsubsection{Aspectos Históricos}

A Internet, segundo Charlab (1996), teve o seu início nos anos 60 quando os militares americanos pediram a cientistas que encontrassem uma maneira de um ilimitado número de computadores se comunicarem não dependendo, única e exclusivamente, de um computador centralizado dirigindo a rede, pois tinham receio que, sendo centralmente administrada, a rede estaria exposta a ataques nucleares. Portanto, em 1969 foi fundada, pelo governo dos Estados Unidos, a ARPA (American Department of Defense Advanced Research Projects Agency) a qual patrocinou uma simples rede para pesquisa, a ARPAnet (Advanced Research Projects Agency Network), dando o passo inicial para a atual Internet (Dillenbourg \& Schneider, 1995; Charlab, 1996). 
A princípio, a rede ligava apenas quatro laboratórios de pesquisa, a fim de testar a nova tecnologia de comunicação conhecida como packet-switching (chaveamento de pacotes), porém, se expandiu rapidamente por universidades e empresas, tornando-se popular no meio acadêmico e de pesquisa (Charlab, 1996). O protocolo de comunicação IP (Internet Protocol), talvez tenha sido a mais poderosa inovação e deu origem ao nome Internet. O IP permite que qualquer número de computadores, ligados em rede, trabalhem como sendo uma única máquina, funcionando como um sistema de correio onde existe cooperação entre autoridades diversas para transportar e entregar as correspondências (Charlab, 1996).

No final dos anos 80, o jogo completo de protocolos da ARPAnet, conhecido como TCP/IP (Transmission Control Protocol/Internet Protocol) tornouse padrão para as maiores redes mundiais de pesquisa, substituiu a maioria destas redes (como UUCP, Bitnet, etc.) e não se restringiu apenas à pesquisa e educação. Deste modo, havia milhões de computadores e milhares de redes utilizando o TCP/IP e foi a partir destas conexões que surgiu a Internet atual. (Dillenbourg \& Schneider, 1995; Charlab, 1996). A Internet é uma união de redes de alcance baseada no protocolo TCP/IP sendo composta até 1996 por, aproximadamente, 50 mil diferentes redes do mundo todo e está se tornando muito fácil de se usar, até para pessoas que não possuem um profundo conhecimento na área de informática (Charlab, 1996).

\subsubsection{Tecnologias Internet}

A Internet é a maior e mais poderosa rede de computadores do mundo (Willis, et al, 1995c). Desenvolvida no final da década de 60, a Internet ganhou popularidade fora da comunidade científica na década de 80 , devido à grande quantidade de professores e alunos usando o e-mail (Carvin, 1995). O crescimento exponencial da Internet tem fornecido oportunidade para novos meios de ensino e aprendizagem, oferecendo uma alternativa para os métodos tradicionais de ensino (Updegrove, 1995). Alunos e universidades usam-na para procurar uma grande variedade de informações em todas as partes do mundo, como em bibliotecas interativas, em bancos de dados, entre outros (Cartwrigth, 1994). Nos últimos dez 
anos tem ocorrido um grande aumento no número de computadores interligados na Internet. Estima-se que a rede está crescendo numa taxa de $10 \%$ a $15 \%$ ao mês e que em 1998 haverá mais de 100 milhões de pessoas que terão acesso à Internet. Nos últimos três anos o aumento crescente de computadores interligados à rede se deve à World-Wide Web (WWW) (Saba, 1996).

O extraordinário crescimento da Internet, utilizando os recursos WWW, tem aumentado exponencialmente e se tornado uma das mídias mais importantes para a distribuição global de informação. As aplicações educacionais desta mídia têm se tornado evidentes especialmente para a EAD, pelo fato de permitir acesso a grande volume de informações e a versão sempre atualizada de um documento. Seu sucesso pode ser explicado por uma combinação de múltiplos fatores (Schatz \& Hardin, 1994):

1. Milhões de usuários estão conectados, portanto, quem pesquisar a Internet com certeza encontrará algo de interesse;

2. O acesso "transparente" a todos os recursos Internet e a facilidade de uso;

3. A disponibilidade de software de domínio público para cliente e servidor em múltiplas plataformas (como por exemplo o PC, o Macintosh), sendo que a facilidade de instalação do software servidor é provavelmente um fator chave para aumentar a quantidade de documentos em todo o mundo;

4. A simplicidade da sintaxe da linguagem HTML, sendo que os fornecedores de informação não precisam de ferramentas sofisticadas para preparar seus documentos.

Em 1996, o crescimento da Internet no Brasil foi o dobro da média anual no mundo, fenômeno este atribuído ao atraso de 2 a 3 anos de implantação da rede no país (Andries, 1997). O autor destaca que até o final de 1997 o tráfego Internet no Brasil deverá dobrar, sendo um dos que mais crescem no mundo e os usuários deverão estar entre 1,5 e 2 milhões de pessoas.

Segundo Takahashi (1997), problemas de infra-estrutura das comunicações para os serviços Internet continuam a afligir todo o mundo devido ao excesso de demanda, intensificada pelas aplicações multimídia e pelo grande número 
de usuários. O mesmo autor salienta que, com relação ao acesso, o problema é quase universal, pois linhas discadas a 28.800 bps não servem para suportar interfaces multimídia. Algumas tecnologias Internet são descritas a seguir, segundo Spodick (1995):

E-mail - é a principal ferramenta da Internet. É simples, portável, não é um mecanismo caro e fornece uma rápida comunicação entre grupos e indivíduos;

Listas de discussão - listservs e USENET newsgroup têm provado seu valor para os usuários da rede. Existem mais de 20.000 listas de discussão;

Telnet - É uma aplicação padrão disponível para todos os usuários Internet. Um dos seus usos mais populares é o acesso a catálogos de bibliotecas;

FTP (File Transfer Protocol) e Gopher - são protocolos para armazenamento e recuperação de arquivos de um sistema de computador remoto;

WWW - esta tecnologia Internet incorporou as capacidades das mais novas ferramentas e adicionou a habilidade de unir várias mídias em um ambiente hipermídia;

SLIP e PPP - são protocolos para utilização de uma interface gráfica na Internet através de uma linha telefônica e modem;

Softwares de Conferência Avançada - NetPhone é um software que permite transferência de áudio em tempo real pela Internet como uma chamada telefônica. CU-SeeMee é uma ferramenta utilizada para fornecimento de vídeo;

Realidade Virtual - este recurso pode ser oferecido através da linguagem VRML (Virtual Reality Modelling Language). 


\section{A World-Wide Web (WWW)}

\subsection{Aspectos Técnicos}

Em 1989, a WWW foi desenvolvida no European Particle Physics Laboratory (CERN) em Genebra pelo cientista da computação Tim Berners-Lee (Carvin, 1995). Foi originalmente projetada para facilitar o crescimento da base do conhecimento não linear através da Internet (Eaton, 1996). Segundo Berners-Lee, et al. (1994) a meta da WWW era ser um monopólio do conhecimento humano tão fácil de atualizar quanto de ler. É descrita oficialmente como “uma iniciativa de recuperar informação hipermídia por uma vasta área visando fornecer um acesso mundial a um grande universo de documentos” (Hughes, 1993).

A WWW é um sistema de hipermídia executado na Internet (Dillenbourg \& Schneider, 1995) cujo veículo de informação padrão é o documento hipertexto, um arquivo texto elaborado em HyperText Markup Language (HTML) (Schneider \& Block, 1995). Estes documentos podem conter textos, sons, figuras, vídeos e podem ser interativos (Barrie \& Presti, 1996). Em um documento é possível saber mais informações sobre um assunto em particular. Através de palavras sublinhadas (links) pode-se recuperar outros documentos escritos por diferentes autores, em várias localizações, e até mesmo recuperar informações multimídia. O sucesso da WWW se deve à apresentação da informação de uma forma não linear (Carvin, 1995).

É composta de múltiplos computadores “servidores”, os quais podem enviar os documentos para os usuários da Internet que "navegam” de servidor para 
servidor através de um software browser (navegador) (Barrie \& Presti, 1996), permitindo o acesso a WWW. Este software lê documentos e pode buscá-los de outras fontes; acessar arquivos por FTP, Gopher e uma variedade de outros métodos; permite pesquisas de documentos e bases de dados, bem como, interfaces para acessar qualquer tipo de programa externo executado em um servidor (Dillenbourg \& Schneider, 1995). Alguns dos protocolos de comunicação que o browser WWW pode acessar, são (Schneider \& Block, 1995):

- HTTP (HyperText Transfer Protocol) - protocolo usado nas conexões à páginas disponíveis em site na WWW;

- FTP - protocolo utilizado para a transferência de arquivos de uma máquina para outra na Internet;

- Gopher - Facilita a localização de arquivos através de menus.

- WAIS (Wide Area Information Service) - É um serviço que permite que o usuário tenha acesso à base de dados na Internet e efetue buscas por documentos através de palavras-chave.

Para especificar a localização de arquivos em servidores, a WWW utiliza os Uniform Resource Locators (URL - Localizador Uniforme de Recursos), como por exemplo: http://www.ifqsc.sc.usp.br/educar/educar.html. Um URL é composto de um protocolo (ex.: http), de um separador padrão “://, do nome do domínio (domain name) onde se encontra o documento (ex.: www.ifqsc.sc.usp.br) e da localização do arquivo, contendo: o diretório, se necessário (ex.: educar); e um nome de arquivo (ex.: educar.html), sendo este último o responsável pelo documento a ser recuperado. Todos estes itens são separado por barras “/”. Portanto, o URL pode ser escrito de acordo com a seguinte sintaxe: protocolo://domínio/diretório/nome do arquivo. Às vezes um URL pode ter ainda um complemento chamado âncora, por exemplo: \#parte1. A âncora acessa um trecho específico de um documento (ex.: parte1) e é utilizada no caso de documentos muito longos.

O URL permite o endereçamento de documentos na WWW, não somente usando HTTP, mas também usando outros protocolos comuns de rede como FTP, Gopher, WAIS (Berners-Lee, et al., 1994). Cada documento tem seu próprio URL para facilitar sua localização.

O servidor informa ao cliente qual tipo de arquivo é acessado. Quando o 
browser não entender o formato de arquivo encontrado (por exemplo: um arquivo no formato Adobe Acrobat), uma janela de ajuda é aberta para o usuário com o objetivo de informá-lo. O cliente pode usar qualquer tipo de programa a fim de exibir informações multimídia, como imagem, som, vídeo. A figura 5 mostra a configuração cliente-servidor da WWW. O cliente WWW pode enviar requisição para o servidor WWW que, por sua vez, retorna os documentos requisitados. Ou pode enviar requisição para o servidor FTP que envia os arquivos requisitados para o cliente WWW. De acordo com o protocolo utilizado, o cliente WWW deverá converter a informação antes de exibi-la para o usuário.

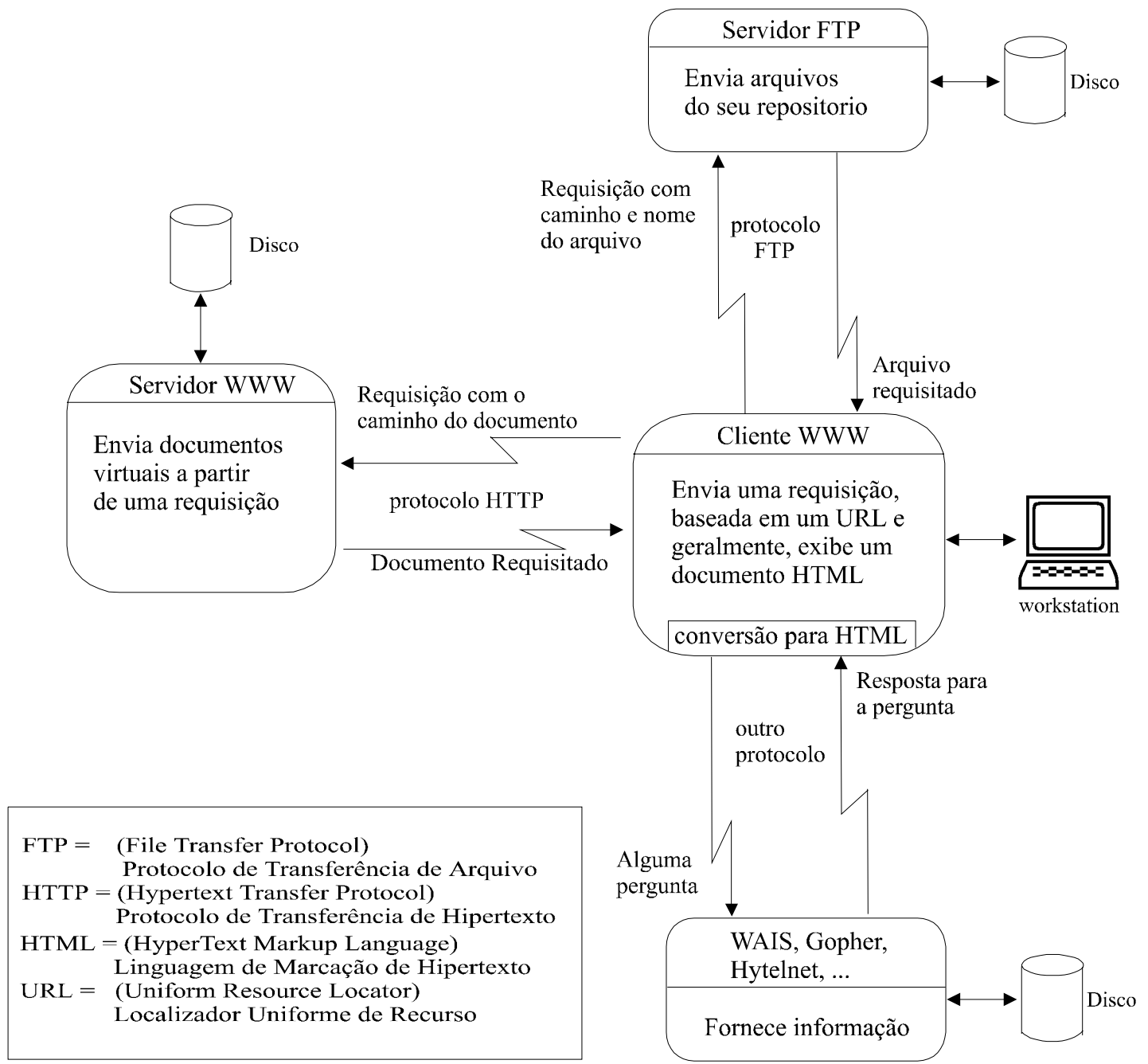

Figura 5 - Configuração Cliente-Servidor da WWW. Fonte: Ibrahim (1994). 


\subsection{Os Usuários da WWW}

Desde que a WWW se tornou uma ferramenta padrão da Internet, os usuários freqüentes são as instituições de EAD. Porém, qualquer instituição pode usar a WWW para melhorar o ensino na sala de aula e usar novas pedagogias. Um dos usos mais populares é para informação de treinamento e pesquisas departamentais. Para usá-la é necessário somente um planejamento organizacional e pelo menos um administrador de sistemas em tempo integral. Cinco aspectos gerais devem ser considerados antes do planejamento de uso da tecnologia WWW (Schneider \& Block, 1995):

1. Aspectos tecnológicos (ex.: softwares para gerar documentos HTML, programas para o servidor, bases de dados, etc.);

2. Aspectos organizacionais: Como treinar todo o pessoal? etc.;

3. Aspectos pedagógicos/psicológicos: Como podemos produzir bons cursos na WWW? Como construir ambientes de ensino e aprendizagem? etc.;

4. Aspectos de mídia: Qual mídia usar no conteúdo educacional? Como mediar o conteúdo educacional existente? - Esta é uma importante questão para as instituições de EAD;

5. Custo: O acesso à Internet ainda é caro e a produção de material WWW pode consumir bastante tempo incluindo treinamentos de instrutores e alunos.

\subsection{Características da Linguagem HTML}

HTML (HyperText Markup Language) é uma linguagem envolvente, utilizada para elaboração de documentos hipertextos, os quais são usados na Internet e recuperados pela tecnologia WWW através de um browser. Um documento HTML é um conjunto de instruções em formato ASCII.

A linguagem HTML utiliza tags (marcações) que informam ao browser como exibir um documento. As tags do HTML são palavras-chave contidas entre os 
sinais de “<” (“menor que”) e “>” (“maior que”), por exemplo: $<\mathrm{P}>$ - indica final de parágrafo. De um modo geral, as tags aparecem em pares, como: $<\mathrm{H} 1>$ texto $</ \mathrm{H} 1>$. O símbolo que termina uma determinada marcação é igual ao que a inicia, antecedido por uma barra (/), indicando o final da marcação. Porém, há marcações que não necessitam de uma indicação de término, tais como: $\langle\mathrm{P}>,\langle\mathrm{BR}>$ - indica quebra de linha, <LI> - para elaboração de uma lista, entre outros. Na linguagem HTML não há distinção entre maiúscula e minúscula, portanto < title> é equivalente a $<$ TITLE $>$ ou $<$ Title $>$, etc.

Uma característica da HTML é a possibilidade de incluir campos de entrada, onde o usuário pode preencher, no formato de formulário, um documento em HTML (Ibrahim \& Franklin, 1995), respondendo a perguntas específicas e até realizando discussões sobre o conteúdo de um curso à distância (Richardson, 1996). De acordo com Schneider \& Block (1995) os formulários são características importantes da linguagem HTML, por permitir a interação do servidor com o usuário, através de uma interface gráfica utilizando os recursos de push-buttons, radio-buttons, janelas para edição de textos e listas com scrolling bar. A figura 6 mostra um exemplo de uma tabela com campos de entrada, push-buttons e scrolling bar. 


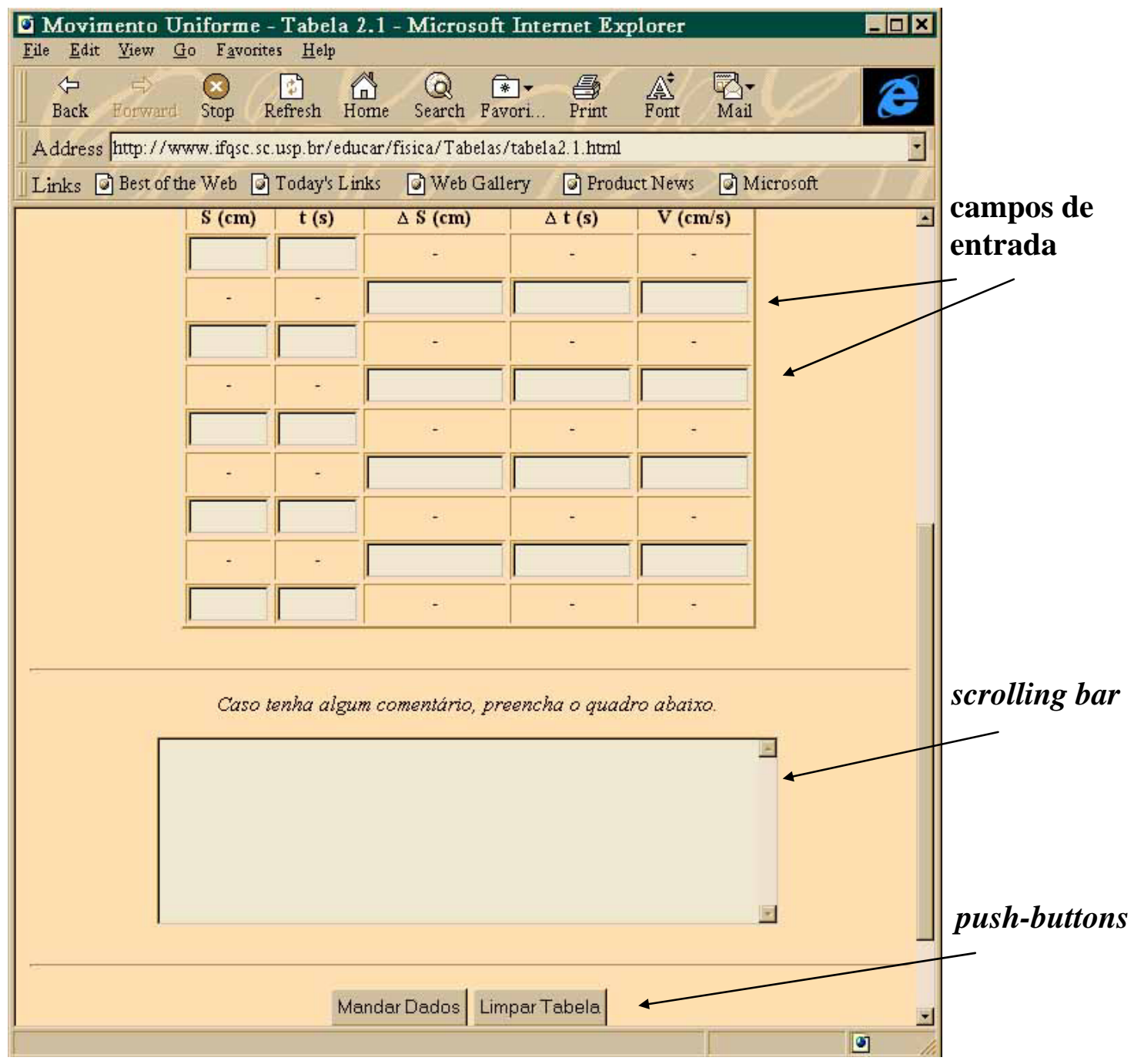

Figura 6 - Exemplo de uma tabela na WWW.

A linguagem HTML compõe uma poderosa interface para vários tipos de bases de dados e pode ser usada como interface para qualquer programa de execução em um servidor. Segundo Schneider \& Block (1995), pelo fato das páginas HTML poderem ser geradas dinamicamente pelo servidor, cada página pode ser elaborada de acordo com as necessidades do usuário, o que é uma característica interessante para os sistemas educacionais. Outra característica da linguagem HTML são os mapas interativos, os quais relatam ao servidor a posição dos "clics" do mouse podendo ser usado para construir ajudas de navegação ao usuário (Schneider \& Block, 1995).

Na figura 7 é mostrado um exemplo de um documento escrito na linguagem HTML o qual possui inserção de uma imagem de extensão gif, links para 
outros documentos e listas - (note que palavras acentuadas possuem símbolos especiais, tais como: Mecânica escreve-se Mec\&acirc;nica):

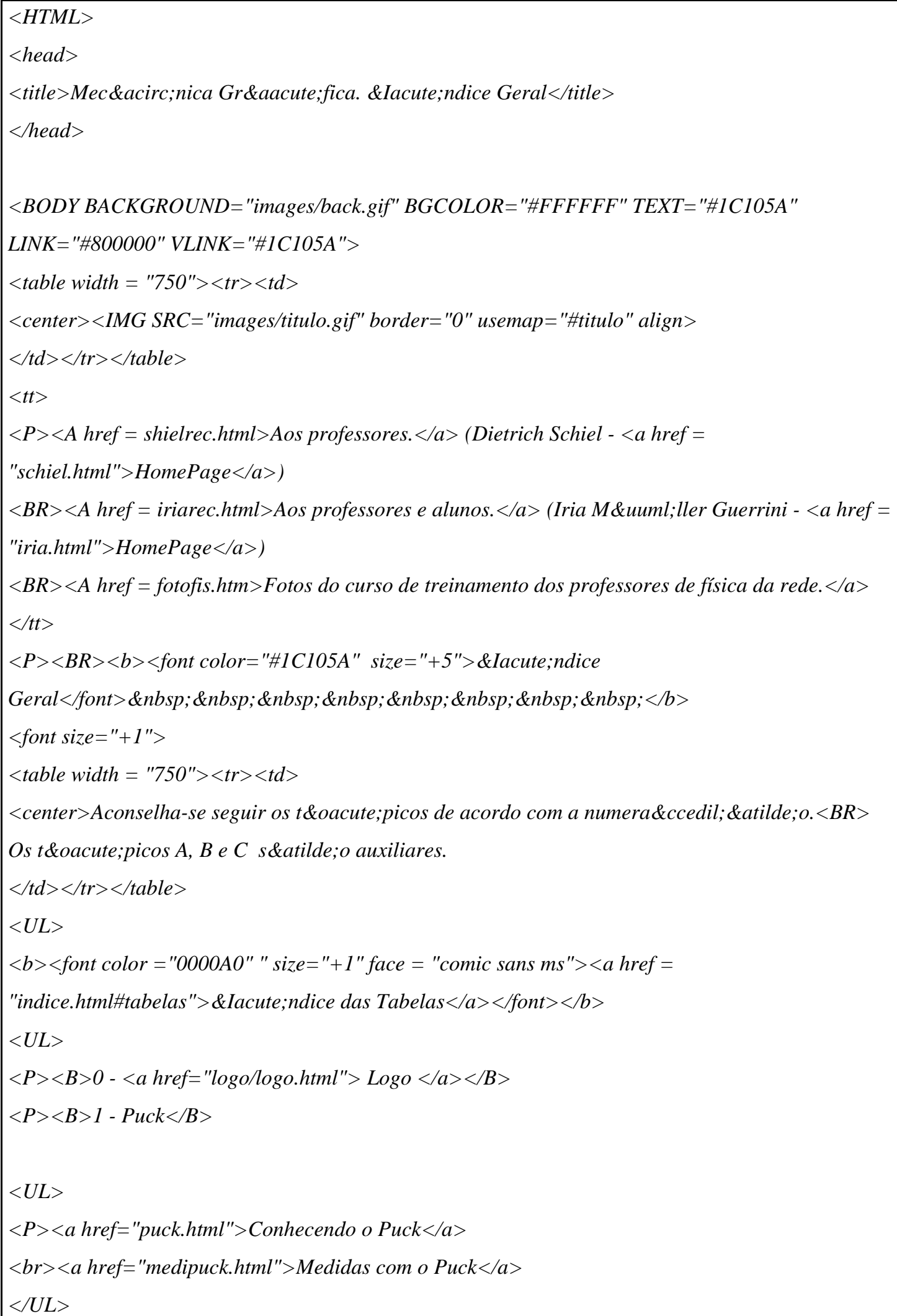


$<P><B>2$ - Movimento Uniforme $</ B>$

$<U L>$

$<P><$ a href="muteoria.html" $>$ Fundamentos Te\&oacute;ricos $</ a>$

$<B R><a$ href="muexpe.html" $>$ Procedimento Experimental $</ a>$

$<b r><a$ href="mulogo.html" $>$ Simula\&ccedil;\&atilde;o em Logo $</ a>$

$</ U L>$

$</$ body $>$

$</$ html $>$

Figura 7 - Exemplo de um documento HTML.

O documento HTML é exibido na tela do computador do usuário de acordo com as tags, com as configurações e com as capacidades do browser utilizado. Os principais browsers do mercado são: o Netscape Navigator e o Microsoft Internet Explorer.

Ambos os browsers possuem recursos em comum, como visualização de tabelas, formulários, formatações de textos, parágrafos, recursos para acessar páginas tridimensionais, animações através de gif's animados e, mais recentemente, o uso da linguagem Java, dentre outros recursos (Reggiani \& Silvestre, 1996).

A figura 8 mostra o documento HTML do exemplo da figura 7 visualizado pelo browser Internet Explorer da Microsoft, que está conectado ao Instituto de Física da USP São Carlos pelo endereço HTTP descrito na parte superior da tela: http://www.ifqsc.sc.usp.br/educar/fisica/indice.html. A faixa azul exibindo o título Programa Educ@r é uma imagem de extensão gif e as palavras grifadas são links para outros documentos. 


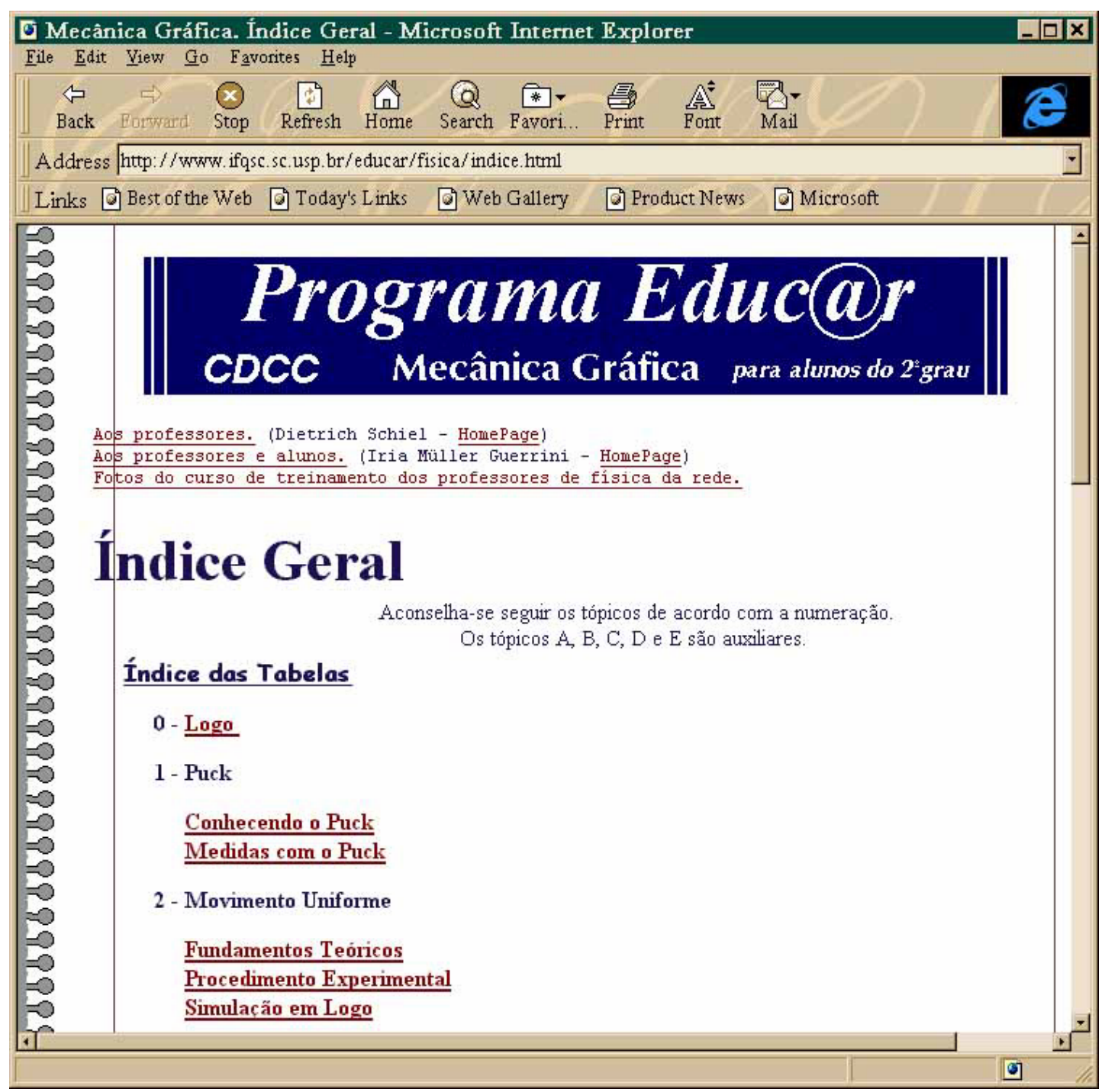

Figura 8 - Apresentação de um documento HTML pelo browser Explorer.

Schneider \& Block (1995) destacam quatro estratégias básicas para se construir documentos HTML:

1. usar um editor de texto simples (inserindo as tags manualmente);

2. usar uma ferramenta HTML que inclua edição de texto especial para inserção automática de tags (como o HotMetal ou HTMLed);

3. usar programas de conversão de texto para documentos HTML simplificados. Estes programas convertem textos elaborados em outros formatos, por exemplo: em Word for Windows para o formato HTML. Ex.: o software Internet Assistant for Word;

4. usar programas que elaborem automaticamente páginas em HTML, 
que mostrem resultados de uma base de dados, questionários on-line e programas de avaliação.

Segundo os autores, a opção 1 não é muito produtiva; a opção 2 é melhor para a produção de um material hipertexto, porém, requer algum treinamento. A opção 3 é a melhor solução para a produção de grandes estruturas de documentos, os quais também podem estar impressos. A opção 4 é uma facilidade para o usuário iniciante. Ele não necessita possuir conhecimentos da linguagem HTML para criar sua página, porém, estes programas não o permitem elaborar páginas mais complexas. Para o usuário iniciante que deseja conhecer algo mais desta linguagem e elaborar páginas criativas, há necessidade, por parte do ambiente em hipertexto, de iniciar o aprendizado de acordo com a opção 1 para adquirir uma noção da linguagem e a partir daí, começar a criar suas páginas em HTML. 


\section{Aspectos Educacionais da WWW}

\subsection{Considerações Gerais}

A WWW é uma ferramenta perfeitamente usada para o progresso da educação (Barrie \& Presti, 1996), possui o poder de atrair o entusiasmo dos alunos (Radcliffe, 1996) e seu ambiente multimídia fornece um verdadeiro sistema integrado de ensino-aprendizagem (Bodzin, 1997). Portanto, é uma ferramenta de EAD com um grande potencial, liberando informação para alunos de uma maneira fácil; permitindo ferramentas mais sofisticadas como hipertexto dinâmico, programas de perguntas e respostas, sistemas de conferência, etc. (Dillenbourg \& Schneider, 1995); permitindo lições interativas (Dyreson, 1996), bem como utilizando documentos com avançados recursos multimídia, contendo sons, imagens, figuras, textos; permitindo uma maior interação e possibilitando elaboração de cursos à distância (Sherry, 1996)

O que difere a WWW da mídia tradicional é que a informação está instantaneamente disponível para o aluno, sempre atualizada, é de alcance mundial e é apresentada de um forma motivante para os alunos a explorarem (Owston, 1997). 


\subsection{Características Educacionais da WWW}

A maior característica da WWW é o potencial de criação de links entre documentos-texto e outras mídias residentes em qualquer computador do mundo que tem acesso à WWW (Alexander, 1995), ou seja, a capacidade de utilizar documentos hipertexto/hipermídia.

Segundo Ibrahim \& Franklin (1995), as características educacionalmente atrativas na WWW, são:

1. a habilidade de possuir documentos com recursos multimídia (Schatz \& Hardin, 1994);

2. a capacidade de hipertexto/hipermídia

3. os fundamentos WWW que permitem EAD.

Há quatro maneiras de se utilizar estas características para ensinoaprendizagem (Alexander, 1995):

1. criar documentos que contenham links hipertexto/hipermídia onde os alunos possam acompanhar uma seqüência de documentos;

2. utilizar a interatividade, fornecendo uma estratégia útil de aprendizagem ativa;

3. possibilitar os alunos a se tornarem autores colaborativos, pois são oferecidas oportunidades a eles para contribuírem na construção de documentos na WWW, unindo seus próprios dados na forma de comentários escritos e orais, imagens, ou links alternativos também utilizados por outros alunos;

4. usar uma série de serviços da Internet para que seja oferecida uma experiência de aprendizagem integrada.

Há várias utilidades da WWW na educação, segundo Schneider \& Block (1995), a saber:

- A WWW como ferramenta de informação: ex.: informação sobre currículos, sobre cursos, etc.;

- Distribuição de material de aprendizagem: ex.: programas, livros (em vários formatos como o Word for Windows);

- Ferramentas Colaborativas; 
- Aplicações educacionais interativas.

Segundo Barrie \& Presti (1996), há três caminhos nos quais a WWW pode ser usada para fins educacionais:

1. motiva a habilidade do aluno para acessar informações;

2. é uma interface integrada para a EAD;

3. é um complemento à sala de aula tradicional e não uma substituição. Até certos requisitos serem encontrados, por exemplo, até possuir habilidade de acessar instantaneamente gráficos e vídeos complexos, a WWW servirá melhor como um curso complementar do que uma substituição à sala de aula tradicional.

\subsubsection{O professor e a WWW}

O papel do professor, diante do uso da hipermídia na educação, é estimular os alunos a "navegarem” pelo conhecimento, fazendo suas próprias descobertas, desenvolvendo sua capacidade de observar, pensar, comunicar e criar (Salvador, 1995). E é através da Internet e WWW que os professores podem ajudar os alunos a entender como "navegar" e tirar vantagem do mundo em rede no qual estão participando (Willis, et al, 1995c). O interesse dos professores pela WWW é devido aos seguintes elementos essenciais (Ibrahim \& Franklin, 1995):

- a disponibilidade de software cliente/servidor para muitas plataformas diferentes;

- a simplicidade da sintaxe da linguagem HTML para a elaboração de documentos hipermídia;

- a liberdade de se usar vários tipos de ferramentas de edição.

- o potencial de possíveis melhorias na interação (Eaton, 1996).

\subsection{Questões Futuras}

A WWW tem mostrado seu potencial de construir Sistemas de 
Informação Educacional em larga escala, devido às suas capacidades de hipermídia e de resgatar distâncias. Porém, não deixam de existir algumas dificuldades, a maioria social e organizacional, tais como: todas as ferramentas necessárias precisam ser encontradas e instaladas, treinamento de pessoal. Pode-se elaborar páginas com formulários interativos empregados nos testes de avaliação e auto-avaliação. Também pode ser usada como interface para dados científicos, artigos, jornais online, etc., sendo um grande potencial para as universidades. Recentes desenvolvimentos tecnológicos aumentam o potencial interativo da WWW. Com novos desenvolvimentos a WWW se tornará ainda mais poderosa e aumentará sua popularidade, são eles (Schneider \& Block, 1995):

- tecnologia Java - a grande promessa para interatividade e multimídia na Internet. É uma linguagem de programação que permite desenvolver programas, independentes de plataforma. $\mathrm{O}$ cliente interpreta os programas escritos em linguagem Java enviados pela rede;

- VRML (Virtual Reality Modelling Language) - a versão da HTML para a realidade virtual. A VRML permitirá que os usuários "naveguem” em salas e espaços tridimensionais, ao invés de "clicarem" com um mouse em telas planas de texto e imagens estáticas. Os alunos poderão visitar museus, observar experiências e participar de conferências e eventos no mundo inteiro em 3D (Richardson, 1996).

- Cgi-bin educacionais, pois facilitam a produção de formulários interativos nas páginas WWW;

Algumas questões futuras, quanto ao envolvimento da WWW na propriedade intelectual e na honestidade acadêmica, são levantadas por Barrie \& Presti (1996):

a) $\mathrm{O}$ que impede alunos de outras universidades de apresentar qualquer artigo da Internet como sendo seus próprios trabalhos?

b) O que os instrutores farão para evitar o plágio?

c) Qual a garantia que um aluno terá de suas informações pessoais e propriedades intelectuais não serem dispersas no universo eletrônico? 
Os autores concluem que com a previsão da Internet expandir acima de 1000\% nos próximos poucos anos, respostas a estas questões legais e éticas deverão ser encontradas.

\subsection{Educação à Distância Usando a Tecnologia WWW}

Como foi descrito anteriormente, ferramentas como a WWW têm sido desenvolvidas para a troca de informações e já estão sendo utilizadas para a EAD. A infra-estrutura da Internet é usada para transportar informações de mentores para alunos quase que transparentemente (Ibrahim, 1994). Para um aluno, uma escola ou uma empresa acessar um curso via WWW é necessário que eles possuam computador com um modem para poderem conectar à Internet através de um provedor de acesso.

Não importa a plataforma que o aluno esteja usando em sua casa ou laboratório, pois a WWW usa essencialmente a mesma interface para acessar uma sala de aula virtual. A vantagem de usar a WWW para liberar materiais de sala de aula é que oferece interface simples, altamente acessível e de plataformas independentes (Dyreson, 1996).

Como cada vez mais colégios, universidades, escolas, empresas e particulares têm se conectado à Internet, cada vez mais possibilidades são abertas para professores distantes superarem o tempo e a distância para chegar aos alunos (Willis, et al, 1995c). A EAD via WWW, comparada com outras tecnologias, possui uma série de melhorias, tais como:

- permite escrita colaborativa;

- os centros de excelência podem distribuir informação em larga escala para todos os usuários da rede e para locais onde o acesso às informações é restrito;

- há software cliente/servidor de domínio público e ferramentas de edição em geral de fácil acesso;

- os materiais instrucionais podem ser corrigidos e atualizados em um 
único servidor WWW e distribuídos a todos os alunos;

- permite distribuição de páginas sem custos de impressão e transporte, reduzindo, desta forma, custos de correio;

- possibilita o feedback dos alunos mais constante e facilmente;

- favorece a interatividade entre professores, alunos e entre alunos.

Pesquisas têm sido feitas para avaliar os aspectos da sala de aula tradicional comparados com a EAD via Internet, usando as tecnologias WWW, email, chat e newsgroup (Schutte, 1996). Os dados indicaram que a EAD via Internet produz melhores resultados do que a sala de aula tradicional. Porém, pesquisas futuras devem continuar sendo realizadas, principalmente para isolar o valor diferencial de cada tecnologia utilizada no curso.

Na figura 9, Ibrahim (1994) mostra um exemplo da interação entre o usuário remoto (neste caso, o aluno) e um software instrucional, via WWW. Alguns links podem acionar a execução de um programa no servidor WWW, gerando um processo que executa as interações pedagógicas com o usuário distante (professor distante). Este processo será executado durante a sessão instrucional e sua saída será enviada ao browser do usuário como documentos HTML. Estes documentos contém campos de entrada que deverão ser preenchidos pelos próprios usuários e que retornarão para o programa instrucional pelo browser do cliente WWW. Também podem conter links para documentos, em qualquer lugar na Internet, fornecendo ao aluno um acesso guiado por este mundo de informações. 
Cliente WWW

1) Envia requisição especial (script cgi-bin) para iniciar o software instrucional

2) Envia o conteúdo de vários campos de entrada do documento recebido para o software instrucional
Requisição do nome do programa instrucional, identificação do processo e campos de entrada do usuário protocolo HTTP

Próxima página instrucional com "links" embutidos ligando o nome do programa e a identificação do processo

\section{Servidor WWW}

Gera o processo instrucional e comunica-se com ele \begin{tabular}{|l|l} 
& campos de
\end{tabular} Pacotes entrada do usuário

\section{Software Instrucional}

Analisa a entrada do usuário e envia a próxima página instrucional baseada nesta entrada

Figura 9 - Cena da interação entre o aluno e um software instrucional via WWW. Fonte: Ibrahim (1994).

\subsubsection{Projeto de Documentos WWW}

No projeto dos materiais a serem colocados na WWW devem ser consideradas sua organização, orientação, navegação, apresentação e interatividade (Oliver, et al., 1996). Também deve haver uma maior atenção para o seu planejamento e desenvolvimento e devem ser considerados dois outros fatores no processo de aprendizagem: a) os alunos; b) como os materiais serão implementados. A aprendizagem através da WWW depende, não somente da qualidade dos materiais, mas também da maneira pela qual estes são usados pelos alunos e implementados pelo instrutor (Oliver, et al., 1996). Segundo estes autores, um problema para projetar documentos WWW é a escolha da estratégia a ser empregada na organização do material. Esta escolha depende da natureza da aprendizagem pretendida. 


\subsubsection{Dificuldades de Uso da WWW}

A WWW diminui distâncias físicas e temporais, favorecendo o acesso à educação, porém, devido à novidade desta tecnologia, podem ocorrer certas dificuldades para os alunos, principalmente técnicas. Tais como: mau funcionamento do hardware; dificuldades de configurar o software para acessar a instituição ou o provedor de acesso à Internet; quando o aluno discar de sua casa ou escola para se conectar com a Internet pode encontrar linhas ocupadas; o tráfego intenso no site da WWW pode dificultar a transmissão das informações ou até mesmo não responder. Adiciona-se ainda, o custo do uso da Internet através de um provedor, se a instituição não puder ser acessada diretamente, ou o custo da ligação interurbana, se o aluno não estiver no mesmo local da instituição e se não houver um provedor neste local (Owston, 1997).

\subsubsection{Custos dos Cursos Via WWW}

Há três principais áreas de custo da WWW, destacadas por Owston (1997): hardware e software, desenvolvimento do curso e suporte contínuo do curso. Os custos de hardware e software para os cursos que utilizam a tecnologia WWW incluem a conexão com a Internet através de um provedor local ou de uma cidade mais próxima (neste caso incluem também o valor do interurbano); deve-se incluir o valor de um computador com um modem e softwares necessários para conexão, como o Windows95 e um browser (Netscape ou Explorer), caso o aluno ou escola não os possuir.

Segundo o autor acima citado, no desenvolvimento do curso devem ser computados custos de tempo de desenvolvimento, do pessoal envolvido, treinamentos, suporte técnico, honorários e reconhecimento profissional. As instituições de ensino podem procurar associações com o setor privado, por exemplo, para uma colaboração no desenvolvimento de cursos usando a tecnologia WWW.

Quando o site WWW estiver operacional, os custos ainda continuarão, pois deverá estar em um progresso contínuo. A manutenção de um site é contínua, através da atualização dos materiais, da verificação dos links existentes para outros 
sites, das melhorias no layout e no design e da adição de funcionalidades. Estas são tarefas consideradas essenciais para um bom site da WWW. As expectativas do usuário para com um bom site é que contenha as últimas características dos browsers (exemplo: tabelas e formulários) e explore os recursos da tecnologia WWW (exemplos: som, vídeo, recursos de Java e outras ferramentas multimídia) (Owston, 1997). 


\section{Avaliação de Programas de Educação à Distância}

\subsection{Considerações Gerais}

Esta fase iniciou-se pela obtenção e revisão dos mecanismos de avaliação de diferentes instituições que estão envolvidas com EAD. Nas pesquisas realizadas, foram encontradas instituições internacionais, as quais forneceram cursos à distância com diferentes tecnologias de comunicação entre alunos e professores, aplicaram avaliações dos cursos e exibiram seus resultados (Porter, et al, 1994; Melton, 1995; Nettles \& Kauffman, 1995; Porter, et al, 1995; Canada, 1996; Minich, 1996; Witherspoon, 1996; Workman \& Stenard, 1996). Certas instituições utilizaram a escala Likert (descrita no item 3.4.3.2) para a obtenção dos dados (Peck \& Wallace, 1993; Biner, et al., 1994; Head \& Lockee, 1994; Sorensen, 1995; Schick, 1996). Com base nesse estudo, alguns programas foram selecionados e apresentados a seguir.

\subsection{Projeto New Directions in Distance Learning (NDDL)}

NDDL é um projeto piloto que envolve Open Learning Agency’s School 
Programs, o Ministry of Education's Technology and Distance Education Brach, escolas de EAD regionais e distritos escolares de British Columbia - Canada. Os objetivos do projeto, são: aumentar o suporte ao aluno e ampliar o sucesso do mesmo, através de programas educacionais inovados e alternativos.

Este Projeto teve início em Setembro de 1993, com 4 cursos de graduação e 8 locais remotos. Em 1996 já possuía 21 cursos de graduação, mais de 400 alunos, 32 locais remotos e as avaliações eram semestrais, durante e após os cursos.

Porter, et al (1994), Porter, et al (1995) e Canada (1996) apresentam avaliação formativa e avaliação final do curso. Ambas distribuídas a alunos, instrutores e mentores do projeto NDDL, para estes participarem na correta descrição dos aspectos do projeto e para informarem as melhorias necessárias neste período. Alguns resultados obtidos na avaliação de 1994/1995 do Projeto NDDL são exibidos na figura 10, onde 5 é “Excelente”, 4 - “Muito Bom”, 3 - “Bom”, 2 - “Médio” e 1 "Fraco”. Os alunos não foram questionados sobre a Internet (e-mail).

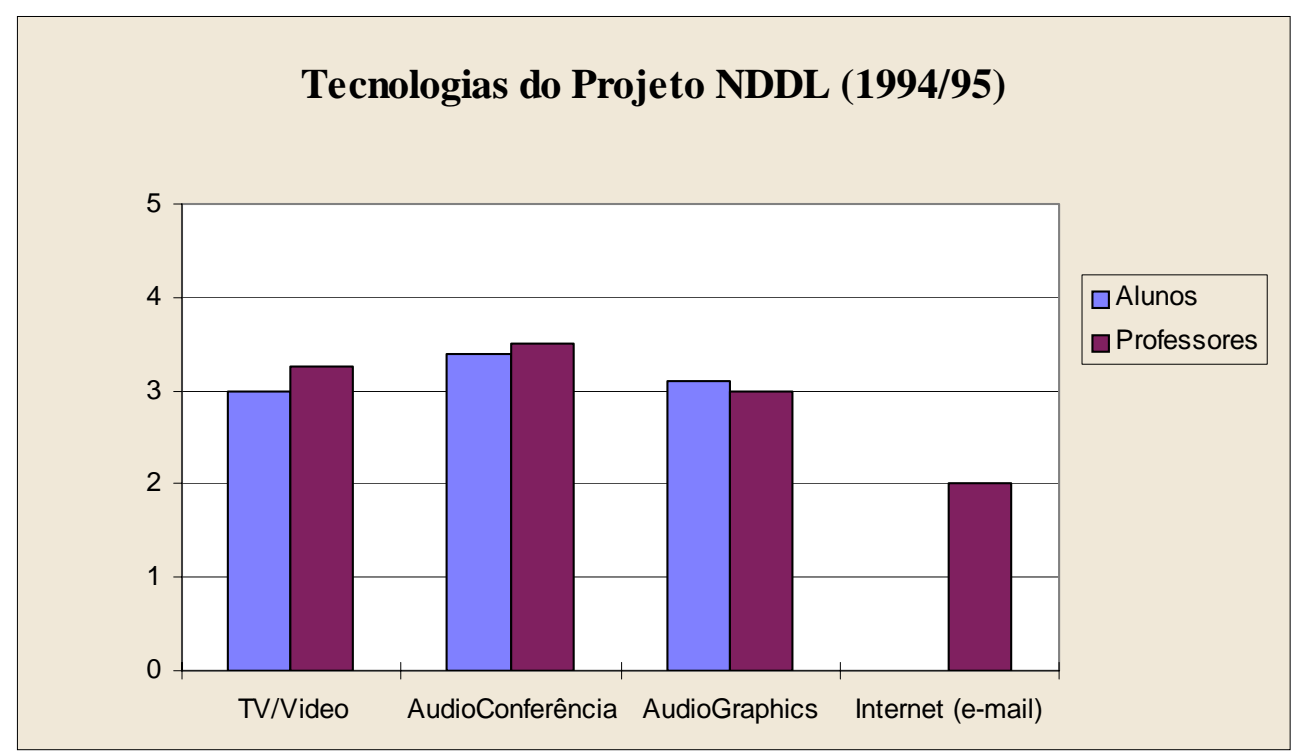

Figura 10 - Resultados obtidos na avaliação 1994/95, relativos às tecnologias utilizadas no Projeto NDDL.

Os autores concluem que o Projeto NDDL obteve êxito em identificar um modelo funcional de cursos à distância e que os resultados obtidos nas avaliações mostram que este é um modelo de aprendizagem eficaz. 


\subsection{Commonwealth Graduate Engineering Program}

Head \& Lockee (1994) conduziram a avaliação dos alunos do Commonwealth Graduate Engineering Program de Virginia Tech, utilizando um questionário como instrumento de avaliação dos alunos on e off-campus. Além de dados na escala Likert, os questionários possuíam feedback escrito, fornecendo oportunidade aos alunos de expor os problemas técnicos e logísticos ocorridos no curso, bem como críticas a fim de melhorar os cursos subsequentes.

Este Programa teve início em 1993 e possuía 38 cursos anuais de graduação, 4 instituições transmitindo o curso, aproximadamente 3.000 alunos oncampus e off-campus, 30 locais remotos pelo país e avaliações semestrais. Para alunos off-campus haviam perguntas adicionais, sendo o questionário dividido em duas partes:

$1^{\text {a }}$ - analisar as principais percepções de instrução do aluno e tratar de tópicos, tais como: realização dos objetivos do curso, pertinência das tarefas externas e performance do instrutor em geral;

$2^{\mathrm{a}}$ - avaliar os fatores do local remoto, como: áudio e qualidade do vídeo, distribuição das tarefas do curso, disponibilidade de livro e material do curso, resolução de problemas e assistência do coordenador local.

Os resultados obtidos nesta avaliação realizada em 1994 são exibidos na Tabela II - onde E - Excelente, B- Bom, A - Adequado e M - Médio - e na Tabela III. 
Tabela II - Resultados obtidos através de questionários usando a escala Likert.

\begin{tabular}{|c|c|l|}
\hline \% & Escala & Descrição \\
\hline 81 & B a E & Qualidade geral de instrução \\
99 & A a E & Recepção visual e áudio \\
91 & A & Apostila e material do curso \\
93 & A & Tempo de distribuição do material \\
97 & A & Processos de inscrição no curso \\
97 & A & Resolução de problemas e assistência dos coordenadores locais \\
70 & M & Valor dos cursos televisivos com relação aos cursos em salas de \\
& & aula tradicionais \\
\hline
\end{tabular}

Tabela III - Resultados obtidos através de feedback escrito dos alunos.

\begin{tabular}{|c|l|}
\hline \% & Descrição \\
\hline 89 & Os objetivos do curso foram alcançados \\
91 & Nível de dificuldade foi o esperado \\
\hline
\end{tabular}

Os alunos avaliaram em 3.1 numa escala de 4.0 a qualidade da instrução no programa. Os dados sobre a qualidade do curso do $2^{\circ}$ semestre de 1993 mostraram uma média de 3.3 para alunos off-campus (local remoto) e 3.5 para alunos oncampus numa escala de 4.0. Os resultados obtidos na avaliação foram utilizados pelos autores com o objetivo de melhorar a qualidade do curso, manter o padrão técnico, conhecer as necessidades dos alunos e fornecer oportunidades educacionais. Portanto, segundo Head \& Lockee (1994) o instrumento de avaliação é aperfeiçoado todos os anos para garantir sua validade. 


\subsection{English as a Second Language Course (ESL)}

Schick (1996) realizou uma avaliação do curso de English as a Second Language (ESL) via Instructional TV (ITV) no West Georgia College. O mecanismo utilizado foi um questionário usando a escala Likert fornecido aos alunos no final de cada 4 meses. Com o objetivo de determinar suas atitudes junto a ITV e as estratégias instrucionais usadas pelos professores, os alunos responderam sobre seu grau de satisfação com o formato ITV incluindo aspectos do ambiente de EAD. Junto ao questionário com escala Likert, os alunos também responderam questões abertas referentes ao conteúdo do curso, ao instrutor e à tecnologia ITV.

Este curso teve início em Janeiro de 1995, sendo que 25 alunos responderam os questionários e as avaliações ocorreram a cada 4 meses. Os resultados preliminares obtidos pelo autor, indicaram que não houve diferença significativa entre alunos do local de origem e do local remoto nas categorias especificadas na Tabela IV. Porém, os alunos do local de origem expressaram maior satisfação com o curso ITV e acreditaram ter aprendido algo mais (item Conhecimento da Tabela IV). Entretanto, a média do Conhecimento no local remoto foi maior durante o Verão. Alguns alunos deram a impressão de que sentiram maior dificuldade com a tecnologia ITV do que a sala de aula tradicional. 
Tabela IV - Resultados preliminares da avaliação. Fonte: Schick (1996).

Onde: Grupo 1 - local remoto

Grupo 2 - local de origem

\begin{tabular}{|c|c|c|c|c|}
\hline Categorias & Grupos & Inverno & Primavera & Verão \\
\hline $\begin{array}{c}\text { Satisfação com o curso } \\
\text { à distância }\end{array}$ & 1 & 3.60 & 3.65 & 3.18 \\
& 2 & 3.84 & 4.24 & 3.40 \\
Conhecimento & 1 & 3.65 & 3.62 & 3.57 \\
& 2 & 3.92 & 4.23 & 3.50 \\
Dificuldade Relativa & 1 & 3.59 & 3.67 & 3.56 \\
& 2 & 3.70 & 3.70 & 3.67 \\
Dificuldades com aspectos & & & & \\
específicos da tecnologia ITV & 1 & 3.55 & 3.50 & 3.48 \\
& 2 & 3.56 & 3.80 & 3.80 \\
\hline
\end{tabular}

Segundo o autor, em termos de melhoramentos no curso:

- muitos alunos comentaram a tecnologia como sendo frustrante, especialmente quando "as coisas não davam certo”;

- a qualidade de transmissão deveria ser melhorada;

- vários alunos também sugeriram que o instrutor visitasse os locais remotos com maior freqüência.

Através dos resultados obtidos, o autor concluiu que esforços contínuos serão necessários para melhorar o sistema utilizado, principalmente na qualidade de transmissão. Os alunos, em seus comentários, apreciaram a conveniência de um curso em casa e desfrutaram da interação com professores de outras partes do Estado fornecida pela ITV. Também sentiram que a instrução não é tão rápida quanto com o instrutor todo o tempo na sala de aula, porém, numa visão geral, a maioria admitiu que a EAD é, de fato, uma alternativa valiosa. 


\section{Programa Educ@r}

\subsection{Definição}

O Programa Educ@r (ver artigo 1 do anexo A) foi desenvolvido pelo Centro de Divulgação Científica e Cultural da USP de São Carlos (CDCC/USP) com o apoio da Vitae, FAPESP e CNPq. Inicialmente foi desenvolvido o seguinte conjunto de cursos à distância via WWW:

1. Matemática para professores de $1^{\mathrm{a}}$ a $4^{\mathrm{a}}$ séries;

2. Mecânica Gráfica para alunos de $2^{\circ}$ grau;

3. Educação Ambiental.

Em cada curso procurou-se aplicar diferentes recursos da tecnologia WWW, para que, ao final do Programa fosse possível avaliar várias possibilidades tecnológicas. Desta forma, o curso de Matemática constitui um curso de instrução “pura” via WWW, bastando o aluno ligar o computador, ler e responder o que aparece na tela - tradicionalmente a Matemática é uma Ciência que dificilmente ultrapassa as dimensões de uma folha de papel. Por outro lado, no curso de Educação Ambiental, a Internet é usada para que alunos de escolas distribuídas por todo o território nacional possam compartilhar resultados de observações ambientais, adquirindo além do conhecimento local, uma visão nacional global da problemática estudada (Schiel \& Magalhães, 1997). O curso de Mecânica Gráfica usufrui dos recursos de tabelas da WWW. Possui tabelas interativas (explicadas no artigo 1 do 
anexo A) exibidas nas figuras 11 e 12 - fornecendo um feedback imediato dos dados coletados pelos alunos na parte experimental.

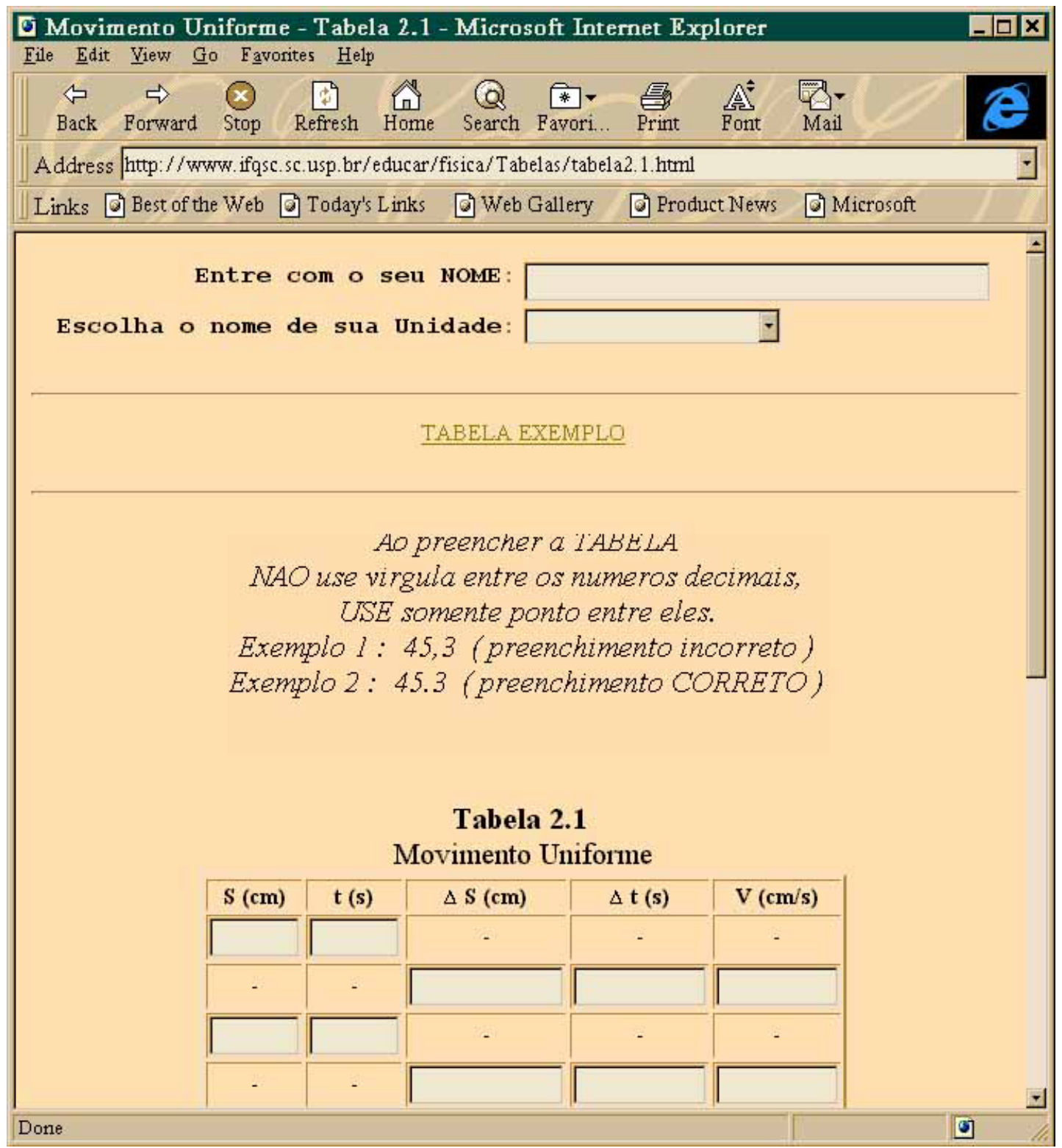

Figura 11 - Exemplo de uma tabela interativa do curso de Mecânica Gráfica 


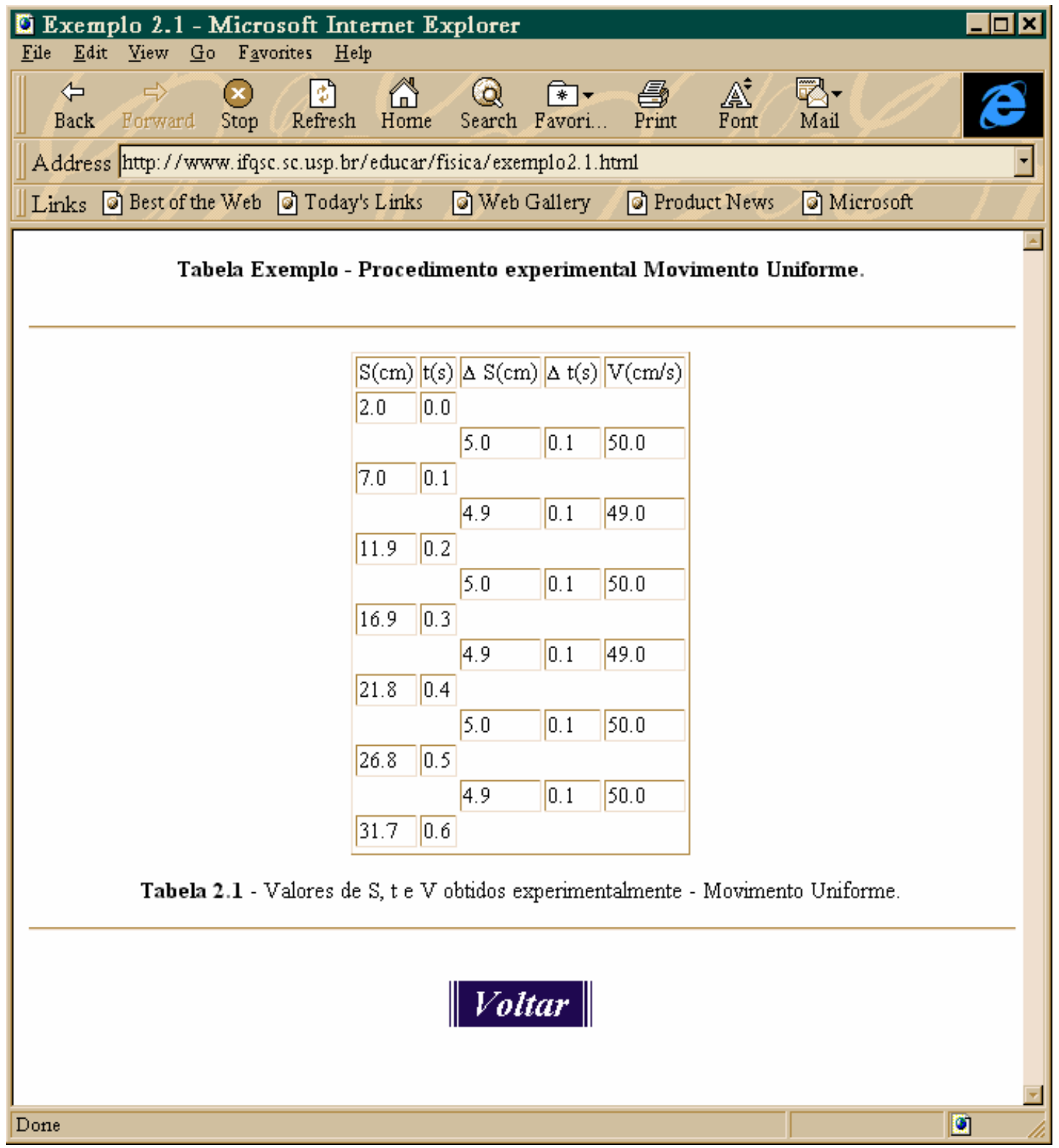

Figura 12 - Exemplo de uma tabela interativa preenchida.

No ano letivo de 1997 o Programa está disponível para 23 Centros de Ciência que estão conectados via Internet com o CDCC/USP em 11 Estados, decorrente de projetos anteriores, envolvendo os participantes do Projeto Experimentoteca. Além disso, está sendo aplicado em mais de 20 escolas na região de São Carlos (Schiel \& Magalhães, 1997).

No Programa Educ@r há um mentor - a prof ${ }^{a}$ Iria Müller Guerrini - e instrutores para as classes, os quais são professores nas escolas e estão presentes na sala de aula. Portanto, neste caso, o instrutor local também será um professor. 


\subsection{Objetivo}

O objetivo do Programa Educ@r é propiciar um ambiente de treinamento e reciclagem de professores e a instrução dos alunos através de atividades distribuídas pela rede. Pretende-se também diminuir a distância propriamente dita, proporcionando e valorizando a participação dos alunos e professores no ambiente educacional, pois a escola estará ligada com outras escolas, com o CDCC/USP e com o mundo através da Internet (Magalhães \& Schiel, 1996).

\subsection{O Curso de Mecânica Gráfica²}

O software do programa de Física foi terminado em outubro de 1996. No ano de 1997, está sendo usado em mais de 20 escolas na região próxima de São Carlos. Também está disponível na "Rede de Centros de Ciência” ligada ao Programa Educ@r e nos Estados do Ceará, Rio Grande do Sul e Distrito Federal através do Programa de EAD em Ciência e tecnologia do CNPq (Schiel \& Magalhães, 1997).

Neste curso, além do material impresso, o aluno pode usufruir dos recursos da Internet com a tecnologia WWW e dispor de experiências quantitativas com o LOGO e o Puck ${ }^{3}$. Mostrada a parte teórica com os materiais do curso, iniciase a parte experimental utilizando o Puck para que o aluno tenha acesso fácil às experiências quantitativas de Física.

A familiaridade com a tecnologia WWW é usada tanto para que o aluno possa rapidamente conferir a correção de seus cálculos obtidos na parte experimental, quanto para obter orientação e contato com o mentor do Programa Educ@r situado em São Carlos/SP. Através do LOGO, o aluno adquire familiaridade

\footnotetext{
${ }^{2}$ Para melhor compreensão da exposição que segue, sugerimos leitura do artigo 1 do anexo A - Mecânica gráfica, um exemplo de Ensino de Física na WWW - e consulta do site http://www.ifqsc.sc.usp.br/educar/fisica/fisica.html

${ }^{3}$ Inventado em São Carlos/SP, o Puck de Hessel (Hessel, 1982) permite o registro de movimentos bidimensionais a um custo bem inferior à fotografia estroboscópica (Schiel, 1996). Ver também http://www.ifqsc.sc.usp.br/educar/fisica/puck.html
} 
com a mecânica, programando seu computador para que este confirme os resultados obtidos experimentalmente com o Puck. Em seu trabalho, o aluno realiza e analisa experiências e programas feitos no computador. Isto ocorre nas seguintes etapas (Schiel, 1996):

1. Familiarização com a linguagem LOGO, aproveitando a motivação que o aspecto lúdico desta linguagem traz;

2. Realização de experimentos com o Puck e obtenção de dados sobre a trajetória deste. De posse destes dados, o aluno calcula a velocidade e aceleração deste corpo. Tabelas interativas permitem que ele possa imediatamente verificar, de forma virtual, se está acertando. Imprevistos, dúvidas e problemas conceituais são respondidos pelo mentor através de e-mail. Todos os cálculos feitos pelo aluno são registrados pela direção do Programa;

3. No final de cada capítulo, o aluno faz um programa em LOGO, procurando confirmar os resultados experimentais.

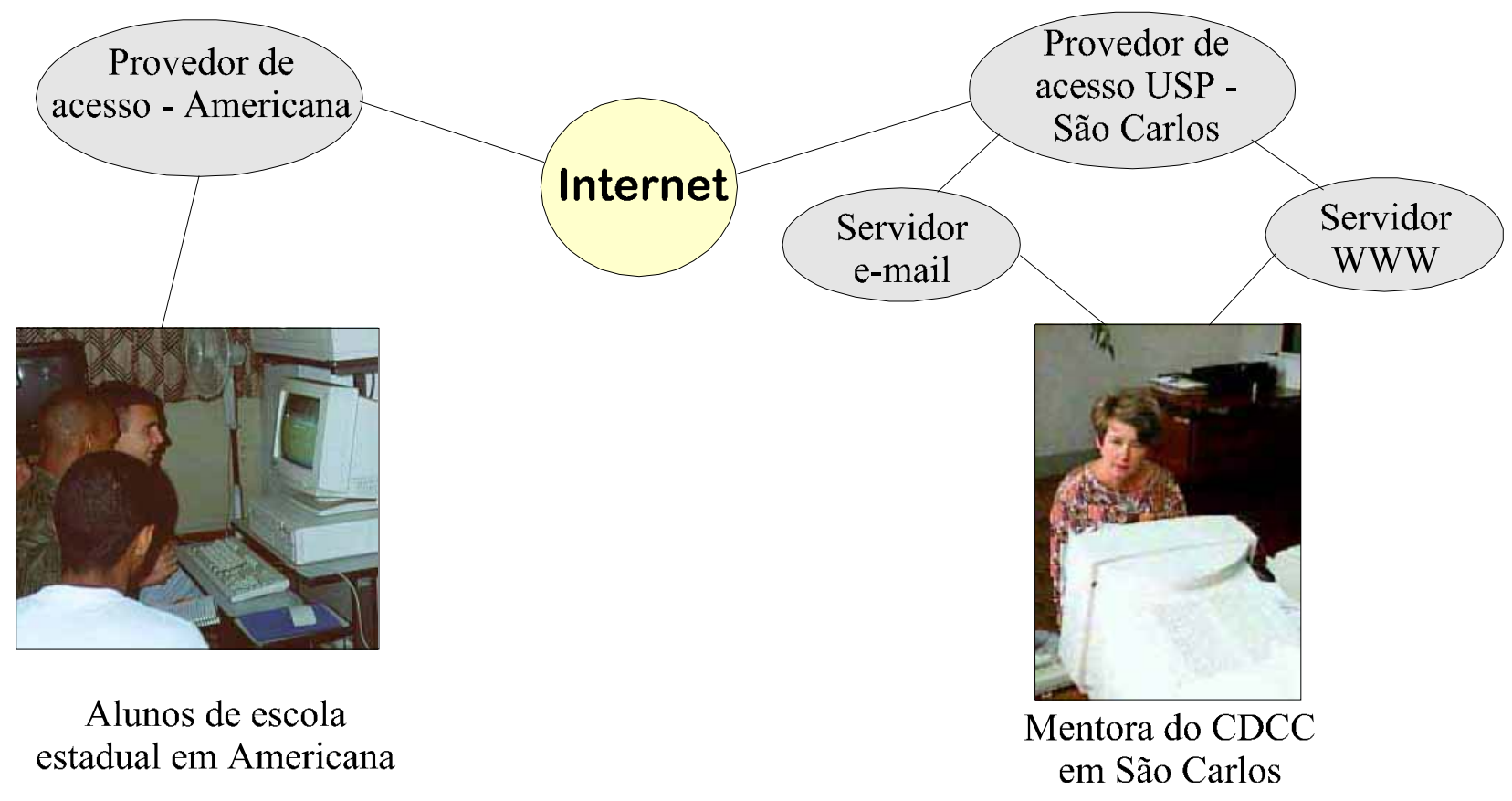

Figura 13 - Esquema simplificado de uma conexão à Internet do Projeto de Física do Programa Educ@r. Os alunos de Americana “dialoga” com o computador e opcionalmente com a mentora em São Carlos. 


\section{Metodologia de Avaliação do Programa Educ@r}

\subsection{Proposta Piloto para a Avaliação}

Baseada na pesquisa bibliográfica realizada, identificou-se a necessidade de haver não apenas uma avaliação de um curso à distância para a realização de um simples estudo com os dados obtidos, mas sim de um sistema de avaliação continuada. Este trabalho propõe um sistema com duas etapas: avaliação do processo e avaliação da aprendizagem. Visando o objetivo deste trabalho e devido à novidade da tecnologia Internet aplicada à EAD, foi realizada a primeira etapa através da avaliação do processo de EAD com relação à tecnologia utilizada, à interação aluno/instrutor/mentor, ao suporte técnico, ao material do curso e ao feedback. A avaliação da aprendizagem com relação ao conhecimento do aluno e se a EAD, utilizando a tecnologia WWW, fornece aprendizagem, ficará para uma segunda etapa e poderá ser empregada em trabalhos posteriores. Para o desenvolvimento de um sistema de avaliação inicial foram necessárias 10 fases:

1- levantamento da questão, a partir da qual se originou este estudo;

2- pesquisa em instituições internacionais de EAD, que aplicam ou aplicaram avaliações de cursos à distância;

3- identificação dos mecanismos de avaliação utilizados;

4- estudo de mecanismos adequados para o Programa em questão; 
5- seleção dos mecanismos e de uma escala para a coleta dos dados;

6- definição dos requisitos para um sistema de avaliação;

7- definição das questões e elaboração ou adaptação dos mecanismos de avaliação para os nossos padrões;

8- coleta e organização dos dados;

9- análise e interpretação dos dados obtidos;

10- revisão dos mecanismos e preparação para reaplicá-los.

10. revisão dos mecanismos de avaliação

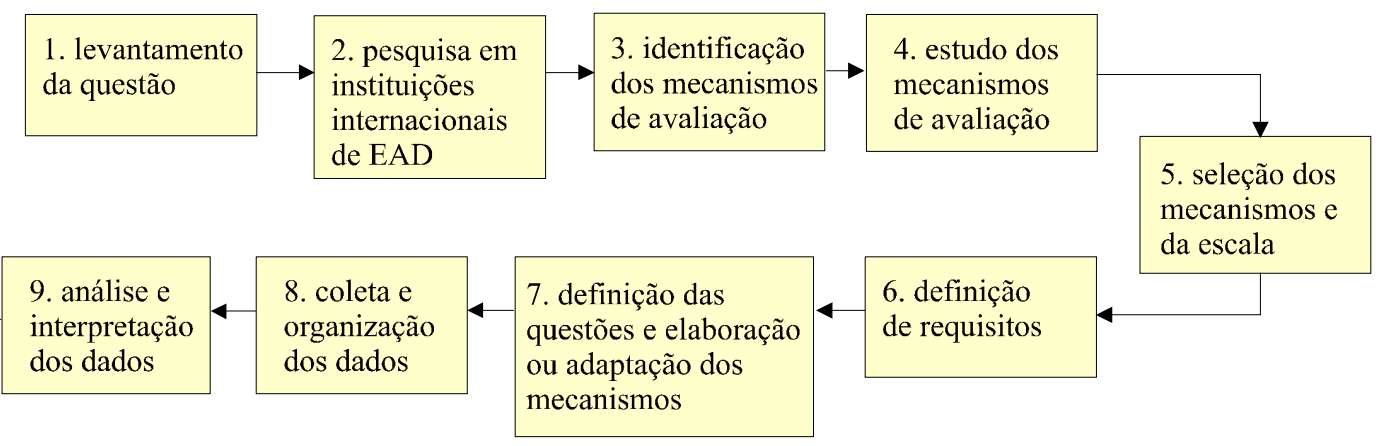

Figura 14 - Fases para o desenvolvimento de um sistema de avaliação inicial.

\subsection{Questão}

Em um curso à distância via Internet usando os recursos da tecnologia WWW, qual o mecanismo utilizado para saber se o objetivo está sendo alcançado, para se conhecer os pontos fortes do curso à distância e o que pode ser melhorado com relação ao material, apresentação das home pages, auxílio dos mentores e instrutores, suporte tecnológico e instrucional, uso da Internet e outras tecnologias? (Magalhães \& Schiel, 1996). Com esta questão em mente, iniciou-se o estudo a partir de uma extensa pesquisa bibliográfica, tendo como referencial a Internet. 


\subsection{Requisitos para a Avaliação}

Nas pesquisas realizadas para verificar o mecanismo de avaliação necessário para o controle da qualidade do curso à distância, observou-se em instituições internacionais de EAD (Peck \& Wallace, 1993; Biner, et al., 1994; Head \& Lockee, 1994; Sorensen, 1995; Schick, 1996) que os instrumentos mais utilizados na obtenção dos dados são os questionários utilizando a escala Likert (Peck \& Wallace, 1993; Preece, 1994). Assim, para avaliar o Programa Educ@r foi desenvolvido um sistema de avaliação através de questionários aplicados em avaliação formativa e no final do curso, os quais foram adaptados do Projeto NDDL da Open Learning Agency situada na província de British Columbia - Canadá.

A partir dos estudos realizados, foram estabelecidos alguns requisitos para o sistema de avaliação:

1- procurar os pontos fortes e críticos de um curso à distância;

2- obter dados quantitativos e qualitativos;

3- promover avaliações durante o curso e após o curso;

4- é de extrema importância que o sistema de avaliação seja um processo contínuo e não apenas um estudo esporádico.

As informações obtidas pelas avaliações através dos questionários deverão ser processadas rapidamente e distribuídas para o pessoal administrativo e pessoal técnico das instituições participantes, a fim de que os problemas ocorridos sejam retificados e melhorias sejam feitas o mais rápido possível. É necessário que todas as instituições integrantes do Programa Educ@r participem das avaliações.

\subsection{Desenvolvimento dos Mecanismos de Avaliação}

Os questionários desenvolvidos para avaliar o Programa Educ@r (ver anexo B) foram aplicados em avaliação formativa, no decorrer do curso e em avaliação conclusiva, após seu final, a fim de identificar as falhas para que a equipe 
do Programa Educ@r possa saná-las, permitindo controlar sua qualidade.

Certas questões foram repetidas nos questionários das avaliações durante e após o curso, para verificar se ocorreram mudanças nos aspectos questionados. Foram aplicados métodos de avaliação quantitativos - através de questões fechadas e qualitativos - através de questões abertas. Como foram as primeiras aplicações do curso e as primeiras avaliações, os dados quantitativos foram coletados para o conhecimento da sua performance. Desta forma, pesquisas posteriores poderão utilizar estas informações para análises futuras.

Questões fechadas e abertas foram elaboradas para alunos, instrutor e mentor. A escala utilizada nas questões fechadas foi a escala Likert com níveis de 1 a 5, respectivamente, “Muito Fraco”, “Fraco”, “Médio”, “Bom” e “Muito Bom”. As questões fechadas versaram sobre as tecnologias utilizadas no curso, suporte técnico, treinamento, relacionamento entre aluno/instrutor/mentor, layout e conteúdo das home pages. As questões abertas abordaram o que o aluno mais gosta e o que menos gosta de aprender no curso; o que o instrutor e o mentor poderiam fazer para melhor ajudar o aluno; se o aluno acha que o curso à distância é melhor, igual ou pior que o curso em sala de aula tradicional; as responsabilidades do instrutor e do mentor; pontos fortes e críticos no relacionamento entre instrutor e mentor; aspectos bem sucedidos e aspectos mal sucedidos do curso e aspectos do Programa Educ@r que poderiam ser melhorados. Os questionários foram testados durante a sua aplicação, procurando verificar se as questões estavam adequadas com o objetivo a ser atingido e se estavam claras para os alunos e professores.

\subsection{Descrição das Atividades Avaliadas}

\subsubsection{Curso em Americana - Nov./Dez. 1996}

Em novembro de 1996, o curso de Mecânica Gráfica do Programa Educ@r foi aplicado pela prof ${ }^{a}$ Wallesandra Araújo Silva em duas classes $\left(1^{\circ}\right.$ e $2^{\circ}$ Colegial noturno) da E.E.P.S.G. João XXIII, na cidade de Americana, Estado de São 
Paulo, situada a $100 \mathrm{Km}$ de São Carlos. A sala de computação se encontrava na Delegacia de Ensino, situada a mais de 100 metros da sala de aula da escola, apesar de estarem em prédios contíguos. Portanto, as mensagens do mentor eram enviadas para o e-mail da Delegacia de Ensino e depois repassadas à prof ${ }^{a}$ Wallesandra para distribuir aos seus alunos. A infra-estrutura era precária, pois só estava disponível um computador conectado à Internet, adquirido com recursos de projeto do CDCC. Devido à exigüidade do tempo só foi possível realizar e analisar os experimentos sobre o Movimento Retilíneo Uniforme.

O sistema de avaliação foi aplicado no curso à distância através de questionários respondidos por alunos, instrutor e mentor (Magalhães, 1996) e através da observação dos alunos. Os experimentos com o Puck e a entrada dos dados na Internet foram realizados durante um dia de aula cada. O $1^{\circ}$ Colegial foi a única classe a usar duas vezes o Puck e usou nos dias 14 e 21 de novembro, a Internet. O $2^{\circ}$ Colegial usou a Internet no dia 2 de dezembro.

Neste teste piloto foram coletados dados de 21 questionários de avaliação formativa, aplicados aos alunos durante o curso, nas classes do $1^{\circ}$ e $2^{\circ}$ Colegial. Também foi aplicada uma avaliação final do curso na classe do $1^{\circ}$ Colegial obtendo dados de 13 questionários. Todos os alunos participantes do curso responderam os questionários. Participaram do curso 9 alunos no $1^{\circ}$ Colegial e no término havia 13 alunos. Na classe do $2^{\circ}$ Colegial havia 12 alunos.

Em face às dificuldades levantadas pela avaliação, foi providenciado o contato com o responsável pelo provedor de acesso de Americana, para tentar sanar o problema da restrição do tempo que o computador fica sem transmitir os dados. Quanto ao local de trabalho, a Delegacia de Ensino providenciou melhorias na sala e até mesmo um outro computador conectado à Internet. Em vista dessas dificuldades e das providências tomadas, os próximos cursos poderão ser melhorados, a restrição de tempo poderá ser resolvida e os locais de trabalhos poderão ser melhor selecionados.

Após a aplicação da primeira parte do sistema de avaliação, foram feitas revisões e atualizações nos questionários, algumas questões foram alteradas, outras foram eliminadas e incluídas. Realizaram-se alterações nos questionários aplicados aos alunos e ao mentor, com base na observação dos alunos feita pelo avaliador presente em sala de aula e nos comentários do professor mentor. Desta forma, os 
questionários ficaram prontos para outra aplicação.

\subsubsection{Curso em Americana - Abril/Maio 1997}

No primeiro semestre de 1997, o mesmo curso foi aplicado nos meses de abril e maio (ver tabelas e mensagens do anexo $\mathrm{C}$ e fotos do anexo $\mathrm{D}$ ), em uma classe do $1^{\circ}$ Colegial noturno da mesma escola em questão, pela prof ${ }^{a}$ Wallesandra, com a mesma infra-estrutura e apresentando o mesmo problema anterior da restrição de tempo. Devido a problemas alheios ao Programa, somente foi possível utilizá-lo uma vez, sendo aplicada apenas a avaliação formativa. Não houve tempo hábil para a conexão do segundo computador à Internet, adiando-se o seu uso para o segundo semestre do mesmo ano.

Neste semestre, a Delegacia de Ensino e a Escola divulgaram, internamente, fotos da aula de Física da prof ${ }^{a}$ Wallesandra, onde os alunos estavam utilizando o Programa Educ@r. Isto serviu de incentivo a outros alunos com relação a esta matéria e ao Programa. Como resultado, houve uma maior presença na sala de aula, participando 31 alunos. Portanto, obtivemos um maior número de questionários retornados numa única avaliação formativa, totalizando 31 questionários, quase a mesma quantidade coletada durante as 3 avaliações do semestre anterior.

Devido à grande quantidade de alunos e à infra-estrutura de apenas 1 computador, tornou-se mais difícil ministrar a aula e alguns alunos tiveram dificuldades em entender o Programa Educ@r. Não houve tempo suficiente para melhor explicar a eles sobre a Internet, muito menos sobre como trabalhar com o computador. Isto favoreceu os alunos que sentaram próximo do computador; os demais alunos dos grupos ficaram prejudicados. Suas reações foram das mais diversas, desde os que entenderam o Programa Educ@r até os que não o entenderam e assim, não responderam devidamente as avaliações. A seguir, na figura 15, é exibida a evolução do número de alunos nos cursos. 


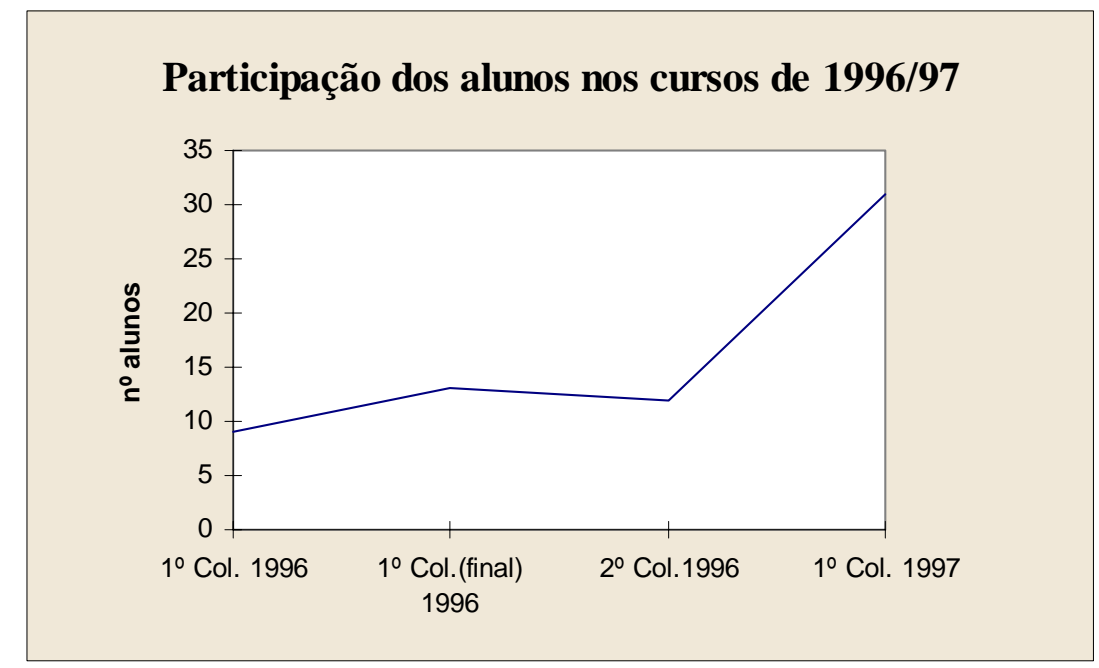

Figura 15 - Evolução do $n^{0}$ de alunos participantes nos cursos de Mecânica Gráfica em 1996/97.

Após os cursos, os questionários estarão disponíveis na Internet no formato de formulários para possibilitar a realização de avaliações on-line em outras escolas participantes no Programa Educ@r.

\subsubsection{Treinamento de Professores - Jan. 1997}

De 25 a 30 de janeiro de 1997, foi realizado um curso de treinamento de professores instrutores (ver fotos do anexo E) com 20 professores de $2^{\circ}$ grau da rede pública de ensino os quais estarão aplicando o curso de Mecânica Gráfica em 1997. Nessa semana foi cumprida toda a programação constante no Programa Educ@r, a qual se acha detalhada na tabela 1 descrita no artigo 1 do anexo A.

\subsection{Resultados da Avaliação}

Na avaliação dos cursos em Americana, realizada neste trabalho, não foram apresentados dados sobre o LOGO. Pelo fato da E.E.P.S.G. João XXIII ser uma escola de ensino modular, houve tempo suficiente apenas para fazer e analisar experimentos sobre o Movimento Retilíneo Uniforme e enviar tabelas interativas 1.1, 1.2 e 2.1, as quais contém dados de Movimentos Unidimensional, Bidimensional e 
Uniforme, respectivamente.

Os dados das questões fechadas foram tabulados numa planilha eletrônica e a seguir, representados graficamente. Os dados das questões abertas foram analisados, as respostas relevantes em comum, selecionadas e os dados, tabulados. As análises foram enviadas para o pessoal administrativo e pessoal técnico do Programa, com a finalidade de providenciar melhorias a serem feitas e informá-los dos pontos de sucesso do curso e de possíveis falhas.

\subsubsection{Cursos com Alunos}

\section{a) Avaliação pelo Instrutor e Mentor}

As primeiras avaliações do curso de Mecânica Gráfica do Programa Educ@r realizadas em 1996, ressaltam como pontos favoráveis ao projeto, no testemunho do instrutor:

- "grande estímulo aos alunos para entendimento da matéria";

- “apoio ao trabalho";

- “auxilia na percepção de erros, ajudando na melhoria do entendimento";

- "proporciona contato com uma tecnologia atual";

- “amplia os horizontes dos alunos e professores";

- “facilita a comunicação entre professores (instrutor/mentor) atualizando-os (reciclando-os)”.

O instrutor afirmou também que os alunos estavam estimulados antecipadamente para a aula na Internet, pois era uma novidade. As maiores dúvidas dos alunos foram relacionadas com o entendimento das páginas, “quedas de ligação” (Internet) e como funciona o Puck. Foi necessária paciência do instrutor para explicar quando havia "quedas de ligação" e que problemas ocorrem em todos os lugares. O instrutor mostrou a utilidade do Programa no atual estágio tecnológico, de comunicação, etc. Na sua opinião, os aspectos desfavoráveis foram com relação a:

- “número de aulas (nesta escola) menor que o necessário”; 
- “número de alunos por computador: apenas 1 computador conectado à Internet inviabiliza melhor resultado";

- "distância entre a sala de aula e a sala de computação” ;

- “demora no recebimento (no meu caso) das respostas" .

Como aspectos que poderiam ser melhorados, o instrutor sugere:

- “um planejamento da matéria junto aos instrutores, para conciliar a Internet, o LOGO e o programa escolar, a fim de melhorar o aproveitamento";

- “maior rapidez nas respostas”.

Para o mentor os aspectos bem sucedidos do curso à distância, foram:

- “a interação Aluno/Programa/Professor presente/Professor distante”;

- "a liberdade na construção do conhecimento";

Como aspecto crítico, o mentor destaca os problemas de acesso à rede na escola. Com relação à educação, o mentor salienta certos aspectos do Programa Educ@r, a saber:

- "é complementar à aula formal, auxiliando o professor e o aluno";

- “o aluno pode construir seu conhecimento com liberdades de ação";

- “coloca o aluno/professor em contato com a informática”.

Com relação à tecnologia, o mentor destaca:

"através da Internet, a troca de informações entre professor distante/professor presente/alunos e o resto do mundo, faz com que a tecnologia seja um instrumento importante no mundo atual”.

Na figura 16 são exibidos os dados da avaliação formativa pelo instrutor e pelo mentor durante o segundo semestre de 1996, utilizando a escala Likert de 5 níveis, onde 1 é “Muito Fraco”, 2 - “Fraco”, 3 - “Médio”, 4 - “Bom” e 5 - “Muito Bom”. O mentor não respondeu sobre o conteúdo das home pages e sobre a metodologia dos hipertextos, pois estes itens tinham sido elaborados por ele, cabendo a outra pessoa avaliar. 


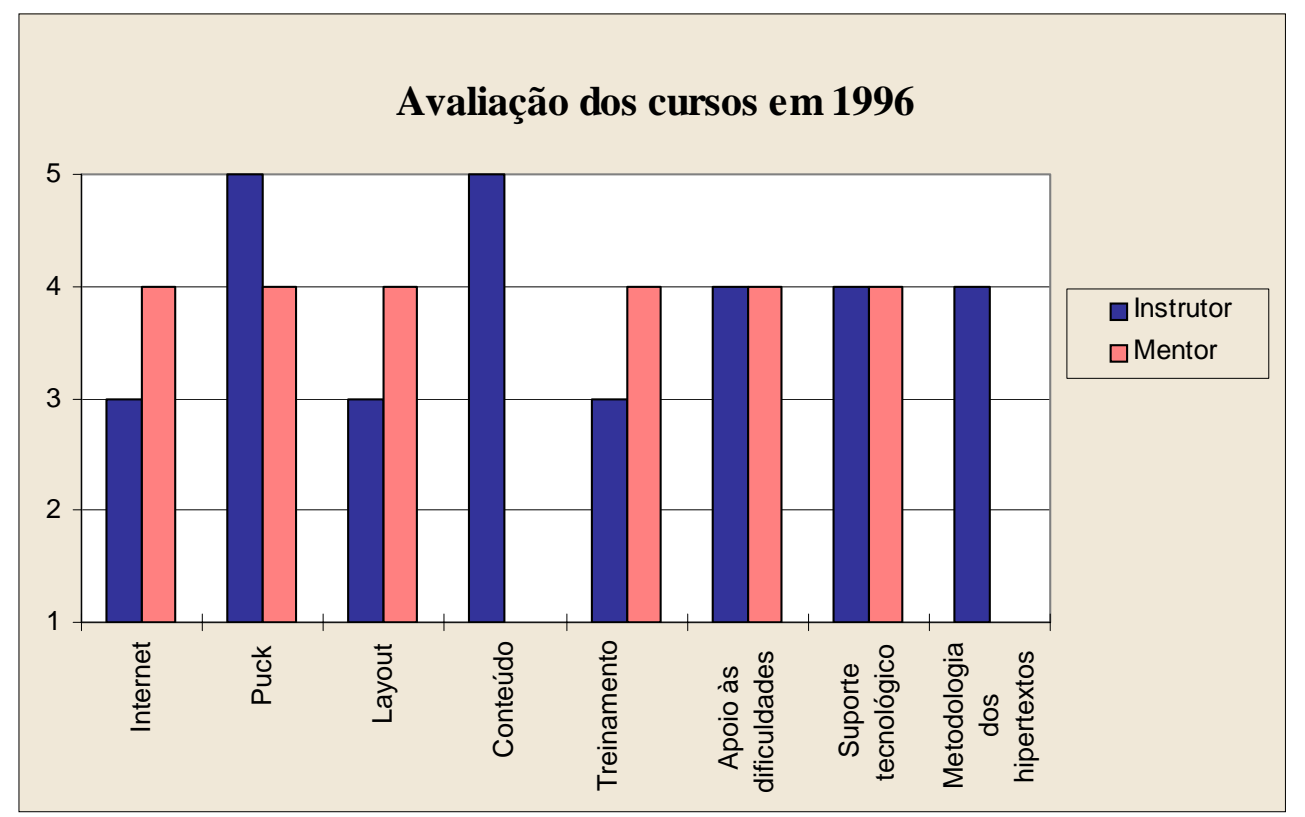

Figura 16 - Avaliação formativa pelo instrutor e pelo mentor durante o $2^{\circ}$ semestre de 1996.

Na avaliação do primeiro semestre de 1997, por motivos imprevistos o instrutor não pode responder o questionário. Neste semestre, o mentor destaca como pontos fortes do Programa Educ@r o fato do instrutor poder auxiliar diretamente os alunos, principalmente na parte experimental, facilitando o trabalho do mentor. $\mathrm{Na}$ sua opinião, o aspecto bem sucedido no curso foi a interação aluno/instrutor/mentor, facilitando o processo ensino-aprendizagem. O mentor salienta que, como a simulação do movimento em linguagem LOGO não foi realizada devido ao tempo escasso, esta parte ficou incompleta. Como itens a serem melhorados, destaca:

- “maior quantidade de computadores para uso dos alunos";

- "ensinar os professores a consertarem o Puck quando este quebrar".

\section{b) Avaliação pelos Alunos}

Em 1996, os alunos do $1^{\circ}$ e $2^{\circ}$ Colegial avaliaram de "Bom” a "Muito Bom” as tecnologias utilizadas no curso, o layout e o conteúdo das home pages, o suporte do instrutor e do mentor. A maioria achou que o curso à distância é melhor que o curso em sala de aula tradicional. Para os alunos, foram pontos positivos:

- o retorno das respostas nas tabelas interativas; 
- a indicação de erros de cálculo;

- a interação com outras pessoas.

Como pontos a serem melhorados, citaram:

- a conexão discada à Internet (bastante problemática);

- o tamanho diminuto da sala de computação;

- a necessidade de mais computadores conectados à Internet;

- o contato com o mentor distante deveria ser imediato, durante a execução do experimento;

- muita curiosidade com respeito ao mentor, sua personalidade, etc.

A figura 17 mostra o grau de satisfação dos alunos com relação ao conteúdo das home pages e às tecnologias Internet e Puck, obtido através das avaliações formativa e final aplicadas no $1^{\circ}$ Colegial, utilizando a escala Likert de 5 níveis, onde 1 é “Muito Fraco”, 2 - "Fraco”, 3 - “Médio”, 4 - “Bom” e 5 - "Muito Bom”.

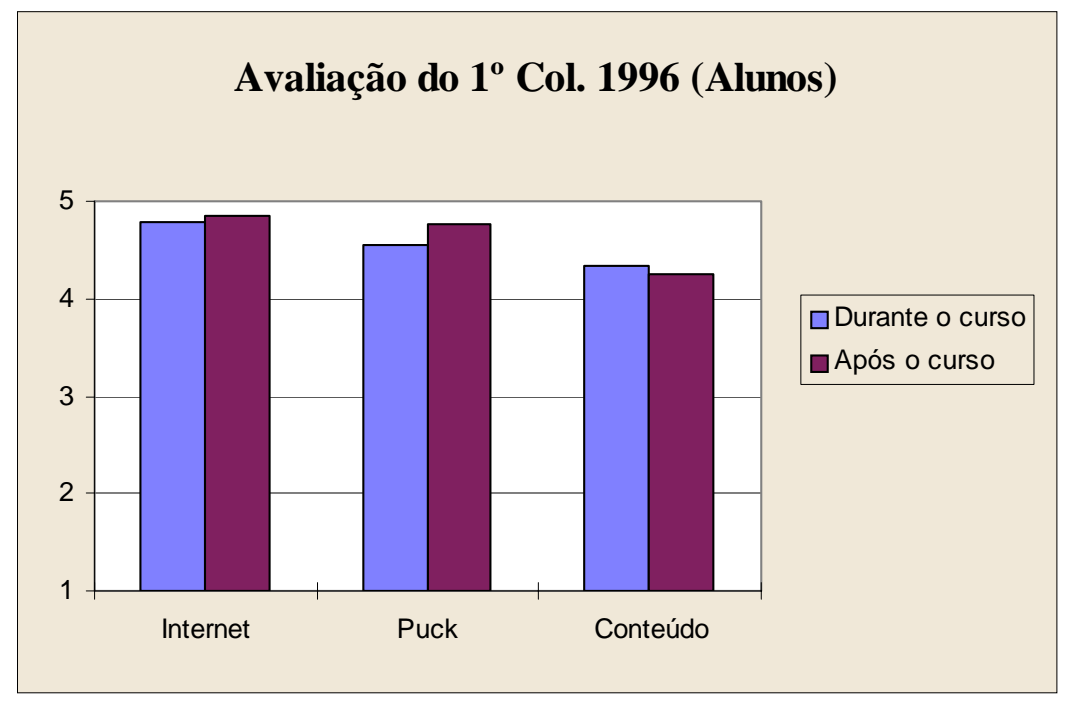

Figura 17 - Avaliação pelos alunos do $1^{\circ}$ Colegial noturno da E. E. P. S. G. João XXIII. Fonte: Magalhães \& Schiel (1997)

Nas tabelas V e VI serão exibidos os resultados das questões abertas da avaliação final aplicada no $1^{\circ}$ Colegial noturno em 1996. 
Tabela V - Resultados da avaliação final em 1996.

\begin{tabular}{|c|l|}
\hline$\%$ & O que os alunos mais gostaram no curso do Programa Educ@r? \\
\hline 34 & de receber as mensagens do mentor durante o curso \\
25 & do Puck \\
17 & quando a conexão estava OK \\
8 & da conexão com a Universidade \\
8 & do contato com o mentor \\
8 & de tudo \\
\hline 100 & \\
\hline
\end{tabular}

Tabela VI - Resultados da avaliação final em 1996.

\begin{tabular}{|c|l|}
\hline \% & O que poderia ser feito para melhorar o curso do Programa Educ@r? \\
\hline 42 & melhorias na conexão à Internet \\
42 & maior quantidade de computadores \\
8 & mais divulgação \\
8 & mais professores \\
\hline 100 & \\
\hline
\end{tabular}

Com relação ao que os alunos menos gostaram, 78\% responderam que não gostaram quando “caía a ligação” e não conseguiam se conectar novamente.

A figura 18 mostra os resultados das questões fechadas da avaliação formativa aplicada no $2^{\circ}$ Colegial em 1996. Foram obtidos dados sobre a satisfação dos alunos com relação às tecnologias Internet e Puck, ao conteúdo e layout das home pages, utilizando a escala Likert. 


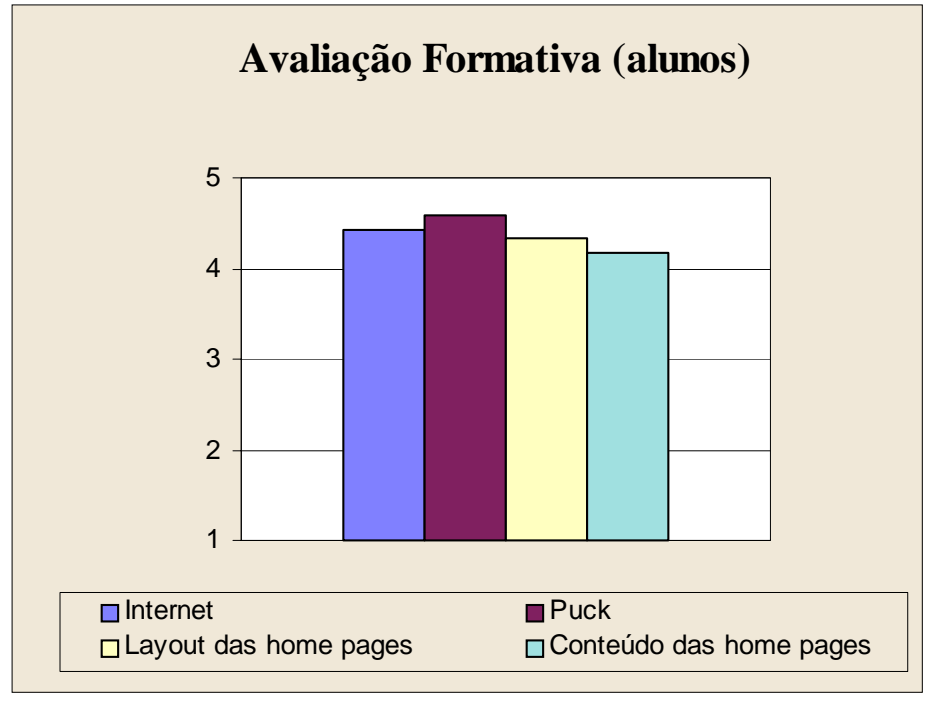

Figura 18 - Avaliação formativa pelos alunos do $2^{\circ}$ Colegial noturno da E. E. P. S. G. João XXIII no $2^{\circ}$ semestre de 1996.

Em 1997, dos 31 questionários respondidos por alunos do $1^{\circ}$ Colegial noturno, 28 foram selecionados. Os alunos avaliaram de "Bom” a "Muito Bom” as tecnologias utilizadas no curso, o layout e o conteúdo das home pages, o suporte do instrutor e do mentor. A maioria achou que o curso à distância é melhor que o curso em sala de aula tradicional. 64\% já haviam trabalhado com computadores. Para os alunos, a interação com outras pessoas foi um ponto positivo do Programa Educ@r.

Como pontos a serem melhorados, citaram:

- mais tempo de aula para aprender melhor;

- mais computadores conectados à Internet;

- mais pessoas disponíveis para orientar os alunos;

A figura 19 mostra os resultados das questões fechadas da avaliação formativa aplicada no $1^{\circ}$ Colegial de 1997. Foram obtidos dados sobre a satisfação dos alunos com relação às tecnologias Internet e Puck, ao conteúdo e layout das home pages e ao suporte do mentor e do instrutor, utilizando a escala Likert. 


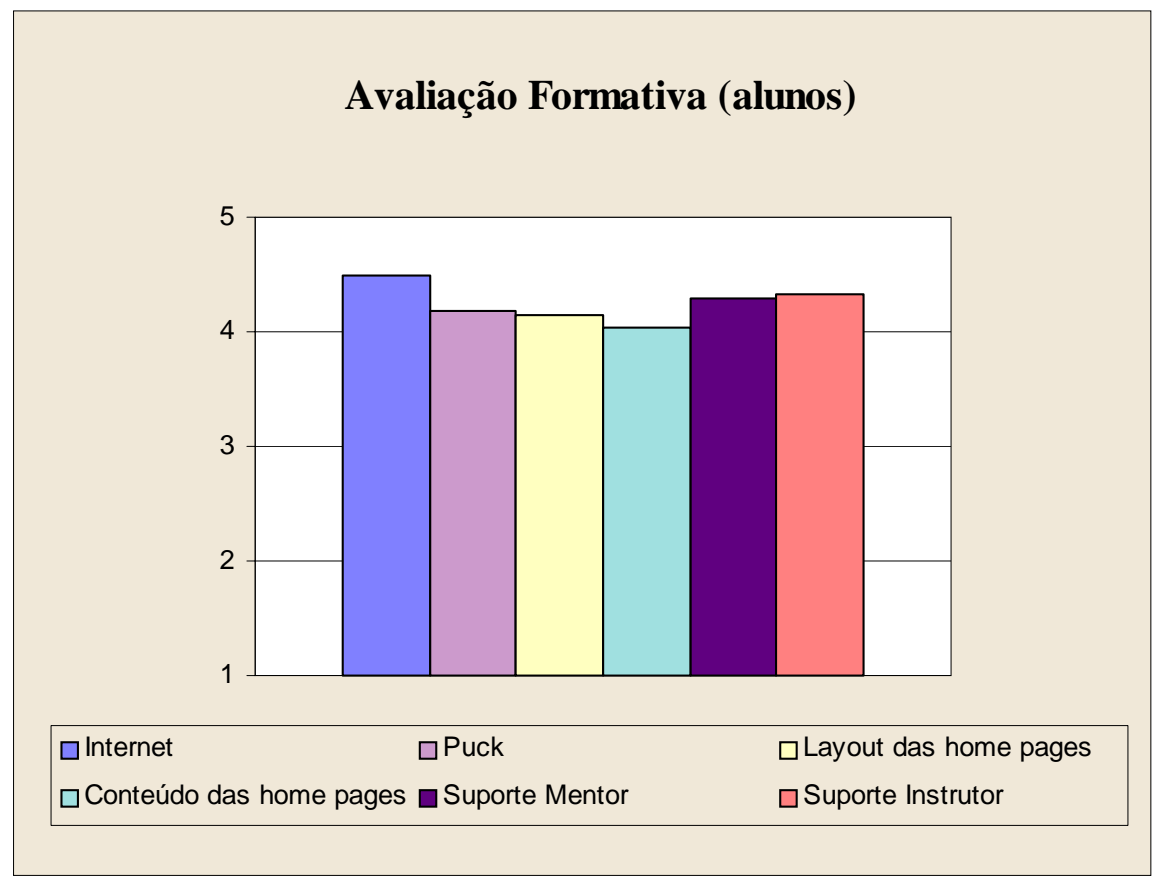

Figura 19 - Avaliação formativa pelos alunos do $1^{\circ}$ Colegial noturno da E. E. P. S. G. João XXIII no $1^{\circ}$ semestre de 1997.

A seguir são destacados alguns testemunhos dos alunos do $1^{\circ}$ e do $2^{\circ}$ Colegial de 1996 e do $1^{\circ}$ Colegial de 1997, referentes às seguintes questões das avaliações formativas:

\section{Porque você decidiu fazer o curso através do Programa Educ@r?}

"é uma proposta interessante e até, porque, acabou com a rotina da aula” (1 $\left.1^{\mathrm{O}} \mathrm{Col}.\right)$

"é uma experiência que ensina, é muito bom trabalhar com este programa" (1 Col.)

“para melhor avaliação de meus resultados” ( $\left.2^{\circ} \mathrm{Col}.\right)$

"porque é um curso que a escola está nos mostrando e que vai ser muito útil” ( $2^{\circ}$ Col.)

"talvez pelo fato de ser uma experiência nova, onde podemos variar e expandir o conhecimento" $\left(1^{\circ} \mathrm{Col} .1997\right)$

"achei interessante mandar esta tabela para estudo, também acho que é muito educativo e foi por incentivo de minha professora, mas acabei adorando. Espero que sigam com este programa” (1 Col. 1997) 


\section{O que mais gosta de aprender através do Programa Educ@r?}

"aprender a matéria que está sendo perguntada e ao mesmo tempo se comunicar com pessoas distantes" $\left(1^{\circ} \mathrm{Col}\right.$.)

"foi a comunicação com vocês. Nós aplicamos o que aprendemos e vocês nos avisaram se está correto ou incorreto" ( $1^{\circ} \mathrm{Col}$.)

"a comunicação através deste programa e a iniciativa de ter experiências com o $2^{\circ}$ grau Estadual” ( $2^{\circ} \mathrm{Col}$.)

"comunicar-se com outras pessoas, para poder usufruir de novas experiências ou talvez de novas culturas" ( $1^{\circ}$ Col. 1997)

“aprender a fazer os cálculos, enviar através da Internet e ver como é prático você aprender este tipo de cálculo através desse programa, e também ver as opções que temos através do micro" ( $\left.1^{\circ} \mathrm{Col} .1997\right)$

"saber que através de pontos de caneta dá para saber o $\Delta$ s e o $\Delta t$ percorrido e também sua velocidade escalar média” ( $1^{\circ}$ Col. 1997)

$\underline{\text { O que o mentor poderia fazer para melhor ajudá-lo no curso? }}$

"talvez se no ano que vem conversar com vocês pelo computador" (1 ${ }^{\circ}$ Col.)

"acho que ele poderia explicar mais coisas, como - se nós errássemos ele diria o por que" ( $2^{\circ} \mathrm{Col}$.)

“foram ótimos, faltou um pouco de diálogo" ( $2^{\circ} \mathrm{Col}$.)

“também analisar os erros e explicar o por que” ( $2^{\circ} \mathrm{Col}$.)

"dar novas dicas, novos caminhos, ajudar-nos a expandir todo o nosso conhecimento, não deixando se tornar algo monótono (tarefa difícil)" ( $1^{\mathrm{o}}$ Col. 1997)

"poderia mandar alguns cálculos através de exemplos ou modelos para facilitar e também mandar dicas para estudo em grupo” ( $1^{\circ} \mathrm{Col}$. 1997)

"ter aulas práticas freqüentemente com a sua turma, e também contato direto conosco" ( $1^{\circ} \mathrm{Col}$. 1997)

“poderia simplificar bem mais suas respostas" (1 Col. 1997)

$\underline{\text { O que o instrutor poderia fazer para melhor ajudá-lo no curso? }}$

“explicar mais detalhadamente” ( $\left.1^{\circ} \mathrm{Col}.\right)$

"ele precisaria tirar as dúvidas de todos os alunos" ( $\left.2^{\circ} \mathrm{Col}.\right)$

“procurar levar mais vezes o aluno para participar do curso” $\left(1^{\circ} \mathrm{Col}\right.$. 1997)

"continuar no mesmo ânimo, nunca desistindo, ajudando-nos a vencer as barreiras (dificuldades)” (1 ${ }^{\circ}$ Col. 1997) 
Você acha que este curso é melhor, igual ou pior que os cursos tradicionais em sala de aula? Por quê?

"igual; só tem uma coisa melhor, você aprende e conhece outras pessoas" $\left(1^{\circ} \mathrm{Col}.\right)$

“melhor, sai da rotina” $\left(1^{\circ} \mathrm{Col}\right.$.)

"acho melhor, porque num computador você se diverte e se interessa mais pela aula” $\left(1^{\circ} \mathrm{Col}.\right)$

"melhor, porque conversa com várias pessoas e com isso, mais idéias" $\left(1^{\circ}\right.$ Col. $)$

"acho melhor, porque com isso nós vamos ter mais acesso aos computadores, havendo mais interesse na participação dos alunos" (10 Col.)

“diferente, porque você não conhece quem está do outro lado” $\left(1^{\circ} \mathrm{Col}\right.$.)

"é bem melhor, porque você troca idéias, foge um pouco do clima antigo de ficarmos preso dentro da sala de aula” $\left(2^{\circ} \mathrm{Col}\right.$.)

"igual, pois é como se as dúvidas que se tem na sala de aula pudessem ser mostradas no computador e as dúvidas do computador resolvidas pelo instrutor" $\left(2^{\circ} \mathrm{Col}\right.$.)

"a resposta, mensagem que vocês mandam, é um pouquinho demorada; já nos cursos tradicionais, você tem seu professor na sua frente e já coloca as questões em dia” ( $1^{\circ} \mathrm{Col}$. 1997)

“é pior por motivo de ter pouco tempo para praticá-lo” ( $1^{\circ} \mathrm{Col}$. 1997)

"mil vezes melhor!!! Simplesmente... "nos tira da rotina”. Torna o trabalho mais digno” ( $1^{\circ}$ Col. 1997)

"eu achei que é melhor, porque as escolas caíram numa rotina danada e isso desmotiva cada vez mais os alunos; tudo o que modifica um pouco é bom" $\left(1^{\circ}\right.$ Col. 1997)

"melhor, porque um pouco é diversão, mas levando a sério é a melhor maneira de saber se o outro lado faz o mesmo que a gente" $\left(1^{\circ} \mathrm{Col}\right.$. 1997)

\subsubsection{Curso com Professores}

$\mathrm{Na}$ avaliação do curso de treinamento de professores instrutores constatou-se que, provavelmente devido ao tempo exíguo de que o professor dispunha, a maior dificuldade consistiu em familiarizar-se com a linguagem LOGO. Os erros experimentais foram outro ponto que causou bastante controvérsia. Os 
professores imaginavam que os resultados inexatos, próprios de qualquer trabalho experimental, fossem confundir o aluno, acostumado à resolução de problemas onde os resultados não apenas são exatos, como constituem números inteiros, quadrados perfeitos ou cálculos trigonométricos com números simples. Percebe-se, aqui, a importância do desenvolvimento de um projeto como o presente, deixando claro que o erro e sua discussão fazem parte necessária da Física Experimental. Perguntou-se aos professores se após este curso, eles estão aptos a trabalhar com seus alunos usando a Internet. 54\% responderam que sim e 46\% que não. As justificativas para as respostas negativas foram:

- necessidade de maior prática;

- período muito curto do curso;

- exigência de maior segurança;

- deveria haver 3 cursos distintos;

- necessidade de trabalhar mais;

- necessidade de fazer um curso de computação;

- dificuldade na linguagem LOGO;

- aprender melhor.

Os professores deram várias sugestões sobre aplicação do Programa Educ@r para seus alunos:

- "a princípio extra classe, em um futuro próximo para a classe toda”;

- “como inicialmente vamos ter somente dois computadores, será aplicado para grupos pequenos de alunos e quando chegar mais computadores, será aplicado para todos”;

- "como atividade curricular, para grupos de alunos, e extracurricular para alunos que demonstrarem maior interesse";

- “dividir a classe em grupos e levar cada vez um grupo";

- "primeiramente trabalhando a parte de simulação dos experimentos em LOGO e depois aplicar a Internet”;

- “em Março - MU; Abril - MUV; Maio - Movimento de Projéteis; Junho - Estudo da dinâmica”;

- “utilizando os experimentos em sala de aula, e em grupos fazendo os relatórios, enviando as tabelas e questões para o Projeto"; 
- “mostrando a importância do conhecimento da computação para se viabilizar a simulação dos fenômenos”;

- “inicialmente serão realizados os experimentos, seguidos de uma discussão teórica. Depois dos alunos apresentarem conhecimentos, serão introduzidos em LOGO”;

- “ $1^{\circ}$ semestre com grupos de 2 a 4 alunos de $2^{\circ}$ e $3^{\circ}$ Colegial e no $2^{\circ}$ semestre para os do $1^{\circ}$ Colegial”;

- " $1^{\circ}$ semestre com uma turma pequena de alunos e no $2^{\circ}$ semestre com turmas maiores”.

Como melhorias a serem aplicadas no curso de treinamento, os professores responderam:

- curso com maior tempo de duração;

- colocar mais monitores;

- dividir em 3 etapas: LOGO, Internet e programação em LOGO dos movimentos;

- mais tempo para fixar o conteúdo;

- número maior de exemplos;

- tempo maior para estudar a apostila sem a parte experimental;

- equipe de apoio para consertos do Puck e esclarecimentos sobre programação;

- ter os Pucks em condições de uso;

- continuar com o bom nível dos temas.

Na figura 20, são mostrados os resultados das questões fechadas da avaliação aplicada durante o curso de treinamento realizado em janeiro de 1997. Foram obtidos dados sobre as tecnologias Internet e Puck, a linguagem LOGO, o conteúdo e layout das home pages e sobre a metodologia dos hipertextos, utilizando a escala Likert. 
Avaliação do curso de treinamento de instrutores -

Jan./1997

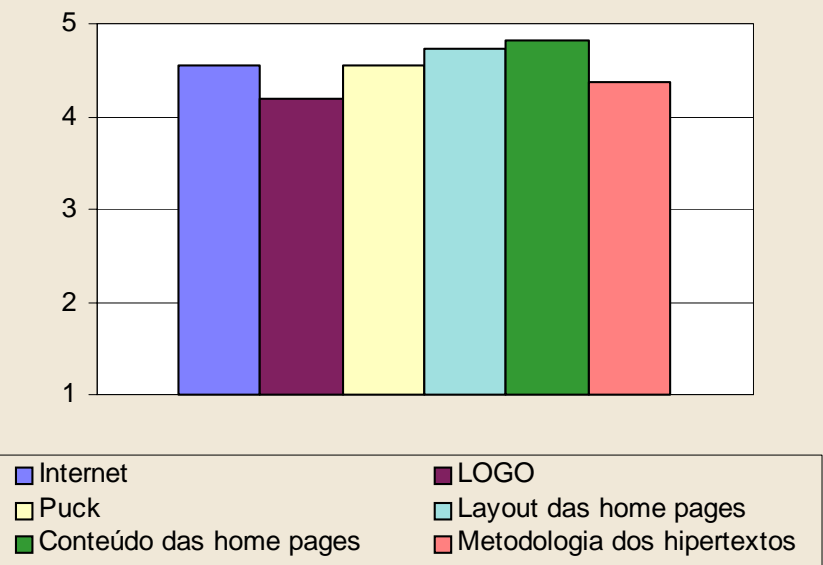

Figura 20 - Avaliação do curso de treinamento de instrutores em Jan. 1997.

\subsection{Discussão dos Resultados}

As primeiras avaliações foram bastante preliminares, pois foram baseadas apenas no curso de Mecânica Gráfica aplicado por uma única escola e num curso de treinamento de professores, porém, os resultados foram animadores para dar continuidade ao Programa. Com as informações obtidas pela avaliação do teste piloto do curso de Mecânica Gráfica, pode-se presenciar facilidades de ensino, bem como certas dificuldades as quais, a princípio, foram sanadas na tentativa de controlar a qualidade do Programa.

Os resultados na escala Likert das avaliações realizadas pelo alunos no decorrer do período de 1996 e 1997 são exibidos na figura 21. O resultado sobre a Internet é ligeiramente inferior para o $2^{\circ}$ Colegial de 1996, pois neste curso ocorreram mais problemas de conexão à Internet - devido a restrição do tempo que o computador ficava sem transmitir os dados, a ligação caía muito e neste dia estava muito difícil conseguir uma linha. Pode-se perceber resultados ligeiramente inferiores no semestre de 1997, apesar dos dados estarem numa faixa entre "Bom" e “Muito Bom”. Acreditamos que esta ligeira diminuição dos valores, esteja associada ao aumento do número de alunos participantes do curso. Recomenda-se melhorar a 
infra-estrutura, aumentando o número de computadores e fazendo um planejamento especial para uma escola de ensino modular noturna, que possuiu um tempo escasso para aplicação do Programa durante o teste piloto. As questões sobre layout das home pages, suporte do mentor e suporte do instrutor que não aparecem no gráfico, não foram propostas aos alunos.

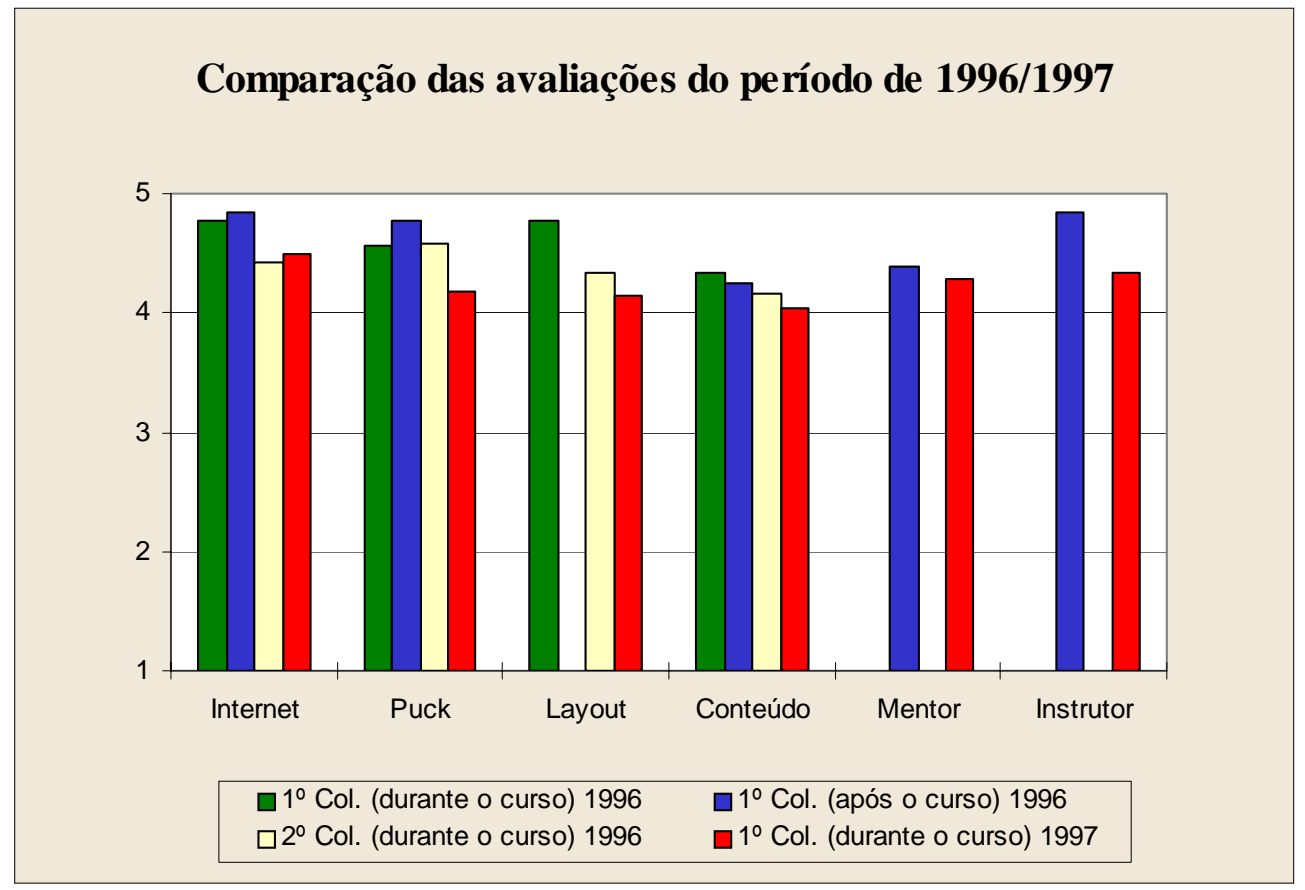

Figura 21 - Comparação das avaliações pelos alunos no período de 1996 a 1997.

De um modo geral, observou-se nos resultados da avaliação que os mais relevantes aspectos do curso de Mecânica Gráfica do Programa Educ@r destacados pelos alunos foram a interação com outras pessoas e o estímulo de trabalhar com computadores, mudando a rotina da sala de aula tradicional. Pode-se também observar através dos resultados que os alunos sentiram a necessidade de mais computadores conectados à Internet e mais pessoas para orientá-los. O instrutor e o mentor aprovaram o Programa como sendo de grande estímulo aos alunos e apoio aos professores e enfatizaram também a interação que a nova tecnologia proporciona.

Os professores instrutores avaliaram entre "Bom” e "Muito Bom” as tecnologias utilizadas no Programa, bem como a metodologia dos hipertextos e as home pages. Também destacaram o curto tempo de duração do curso de treinamento de professores; este deveria ser mais prolongado, devido à grande quantidade de 
informação a ser transmitida.

No curso à distância do West Georgia College (descrito no item 7.4) os resultados foram parecidos com os do Programa Educ@r do Brasil. Em ambos os cursos, os alunos criticaram a eficiência das tecnologias Internet e Instructional TV (ITV) e elogiaram a interação com professores.

Nos dados apresentados pelo teste piloto, o Programa Educ@r é elogiado. Os resultados são considerados bons e isso tudo pode ser atribuído à novidade da tecnologia e à oportunidade proporcionada. Mesmo participando de um curso com condições precárias de infra-estrutura - descritas no item 9.5, - número e características diferentes de alunos e não utilizando as mesmas tecnologias, os alunos fizeram uma boa avaliação do Programa, quando comparado com o Programa canadense NDDL - descrito no item 7.2. Porém, não queremos dizer que o Programa Educ@r é melhor, visto que a postura cultural e o nível crítico de alunos de sociedades diferentes não podem ser comparados entre si.

\subsection{Conclusão}

\subsubsection{Importância deste Trabalho}

Este trabalho mostrou que é de suma importância a existência de um sistema de avaliação na EAD com o objetivo de aferir a qualidade do curso. Com embasamento nas pesquisas realizadas, foi proposto um sistema de avaliação com mecanismos de coleta e análise de dados, com a finalidade de colaborar com as pesquisas na área. Os questionários aplicados serviram para levar o conhecimento necessário para o pessoal administrativo e técnico do Programa Educ@r.

Os resultados obtidos das avaliações foram utilizados para melhorar a qualidade do curso, manter o padrão técnico, aferir as necessidades dos alunos e fornecer oportunidades educacionais para alunos e professores das escolas que aplicarão o curso, servindo ademais, para a realimentação do Programa. Portanto, o sistema de avaliação, bem como seus mecanismos, deverão ser sempre aperfeiçoados 
e atualizados para garantir sua validade. Com estes resultados, pode-se notar que o Programa Educ@r ofereceu oportunidade para os alunos revisarem os dados coletados com o Puck e inseridos nas tabelas interativas, percebendo seus erros, através do feedback das mesmas, e que os mecanismos de comunicação da Internet utilizados neste Programa - o e-mail e a WWW, constituem um meio válido para a EAD.

\subsubsection{Trabalhos Futuros}

Como foi visto anteriormente, este trabalho propõe um sistema de avaliação de um projeto de EAD com duas etapas: avaliação do processo e avaliação da aprendizagem. Na primeira etapa, sugerimos e aplicamos mecanismos de avaliação e analisamos as informações obtidas. Nos dados quantitativos coletados, poderão ser aplicadas outras análises estatísticas e talvez, até comparações sobre esses trabalhos.

Deverá haver uma continuidade sistemática desta forma de avaliação em todos os locais onde este projeto está sendo aplicado, acrescentando a avaliação da aprendizagem. 


\section{Anexo A}

1. Artigo "Mecânica Gráfica, um exemplo de Ensino de Física na WWW", submetido à publicação no periódico Revista Brasileira de Ensino de Física, 1997.

2. Artigo "A Method for Evaluation of a Course Delivered via the World Wide Web in Brazil”, aceito para publicação no periódico The American Journal of Distance Education, v.11, n.2, Summer 1997.

3. Artigo "Educação à distância usando a tecnologia WWW", aceito para publicação no periódico Em Aberto, n.70, outubro 1997. 


\title{
MECÂNICA GRÁFICA, UM EXEMPLO DE ENSINO DE FISICA NA WWW
}

\section{(GRAPHICAL MECHANICS AS AN EXAMPLE FOR PHYSICS EDUCATION IN WWW)}

\author{
Dietrich Schiel \\ Iria Müller Guerrini \\ Renata Moraes de Freitas \\ Sérgio Henrique Oliveira Pereira \\ Euclydes Marega Junior \\ Mônica Giacomassi de Menezes de Magalhães \\ Endereço para correspondência: Centro de Divulgação Científica e Cultural / USP \\ Caixa postal 369 CEP 13560-590 São Carlos SP \\ Fone (016) 2723910 \\ e-mail Dietrich@ifqsc.sc.usp.br
}

\section{RESUMO}

Este curso à distância destina-se a alunos e professores do $2^{\circ}$ grau. São realizadas experiências quantitativas sobre a mecânica do ponto material. Os alunos calculam velocidade e aceleração de um puck de mesa de ar em movimento num plano horizontal ou inclinado. São analisados movimento circular e de um corpo sujeito à força de uma mola. Os alunos enviam seus cálculos via Internet a um computador central onde são avaliados automaticamente e estabelece-se um diálogo com monitores reais. Além disso os alunos programam o computador em linguagem LOGO, simulando os movimentos obtidos experimentalmente. Adicionalmente os alunos obtém órbitas gravitacionais de planetas ou satélites.

\begin{abstract}
In this Distance Education Course high school students and teachers execute quantitative experiments with an air puck on an horizontal or inclined plane. There are also analyzed circular movement and the movement of a body accelerated by a spring. Velocity and acceleration are calculated by students and submitted to a central computer which realizes an automatic correction. Results are also commented by real tutors. Students also program their computer in LOGO language, reobtaining the experimental trajectories and additionally extend their work to gravitational orbits of planets or satelites.
\end{abstract}




\title{
MECÂNICA GRÁFICA, UM EXEMPLO DE ENSINO DE FÍSICA NA WWW
}

\author{
D. Schiel, I. M. Guerrini, R. M de Freitas, S. H. O. Pereira, Euclydes Marega Junior \\ M. G. M. Magalhães \\ Centro de Divulgação Científica e Cultural - USP - 13560 São Carlos - SP - Brasil
}

\section{INTRODUÇÃO}

É um fato conhecido que, ao desenvolver as primeiras idéias da mecânica, Newton percebeu que a análise do movimento não uniforme poderia levar a cálculos repetidos num número extremamente grande de vezes, relativos a intervalos de tempo muito pequenos. Como isto seria impossível resolveu o problema de forma analítica criando para isto um ramo novo da matemática, o cálculo diferencial e integral. Hoje esta impossibilidade: está sendo removida com a velocidade de cálculo possível nos computadores e podemos, por exemplo, prever a trajetória de uma sonda espacial sem conhecer sua equação analítica. No presente projeto o aluno do $2^{\circ}$ grau, que participa deste programa, chega a calcular órbitas gravitacionais sem que venha a saber o que é uma equação diferencial. Para a realização desta tarefa o aluno e seu professor são orientados à distância pelo grupo de colaboradores do Centro de Divulgação Científica e Cultural da Universidade de São Paulo, cidade de São Carlos - SP (CDCC-USP).

As idéias básicas para a presente proposta surgiram juntamente com as primeiras aplicações didáticas do computador, no começo da década de 70 . Tinha sido criado a linguagem BASIC com o objetivo de tornar a programação de computadores acessível a leigos. Elisha Huggins' desenvolveu uma proposta de analisar movimentos gravitacionais registrados de forma estroboscópica com auxílio de programas feitos na citada linguagem. Posteriormente Seymour Papert ${ }^{2}$ criou a linguagem LOGO com propósitos educacionais e inventou-se em São Carlos - SP o puck de $\mathrm{Hessel}^{3}$ que permite o registro de movimentos bidimensionais a um custo bem inferior à fotografia estroboscópica. $\mathrm{Na}$ presente proposta de trabalho o aluno adquire familiaridade com a mecânica programando seu computador para que este reobtenha resultados obtidos experimentalmente. A facilidade de comunicação via $W_{W W} W^{4}$ é usada tanto para que o aluno possa rapidamente conferir a correção de seus cálculos quanto para obter orientação por monitores. A proposta de Huggins está presente em trabalhos educacionais em São Carlos desde a visita deste pesquisador ao Brasil em $1971^{5}$. Um primeiro desenvolvimento completo da proposta completa, usando LOGO foi realizado por Roberta Giglioti, que na época de seu trabalho tinha entre 13 e 14 anos. Roberta foi premiada por isso no $36^{\circ}$ Concurso Cientistas de Amanhã.

Em seu trabalho o aluno realiza e analisa experiências e programas feitas no computador. Isto ocorre nas seguintes etapas:

1 - Familiarização com a linguagem LOGO, aproveitando a motivação que o aspecto lúdico desta linguagem traz.

2 - Realização de experimentos quantitativos e obtenção de dados sobre a trajetória descrito a seguir. De posse destes dados o aluno calcula velocidade e aceleração desse corpo. Tabelas interativas permitem que $o$ aluno possa imediatamente verificar, de forma 
virtual, se está acertando. Imprevistos, dúvidas e problemas conceituais são respondidos por monitores de carne-e-osso. Todos os cálculos feitos pelo aluno são registrados pela direção do programa.

3 - No final de cada capítulo o aluno faz um programa em LOGO, procurando reobter os resultados experimentais.

4 - Na fase final o aluno produz programas relativos a situações não realizáveis em laboratório: o movimento central gravitacional.

\section{EQUIPAMENTO}

Este programa destina-se a ser trabalhado em sala-de-aula ou laboratório. A sala deve ser equipada com 10 ou mais computadores, um dos quais ligado à Internet. O projeto também pode ser desenvolvido tendo-se apenas 1 computador. Neste caso a parte experimental pode ser realizada e pode ocorrer a orientação à distância, via Internet. A parte de programação em LOGO será porém prejudicada, podendo o professor desenvolvê-la com alguns poucos alunos, que apresentam os resultados aos demais.

O equipamento experimental básico é um puck de mesa de ar, especialmente projetado o "puck de Hessel" (fig.1)

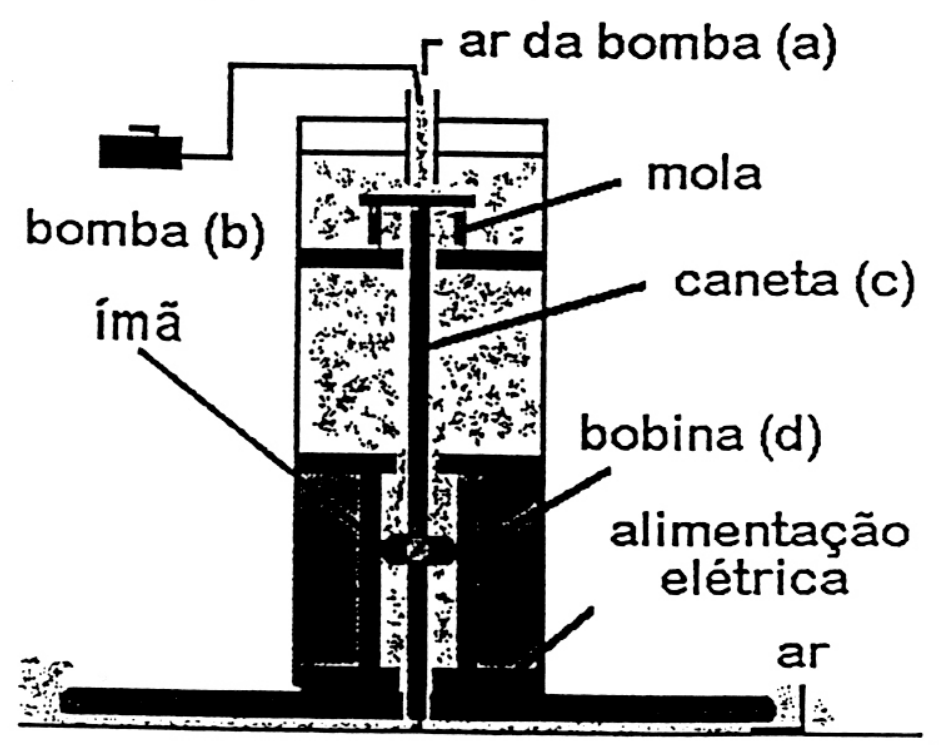

Figura 1 Puck de Hessel. $\mathrm{O}$ ar (a) de uma bomba de aquário (b) é injetado no sistema e produz um colchão de ar em sua base. Uma canetinha (c) está presa a um anel de ferro no interior de uma bobina (d) na qual passa corrente altemada $(60 \mathrm{~Hz})$. A canetinha oscila nesta frequência marcando as posiçōes deste corpo sobre uma mesa de vidro.

Os experimentos com o puck podem ser realizados por uma pessoa (professor ou aluno). A mesa de vidro aparece marcada por uma sequencia de pontos resultantes do funcionamento descrito na legenda da Fig. 1. Enquanto a tinta na mesa está úmida passa-se uma folha de papel sobre a trajetória, impressionando o papel, que será analisado indi-

\footnotetext{
- A frequencia de $60 \mathrm{~Hz}$ foi verificada com estroboscópio. Muitas vezes é suposta, equivocadamente, uma frequència de $120 \mathrm{~Hz}$ devido à "retificação de meia-onda".
} 
vidualmente por cada aluno. Como a realização de cada experimento dura poucos segundos, em menos de 10 minutos podem ser produzidas trajetórias para serem analisados por 40 alunos.

\section{CONTEÚDO}

O curso é desenvolvido ao longo do $1^{\circ}$ e $2^{\circ}$ anos do $2^{\circ}$ grau, sendo os tópicos os tradicionalmente usados nestes anos. A tabela abaixo relaciona os tópicos e as atividades.

\begin{tabular}{|c|c|}
\hline & \\
\hline Introdução ao Logo & $\begin{array}{l}\text { alunos executam pequenos programas geométricos. } \\
\text { seguida produzem um pequeno programa que produz } \\
\text { a série de pontos eqüidistantes. }\end{array}$ \\
\hline \begin{tabular}{|l|} 
Puck \\
Conhecen \\
Medidas \\
Manutenc \\
\end{tabular} & $\begin{array}{l}\text { Experiências iniciais, ainda sem finalidade de discussão } \\
\text { da Física. O aluno faz medidas de espaço e tempo para } \\
\text { movimentos unidimensionais e bidimensionais aprenden- } \\
\text { do a identificá-los. }\end{array}$ \\
\hline \begin{tabular}{|l|} 
Movimento Uniforme \\
Fundamentos Teóricos \\
Procedimento Experimental \\
Simulação em Logo
\end{tabular} & $\begin{array}{l}\text { O puck atravessa a mesa numa velocidade de aproxima- } \\
\text { damente } 50 \mathrm{~cm} / \mathrm{s} \text {. Os alunos calculam as velocidades atra- } \\
\text { vés de } v=\Delta \mathrm{s} / \Delta \mathrm{t} \text {, preenchem uma tabela interativa no } \\
\text { computador. O resultado é imediatamente avaliado. Os } \\
\text { alunos programam o computador para simulação do ex- } \\
\text { perimento. }\end{array}$ \\
\hline $\begin{array}{l}\text { Movimento Uniformemente } \\
\text { Variado } \\
\text { Fundamentos Teóricos } \\
\text { Procedimento Experimental } \\
\text { Simulação em Logo }\end{array}$ & $\begin{array}{l}\text { Inclina-se a mesa. O puck desce em movimento acelerado. } \\
\text { Os alunos obtém as velocidades e em seguida as acelera- } \\
\text { çōes através de a }=\Delta \mathrm{v} / \Delta t \text {. Novamente o resultado é avali- } \\
\text { ado através de uma tabela interativa (ver abaixo). Simula- } \\
\text { ção como antes. }\end{array}$ \\
\hline $\begin{array}{l}\text { Projéteis } \\
\text { Teóricos } \\
\text { Experimental } \\
\text { n Logo }\end{array}$ & $\begin{array}{l}\text { A análi- } \\
2 \text { movi- }\end{array}$ \\
\hline $\begin{array}{l}\text { Circular } \\
\text { s Teóricos } \\
\text { o Experimental } \\
\text { m Logo }\end{array}$ & $\begin{array}{l}\text { to da superfície da mesa. O } \\
\text { ado somando-se as acelera- } \\
\text { e a aceleração centrípeta é }\end{array}$ \\
\hline $\begin{array}{l}\text { Dinâmica } \\
\text { os Teóricos } \\
\text { tto Experimental } \\
\text { em Logo }\end{array}$ & $\begin{array}{l}\text { acelerado por uma mola de } \\
\text { m ponto fixo na mesa. }\end{array}$ \\
\hline $\begin{array}{l}\text { Movimento Gravitacional } \\
\text { Fundamentos Teóricos } \\
\text { Procedimento Experimenta } \\
\text { Simulação em Logo }\end{array}$ & $\begin{array}{l}\text { le movimento circular é substituído } \\
\text { central com conservação da velo- } \\
\text { lento gravitacional é obtido apenas } \\
\text { indo a força central anterior por } \\
r^{2} \text {. O movimento obtido é elíptico }\end{array}$ \\
\hline
\end{tabular}

Tabela 1 Seqüuência da programação do curso 


\section{INTERATIVIDADE}

Neste programa o aluno e seu professor são constantemente orientados à distância. Desta forma aluno, professor, professor distante e a direção do programa constituem uma comunidade que permanentemente está a discutir o conteúdo. Contribuem para isto o computador central em São Carlos e o corpo e monitores do CDCC-USP, onde este projeto é orientado. Foram criadas algumas facilidades computacionais especiais, usando a tecnologia inerente aos programas disponiveis no world wide web:

Tabelas interativas - $\mathrm{O}$ aluno preenche uma tabela na página $w w w$ em que está recebendo orientação. Nesta página são colocados os espaços e tempos medidos e velocidade e aceleração calculados pelo aluno. Esta tabela é enviada à direção do projeto onde o computador central faz uma primeira correção dos cálculos. Esta avaliação é imediatamente devolvida ao participante.

Envio e comentário aos programas - Os programas em Logo são feitos no próprio computador usado para a orientação. Um browser contido na página de orientação permite localizar o programa e enviá-lo via e-mail. Estes programas são analisados pela equipe que gerencia o projeto.

Diálogo intermediado pelo computador - O objetivo principal deste programa é que venha a ser constituído um grupo de discussão à distância. Desta forma o diálogo informal constitui uma peça-chave. Com esta finalidade nos locais apropriados há nas páginas de orientação oportunidade para o envio de perguntas e comentários via e-mail. Evidentemente o e-mail simples também constitui ferramenta importante para este diálogo.

Para melhor compreensão do acima referido sugerimos consultar a página deste progra$\mathrm{ma}^{6}$.

\section{EXEMPLO DE PROGRAMA EM LOGO}

Reproduzimos, a título de ilustração, um programa que permite a simulação do movimento retilíneo uniforme, tal como é apresentado na página de orientação. Nos primeiros programas oferece-se ao aluno o programa elaborado, em seguida é apresentado apenas o algoritmo e finalmente simples diretrizes para o desenvolvimento próprio de programas. Existe, ainda, a opção de se apresentar o programa pronto e pedir ao aluno explicar a função de cada comando. 


\section{ALGORITMO}

1. Dar um nome para o programa

2. A variável a ser usada é vx

3. Limpar a tela

4. Levantar o cursor

5. Definir o ponto inicial "s"; fazer "s $=0$

6. Definir o intervalo de tempo em que cada ponto será marcado; por exemplo $\mathrm{dt}=1 / 60$

7. Definir onde o movimento vai começar

8. Definir o tamanho do ponto

10. Chamar uma sub-rotina para fazer o movimento

\begin{tabular}{|l|l}
\hline 11. Terminar o programa & enc \\
\hline
\end{tabular}

\section{W}

1. Dar um nome à sub-rotina

2. Definir onde o movimento vai começar

3. Descer o cursor

4. Andar um passo

5. Levantar o cursor

6. Definir onde vai estar o próximo ponto

pela equação do movimento

7 chamar a sub-rotina de novo

8. Terminar a sub-rotina
PROGRAMA

to $\mathrm{mu}: \mathrm{vx}$

cs

$\mathrm{pu}$

make "s 0

make "dt $1 / 60$

setxy 00

setpensize [2 2]

make "escala 28.6 (use a escala encontrada por você)

passos

end

\begin{tabular}{|l|}
\hline to passos \\
\hline setxy :escala * :s 0 \\
\hline pd \\
\hline fd 1 \\
\hline pu \\
\hline make "s :s +: $\mathrm{vx}^{*}: \mathrm{dt}$ \\
\hline passos \\
\hline end
\end{tabular}

Tabela 2 Programa em Logo para simulação de movimento uniforme. A escala mencionada na linha 9 é obtida previamente pelo aluno que mede com a régua uma figura, feita por meio da linguagem Logo, na tela do computador.

Percebe-se que este programa obtém os pontos da trajetória fazendo cálculos em loop: cada ponto é obtido a partir do anterior como se aquele fosse o ponto inicial.

Interessados podem obter o software Logo no nosso endereço ${ }^{7}$ onde encontrarão também literatura referente. Recomendamos especialmente o texto de Jim Muller ${ }^{3}$, que traz aplicaçōes as mais diversas desta linguagem de programação.

\section{PRIMEIROS RESULTADOS DE APLICAÇÃO}

O software deste programa foi terminado em outubro 1996. No $1^{\circ}$ semestre de 1997 foi realizado treinamento de professsores que estão para aplicá-lo no $2^{\circ}$ semestre em mais de 20 escolas na região próxima de São Carlos. Além disto está disponivel na "Rede de Centros de Ciência”, 23 Centros ligados ao CDCC-USP em 11 Estados brasileiros.

Em novembro 1996 este método foi usado numa classe do curso noturno na cidade de Americana (Estado de São Paulo). Nesta escola, colégio João XXIII, só estava disponí- 
vel um computador, adquirido com recursos de projeto nosso. Devido à exigüidade do tempo só foi possivel chegar-se a fazer e analisar experimentos sobre o movimento retilíneo uniforme.

Foi feita uma avaliação através de questionários respondidos pelos alunos ${ }^{9}$. Ressaltamse no testemunho da professora Walessandra como pontos favoráveis ao projeto: o estímulo para entendimento do conteúdo, contato com a tecnologia atual, ampliação dos horizontes e facilidade de comunicação com orientadores distantes, possibilitando atualização do professor. Para os alunos foram pontos positivos o retorno de respostas nas tabelas interativas, a indicação de erros de cálculo. Como pontos a serem melhorados citaram a conexão discada à Internet (bastante problemática), tamanho da sala de computação (na Delegacia de Ensino). Sugeriram que o contato com o professoor distante deveria ser imediato, durante a execução do experimento. Demonstraram muita curiosidade com respeito ao instrutor distante, que tipo de pessoa seria, etc.

De 25 a 30 de janeiro de 1997 foi realizado um curso de treinamento com 20 professores de $2^{\circ}$ grau da rede pública de ensino que usarão esta sistemática em 1997. Nesta semana foi cumprida toda a programação constante na tabela 1 . Constatou-se que, provavelmente devido ao tempo exíguo que o professor dispunha, a maior dificuldade consistiu em familiarizar-se com a linguagem Logo. Outro ponto que causou bastante controvérsia foram os erros experimentais. Alguns professores imaginavam que os resultados inexatos, próprios de qualquer trabalho experimental, fossem confundir o aluno, acostumado à resolução de problemas onde os resultados não apenas são exatos como constituem números inteiros, quadrados perfeitos ou cálculos trigonométricos com números simples e memorizáveis. Percebe-se aqui a importância do desenvolvimento de um projeto como o presente, deixando claro que o erro e sua discussão fazem parte necessária da Física Experimental.

\section{CONCLUSÃO}

Com este trabalho mostramos ser possível inovar o conteúdo de Física no $2^{\circ}$ grau usando o potencial representado pelo computador. O teste-piloto mostra ainda que que os mecanismos de comunicação da Internet constituem um meio válido para o ensino à distância.

\section{AGRADECIMENTO}

Este trabalho não seria possivel sem as contribuições financeiras de VITAE, FAPESP, CNPq e da pró-reitoria de pesquisa da USP. Contribuiram, ainda, Álvaro Garcia Neto, Luiz Henrique Godoy, Roberta Giglioti e Walessandra Araújo Dias. 
Referências:

'Huggins E. Graphical Mechanics. Wentworth, COMPress, Inc. / Dartmouth College, 1979.

${ }^{2}$ Papert S. Logo: Computadores e Educação. São Paulo, Brasiliense, 1988.

${ }^{3}$ Hessel R. Discos sustentados por colchāo de ar, uma nova proposta - Rev. Ens. Fis.:4 (3), Dez 1982

“Schiel, Dietrich., Magalhães, Mônica G. M. Educação à Distância Usando Tecnologia WWW. - Em Aberto, $n^{\circ} 70$, MEC/INEP julho 1997.

${ }^{5}$ Mascarenhas, S. Um Survey Sobre o Uso de Tecnologias Avançadas no Ensino; texto de palestra no InfoUSP, São Paulo, CCIUSP, junho 1997.

${ }^{6}$ Programa Educ@r, projeto de Física http://www.ifqsc.sc.usp.br/educar/fisica/fisica.html

${ }^{7}$ Programa Educ@r, página sobre LOGO, http://www.ifqsc.sc.usp.br/fisica/logo/logo.html - final da pagina de abertura.

${ }^{8}$ Muller, J. The Logo Sourcebook - Exploring Logo On and Off the Computer $\odot$ 1996. Download gratuito em http://www.softronix.com ( $4 \mathrm{Mb}$, exige acrobat reader)

${ }^{9}$ Magalhāes, Mônica G. M. Relatório de avaliação de teste-piloto do programa de Física - CDCC-USP

Dez. 1996 


\title{
A Method for Evaluation of a Course Delivered via the World Wide Web in Brazil
}

\author{
Mônica G. Menezes de Magalhães and Dietrich Schiel
}

\begin{abstract}
This paper describes the application of evaluation methods to a distance course, and discusses the need for ongoing evaluation to control the quality of distance education courses. During the last quadrimester of 1996, a course in Graphic Mechanics was offered in Brazil through a distance education program entitled "Programa Educ@r"1 via the World Wide Web. Evaluation method and data analysis were developed and applied during the period of the course, and results of the evaluation are discussed.
\end{abstract}

\section{Introduction}

Distance education programs are increasing in number and becoming one of the most important new trends in education. These programs, delivered using current technologies, provide new ways for students to learn and a variety of methods for facilitating interaction between students and teachers. Developing program materials for delivery through new technologies, such as the World Wide Web (WWW), are new initiatives in Sao Carlos, State of Sao Paulo, Brazil, and it is difficult to find information on and methods for evaluating these programs. With the objective of filling this gap, an evaluation of the distance course of Graphic Mechanics was conducted through an ongoing evaluation system of data collection and analysis.

In Brazil, twenty-three Science Centers are connected via the Internet to the Center of Scientific and Cultural Divulgation at the University of São Paulo. Twenty schools are also connected to the same network. The Graphic Mechanics course is among several programs developed for the project entitled "Programa Educ@r." Still in the beginning stage, the following programs are also being developed for the project: environmental education; mathematical training for primary school teachers; and physics for high school students. This paper describes an evaluation of the Graphic Mechanics course in the "Programa Educ@r" project. The Distance Education Programs are increasing and becoming one of the most important

\section{A Graphic Mechanics Course via the WWW}

The basic experimental equipment for the Physics program consists of an air puck (Hessel 1982). This specially designed puck enables the user to register its position on the table with an oscillating pen. Similar to using a strobephoto (Huggins 1979), the student can obtain specific positions at a defined time. The principal objective is to interpret movements and write programs in LOGO (Papert 1980) in order to simulate the experimental data obtained. By beginning with a constant velocity and passing through one-dimensional and twodimensional accelerated movement, the student simulates central movement in a circle and central movement with the puck being pulled by a centrally fixed spring. All of these 
movements are replicated by simulation in LOGO. The last step of the process consists of instructing the student to replace the central force of the spring with na attraction force that is proportional to the inverse square of the distance. The student will obtain an elliptic gravitational orbit, which clearly shows a higher velocity near the attracting center, in accordance with Kepler's second law. The student can also replicate the gravitational movement of a satellite attracted by a planet which is, in turn, attracted by a star, and test what will occur if the inverse square attraction law is altered. All of these calculations are performed without reference to differential and integral calculus.

This physics program is used in distance education courses delivered via the WWW. The student executes the experiments described above directed solely by instructions presented on a home page (http://www.ifqsc.sc.usp.br/educar/fisica/fisica.html-in Portuguese). The student registers the results obtained from experiments onto this same Web page, thus completing an interactive table. The results of acceleration and velocity obtained by the student are verified automatically through the main server and the results are returned to the student. At the same time, these results are sent to a staff member who is able to comment on these results and give additional instructions to students who have difficulties. The programs written in LOGO are sent to the staff using a special browser on the home page. This enables the staff to guide the student through difficulties such as missing spaces in commands, which, while they may seem minor, can seriously hinder the work. The student spends a great deal of time on experimental work, calculations, and programming, and relatively little time sending messages. Because of the small amount of time spent on the Internet, this program can function well even in places such as Brazil, where a fast data highway does not yet exist.

\section{Evaluating the Distance Course}

Apart from the reliance on well defined programs, the success of distance education depends on appropriate didactic material, suitable resources to deliver instruction to the students, and qualified human resources. When coupled with a complete diagnosis of the students' needs and the needs of the region, evaluations performed during and after the course can produce highly positive results. At this time in Brazil there are very few programs that consider all of these factors in their evaluations (Alves 1996).

The evaluation process is fundamental to achieving quality control in distance education. It facilitates the identification of possible flaws in the instructional system and guides the changes needed to improve distance education programs.

The lack of quality control in distance and traditional systems is one of the shortcomings of the educational process. To avoid this problem, it is necessary to have an ongoing evaluation system for distance education courses. Data gathered through student and teacher questionnaires can be analyzed to identify course strengths and weaknesses, as well as technical problems encountered by participants. These data can be used to improve the quality of distance courses and programs from their inception.

\section{Methods Used to Evaluate the Course}

Formative evaluations were developed (Willis 1992; Thorpe 1993; Preece et al. 1994) for the Graphic Mechanics course. These evaluations employed both quantitative and qualitative data collection methods, including participant observations, and questionnaires (Willis 1992; Thorpe 1993; Preece et al. 1994; Moore and Kearsley 1996). 
In researching the methods used by distance education institutions (Head and Lockee 1994; Porter, Fallick, and Dagert 1994; Schick 1996), we noticed that the method often employed to obtain data and to determine strengths and weaknesses was questionnaires using a Likert scale. Therefore, questionnaires were developed and then administered during and after the course. The evaluations administered during the course identified aspects of the program that the participants considered successful and unsuccessful. The evaluations administered after the course helped to verify whether or not the difficulties were resolved, and if not, how they could be resolved in the future.

The questionnaire included open-ended and close-ended questions that were developed to assess the reactions of the students, the instructor (on-site teacher), and the mentor (distance teacher). A 5-point Likert scale (Peck and Wallace 1993; Preece et al. 1994) with the following point values was used: $1=$ very poor, $2=$ poor, $3=$ average, $4=$ good, and $5=$ very good. The close-ended questions were designed to elicit responses on the use of technology, technical support, training, interaction between students/instructor/mentor, homepage layout, and homepage content. The open-ended questions focused on such topics as: student preferences; improving instruction; comparison of the distance course to a traditional course; instructor and mentor responsibilities; strengths and weaknesses of the interaction; course strengths and weaknesses; and suggestions for the improvement of "Programa Educ@r."

\section{Results}

In November 1996, the Graphic Mechanics course was offered for the first time in two public high school classes in Americana, State of Sao Paulo, Brazil. There was only one computer connected to the Internet, and due to time constraints, it was only possible to create and analyze the experiments on uniform rectilinear motion.

Questionnaires from students, instructor, and mentor were used in the evaluation of the distance course (Magalhaes 1996). In this pilot test, data were collected from twenty-one questionnaires administered during the course and thirteen questionnaires at the conclusion of the course. The data were compiled in an electronic spreadsheet and formulated graphically. The data from the open-ended questions were analyzed, the common responses selected and compiled, and then displayed graphically. Finally, the analyses were sent to the program staff to provide information on how to improve the course and to inform the course's strengths and weaknesses.

The first instructor evaluations of the Graphic Mechanics course in the "Programa Educ@r" revealed the following favorable instructional aspects of the project: it provided a stimulus to student understanding of the content; it allowed the actual use of the technology; it broadened student horizons; it facilitated communication with distance instructors; and it allowed for instructor improvement. The mentor indicated that the most successful aspects of the distance course were: the interaction between students/instructor/mentor; the students' freedom to construct knowledge; and the support provided to both teacher and students as a supplement to the formal class. The mentor also emphasized that the information exchange between students, instructor, and mentor and the outside world via the Internet makes this technology an important tool.

The students rated the following course aspects as "good" and "very good": the technology; the home page layout and content; and the instructor and mentor support. Most students thought that the distance course was better than the traditional course. Other positive aspects identified by the students were: responses given in the interactive tables; the 
indication of calculus errors; and the interaction with other people. We could perceive that the students expressed a great deal of curiosity during the courses about the identify of the mentor. Points for improvement that were mentioned included the Internet dial-up connection and the small size of the computation room. Students suggested that contact with the distance mentor should be immediate during the execution of the experiments. We contacted the Internet Provider support to try to resolve the problem of the connection. Improvements were implemented in time for the next course to be offered during the first semester of 1997. Figure 1 shows the results of the formative evaluations administered to a typical class during and after the course. The following point values are in the Likert scale where 1 = very poor, 2 = poor, 3 = average, $4=$ good, and $5=$ very good. As seen, there is little significant difference between the two results.

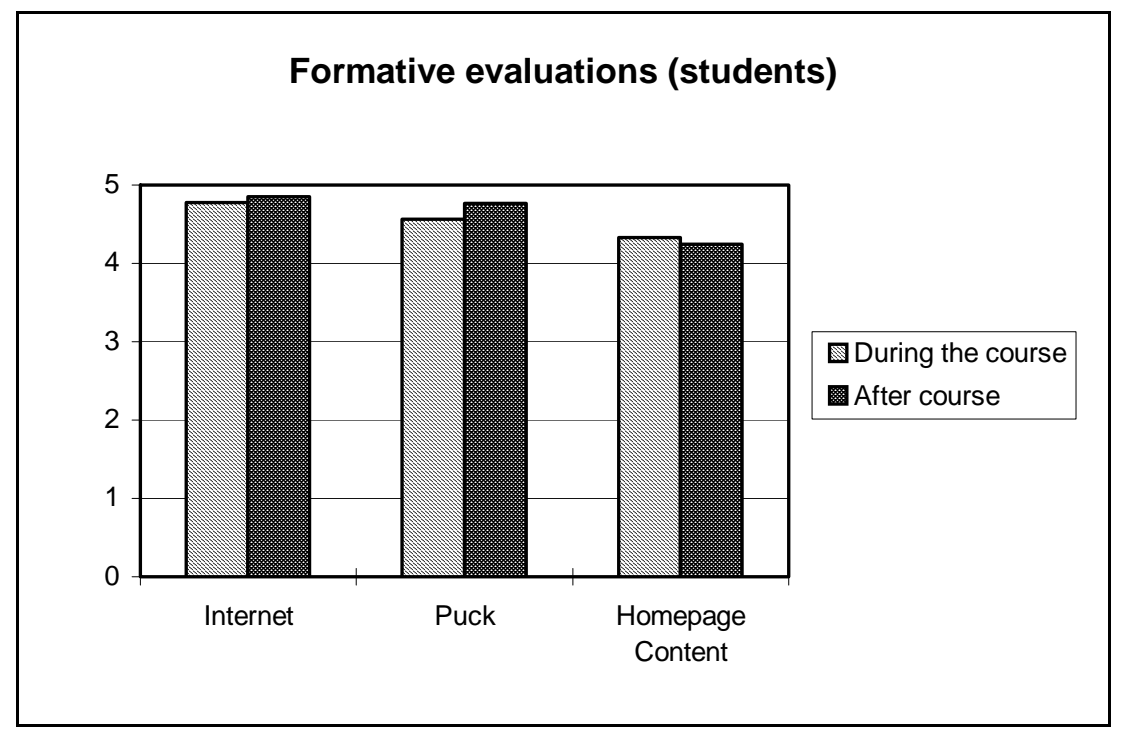

Figure 1 - Formative Evaluations of a Typical Class.

In January 1997 a training course was conducted for twenty teachers who will use this system in 1997. During the week of training, the first interactive table was completed. The greatest difficulty of the training was familiarizing teachers with LOGO during such a limited time frame. Another point that caused some controversy concerned experimental errors; the teachers worried that the inexact results, a peculiar feature of any experimental work, would confuse the students. They are accustomed to problem resolution in which the results are not only exact but constitute integers, perfect squares, or trigonometric calculus with simple numbers. It becomes evident that developing a project such as the present one, which highlights error and encourages discussion-necessary elements of Experimental Physics-is very important.

\section{Conclusion}

We have demonstrated in this paper the need for ongoing evaluation of distance education programs to control the quality of distance courses. It is our hope that this paper contributes to the present understanding in the field. The results of the applied evaluations showed that the "Programa Educ@r" offered students the opportunity to examine data obtained with the puck and inserted into interactive tables, and to observe their errors through feedback of these tables. The pilot test also showed that Internet communications are effective for distance education. 


\section{Notes}

1. Supported by Vitae, FAPESP, and CNPq.

\section{References}

Alves, J. R. M. Educacao a distancia e as novas tecnologias de informacao na aprendizagem. Paper presented at the Engenheiro 2001, 7\#187\# Teleconferencia, October, 1996.

Head, T., and B. Lockee. Forming the future from the past: Student-centered evaluation of distance learning at Virginia Tech. Paper presented at the Tenth Annual Conference on Distance Teaching and Learning in Madison, Wisconsin, August, 1994.

Hessel, R. 1982. Discos sustentados por colchao de ar, uma nova proposta. Revista Ensino de Fisica 4(3): 3-22.

Huggins, E. 1979. Graphical Mechanics. USA: Wentworth, COMPress, Inc. \& Dartmouth College.

Magalhaes, M. G. M. 1996. Avaliacao de teste-piloto do programa de Fisica. São Carlos, Brasil: Relatorio Tecnico CDCC-USP.

Moore, M. G., and G. Kearsley. 1996. Distance Education: A Systems View. Belmont, CA: Wadsworth Publishing.

Papert, S. 1980. Mindstorms-Children, Computers and Powerful Ideas. New York: Basic Books.

Peck, R. M., and C. M. Wallace. 1993. Evaluating distance education courses: Initiative, methodology, and application. In Distance Education Futures, ed. T. Nunan, 527-538. Eleventh Biennial Forum of Australian and South Pacific, External Studies Association, Adelaide, AU.

Porter, D., A. Fallick, and T. Dagert. 1994. New Directions in Distance Learning: The year in review. Open Learning Agency. British Columbia, CA.

Preece, J., Y. Rogers, H. Sharp, D. Benyon, S. Holland, and T. Carey. 1994. HumanComputer Interaction. 601-639. Wokingham: Addison-Wesley.

Schick, J. A. 1996. Bridging distances between languages and cultures via distance education. Gatherings Newsletter, West Georgia College School of Education, (9)2.

Thorpe, M. 1993. Evaluating Open \& Distance Learning. 2d ed. London: Longman.

Willis, B. 1992. Instructional Development for Distance Education. ERIC Document Reproduction Service, ED 351007. 


\title{
EDUCAÇÃO À DISTÂNCIA USANDO TECNOLOGIA WWW
}

\author{
Dietrich Schiel" e Mônica Giacomassi de M. Magalhães"*
}

\section{A TECNOLOGLA WORLD-WIDE-WEB}

Uma das características da Educação à Distância é o fato da comunicação entre alunos e professores ser mediada por alguma forma de tecnologia. A mais nova tecnologia utilizada na Educação à Distância é a World-Wide Web (WWW), uma recente ferramenta da Internet.

A WWW possibilita a elaboração de cursos com avançados recursos de multimídia (Sherry, 1996), permite acesso a grande volume de informações e a versão atualizada de um documento (Ibrahim, 1994), libera informação para alunos de uma maneira fãcil, permite a utilização de mecanismos sofisticados como hipertextos, sistemas de conferências, programas de questões e respostas, etc. (Dillenbourg; Schneider, 1995).

A maior caracteristica da WWW é o potencial de criação de links entre documentos textos e outras mídias residentes em qualquer computador do mundo que tem acesso à WWW (Alexander, 1995), ou seja, a capacidade de utilizar documentos hipertexto/hipermídia.

O papel do professor, diante do uso da hipermidia na educação, é estimular os alunos a "navegarem" pelo conhecimento, fazendo suas próprias descobertas, desenvolvendo sua capacidade de observar, pensar, comunicar e criar (Salvador, 1995). O interesse dos professores pela WWW é devido à disponibilidade de software cliente-servidor para muitas plataformas diferentes, a simplicidade relativa da sintaxe da linguagem HTML, usada na elaboração de documentos hipermidia e a liberdade de se usar vários tipos de ferramentas de edição (Ibrahim; Franklin, 1995).

As várias utilidades da WWW na Educação são (Schneider; Block, 1995):

- a WWW como ferramenta de informação, por exemplo informação de currículo e cursos, etc.;

- distribuição de material de aprendizado por ex. livros, programas;

- ferramentas colaborativas;

- aplicações educacionais interativas.

A WWW tem mostrado seu potencial de construir Sistemas de Informação Educacional em larga escala, devido às suas capacidades de hipermídia e de resgatar distâncias, não deixando de existir algumas dificuldades. Pode-se elaborar páginas com formulários interativos para serem empregadas nos testes de avaliação e auto-avaliação. Também pode ser usada como interface para dados cientificos, papers, jornais on-line, etc., sendo um grande potencial para as universidades. Recentes desenvolvimentos tecnológicos aumentam o potencial interativo da WWW. Com estes desenvolvimentos a WWW se tornará ainda mais poderosa e aumentará sua popularidade. (Schneider; Block, 1995)

- Centro de Divulgaçðo Cientinicã e Cütural (CDCC) - USP - São Carlos

" UNESP - Rio Claro 
No processo de ensino/aprendizagem, a utilização de tecnologias como a Internet, representa caminhos para apresentar a informação e fornecer mais interação entre alunos e instrutores do que tecnologias anteriores, tornando a Educação à Distância mais plausível e poderosa (Moore; Kearsley, 1996).

\section{UM EXEMPLO - O PROGRAMA EDUC@R*}

23 Centros de Ciência no Brasil estão conectados via Internet com o Centro de Divulgação Científica e Cultural da USP/São Carlos, em decorrência de projetos anteriores (Experimentoteca) desenvolvidos com apoio de VITAE e CAPES/PADCT. Em outro projeto 20 escolas estão conectadas na mesma rede. Inicialmente estamos desenvolvendo um programa de Educação Ambiental, treinamento de professores de Matemática de escolas de $1^{\mathrm{a}}$ a $4^{\mathrm{a}}$ séries e também um programa de Fisica para alunos de $2^{\circ}$ grau, que será detalhado a seguir.

\section{ENSINANDO MECÂNICA GRÁFICA NA WWW}

O equipamento experimental básico deste programa de Física é um puck de mesa de ar, criado em 1980 (Hessel 1982). Com este instrumento o usuário registra as posições na mesa por uma caneta oscilante. Como em uma fotografia estroboscópica, o aluno pode obter posições em tempo definido. O principal objetivo é interpretar movimentos e escrever programas em linguagem LOGO, simulando os dados experimentais obtidos. Começa com velocidade constante, passando pelo movimento acelerado unidimensional e bidimensional e chega em movimento central em um circulo e movimento central com o puck sendo puxado por uma mola fixada centralmente. Todos estes movimentos são reobtidos na simulação com o LOGO. O último passo consiste em orientar o aluno a substituir a força central da mola por uma força de atração proporcional ao invés do quadrado da distância. Ele obterá uma órbita gravitacional elíptica, a qual mostra claramente velocidade mais alta perto do centro de atração, devido a $2^{\mathrm{a}}$ lei de Kepler. $\mathrm{O}$ aluno também pode obter o movimento gravitacional de um satélite atraído por um planeta que é atraído por uma estrela, testar o que acontecerá se nós alterarmos a lei de atração do inverso do quadrado, etc. Todos estes cálculos são feitos sem mencionar cálculo integral e diferencial. Convém observar aqui que a linguagem LOGO foi proposta por no início da década de $80 \mathrm{com}$ a finalidade especifica de se criar um instrumento onde, ao invés do aluno ser instruído por um tutorial, ele encontre um meio de "ensinar" o computador, desenvolvendo seu próprio conhecimento.

Este método foi testado com uma garota de 13 a 15 anos, Roberta Giglioti, que desenvolveu o programa durante 2 anos, de 1993 a 1995. Ela foi premiada por isto pelo Programa "Cientistas de Amanhã".

Esta programação foi adaptada para programas de Educação à Distância via WWW. O aluno executa os experimentos menciona dos acima, dirigido por instrutores em uma homepage (http://www. ifqsc.sc.usp.br/educar/fisica/fisica.html). Em seguida o aluno registra os dados obtidos nesta página e completa uma tabela interativa. Os resultados de aceleração e velocidade obtidos pelo aluno são verificados automaticamente pelo servidor principal e este resultado é retornado ao aluno. Ao mesmo tempo estes resultados são enviados para o monitor distante poder comentá-lo e dar instruções adicionais aos alunos que têm dificuldades. Os programas escritos em LOGO são aguardados também para serem enviados, por um browser especial na página, para o monitor distante. Isto possibilitará o monitor orientar o aluno nas dificuldades que foram

\footnotetext{
Apoio: VITAE, FAPESP, CNPq
} 
observadas que poderiam bloquear seriamente o trabalho - como deixar espaços nos comandos. $O$ aluno gasta muito tempo no trabalho experimental, cálculos e programação e pouco tempo enviando mensagens. Isto possibilita o trabalho na Internet mesmo com transmissão lenta, como no Brasil. O inicio da atividades com os aluno foi em setembro de 1996.

\section{PRIMEIROS RESULTADOS DA APLICAÇÃO DO CURSO DE FÍSICA}

Após o término da elaboração do software em outubro 1996, este método foi usado numa classe do curso noturno na cidade de Americana (Estado de São Paulo). Nesta escola, colégio João XXIII, só estava disponivel 1 computador, adquirido com recursos de projeto nosso. Devido à exigüidade do tempo só foi possivel chegar-se a fazer e analisar experimentos sobre o movimento retilineo uniforme.

Foi feita uma avaliação através de questionários respondidos pelos alunos (Magalhães, 1996). Ressaltam-se no testemunho da professora Walessandra como pontos favoráveis ao projeto: o estímulo para entendimento do conteúdo, contato com à tecnologia atual, ampliação dos horizontes e facilidade de comunicação com orientadores distantes possibilitando atualização do professor. Para os alunos foram pontos positivos o retorno de respostas nas tabelas interativas, a indicação de erros de cálculo. Como pontos a serem melhorados citaram a conexão discada à Internet (bastante problemática no caso específico), tamanho da sala de computação (na Delegacia de Ensino). Sugeriram que o contato com o monitor distante deveria ser imediato, durante a execução do experimento. Demonstraram muita curiosidade com respeito ao instrutor distante, que tipo de pessoa seria, etc.

De 27 a 31 de janeiro de 1997 foi realizado um curso de treinamento com 20 professores que usam esta sistemática em 1997. Nesta semana foi cumprida toda a programação prevista. Constatou-se que, provavelmente devido ao tempo exíguo que o professor dispunha, a maior dificuldade consistiu em familiarizar-se com a linguagem Logo. Outro ponto que causou bastante controvérsia foram os erros experimentais. Os professores imaginavam que os resultados inexatos, próprios de qualquer trabalho experimental, fossem confundir o aluno, acostumado à resolução de problemas onde os resultados não apenas são exatos como constituem números inteiros, quadrados perfeitos ou cálculos trigonométricos com números simples. Percebe-se aqui a importância do desenvolvimento de um projeto como o presente, deixando claro que o erro e sua discussão fazem parte necessária da Física Experimental.

\section{DESDOBRAMENTOS E CONCLUSÕES}

O software do programa de Física foi terminado em outubro 1996. No ano letivo de 1997 ele será usado em mais de 20 escolas na região próxima de São Carlos. Além disto estará disponivel na "Rede de Centros de Ciência" ligada ao programa Educ@r e nos Estados do Ceará, Rio Grande do Sul e Distrito Federal através do Programa de Educação à Distância em Ciència e Tecnologia do CNPq.

Como foi mencionado, além do projeto de Física estão em desenvolvimento um curso para treinamento de professores de $1^{a}$ a $4^{\mathrm{a}}$ série em Matemática e outro em Educação Ambiental. Em cada um procuramos aplicar uma outra faceta da tecnologia WWW, para que, ao fim do programa tenhamos uma possibilidade em avaliar um leque de possibilidades tecnológicas. Desta forma o curso de Matemática constitui um curso de instrução "pura" via WWW, bastando ao aluno ligar n computador, ler e responder o que aparece na tela - tradicionalmente a Matemática é uma Ciência 
que dificilmente ultrapassa as dimensões de uma folha de papel. Por outro lado na Educação Ambiental a Internet é usada para que alunos de escolas espalhadas pelo território nacional possam compartilhar resultados de observações ambientais, adquirindo, além do conhecimento local, uma visão nacional da problemática estudada.

Mostramos, no caso relatado, ser possivel inovar o conteúdo de Física no $2^{\circ}$ grau usando o potencial representado pelo computador. O teste-piloto mostra ainda que os mecanismos de comunicação da Internet constituem um meio válido para o ensino à distância.

AGRADECIMENTOS: Entre inúmeras contribuições que tornaram este trabalho possivel destacamos as de Álvaro Garcia Neto, Euclydes Marega, Íria Muller Guerrini, José Galízia Tundisi, Luiz Henrique Godoy, Maria Dolores Ceccato Mendes, Peter Krauss, Renata Moraes de Freitas, Roberta Giglioti, Sérgio Henrique Pereira, Sílvia A. Martins dos Santos e Walessandra Araújo Dias.

\section{REFERÊNCIAS}

ALEXANDER, S. Teaching and Learning on the World-Wide Web. In: AusWeb95 Australian WorldWideWeb Conference, 1., Australia, 1995.

DILLENBOURG, P.; SCHNEIDER, D. Collaborative Learning and the Internet. In: ICCAI 95, 1995.

HESSEL R. Discos sustentados por colchão de ar, uma nova proposta - Rev. Ens. Fis.:4 (3), Dez 1982

HUGGINS E. Graphical Mechanics. Wentworth, COMPress, Inc./Dartmouth College, 1979.

IBRAHIM, B. Distance Learning with the World-Wide Web. In: International Conference on "Open and Distance Learning - Critical success factors". Geneva, 10-12 October, 1994.

IBRAHIM, B.; FRANKLIN, S. D. Advanced Educational Uses of the World-Wide Web. In: International World-Wide Web Conference, 3., Darmstadt, Germany, 1995. v.27, p.871-877.

MAGALHÃES, M. G. M. Relatório de avaliação de teste-piloto do programa de Física. CDCC/USP. 1996.

MOORE, M.; KEARSLEY, G. Distance Education: A Systems View. Wadsworth:CA. 1996.

PAPERT S. Logo: Computadores e Educação. São Paulo, Brasiliense, 1988.

SALVADOR, V. L. G. Hipermídia Interativa - a educação do futuro, no presente. Tecnologia Educacional. v.22, (123/124), p.22-23, mar./jun. 1995.

SCHNEIDER, D.; BLOCK, K. The World-Wide Web in Education. Andrea, 2(5), 12 June, 1995.

SHERRY, L. Issues in Distance Learning. International Journal of Distance Education, 1(4), 1996. p.337-365. 


\section{Anexo B}

Questionários de avaliações formativas e finais para o aluno, instrutor e mentor e para o curso de treinamento de professores. 


\section{Programa Educ@r}

Com o envio deste formulário você estará nos ajudando a melhorar este curso. Suas experiências e observações são partes fundamentais neste Programa. Lembre-se que é o Programa Educ@r que está sendo avaliado e não você. MUITO OBRIGADA POR SUA COLABORAÇÃO

\section{Avaliação Formativa do Curso para o Aluno}

Idade:

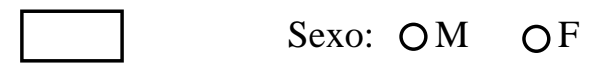

Série:

Grau:

Escola:

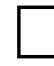

Cidade/Estado:

Curso a ser avaliado:

O Matemática

O Física

O Biologia

1) Porque você decidiu fazer o curso através do Programa Educ@r?

2) O que você mais gosta de aprender através deste Programa?

3) $\mathrm{O}$ que você menos gosta de aprender através deste Programa?

4) Como você classificaria os seguintes elementos:

Uso da Internet

O Muito Bom

O Bom

O Médio

O Fraco

O Muito Fraco

Uso da linguagem LOGO
O Muito Bom
O Bom
O Médio
O Fraco
O Muito Fraco 
Experimentos práticos usando o Puck
O Muito Bom
O Bom
O Médio
O Fraco
O Muito Fraco

Apresentação das páginas do curso do Programa Educ@r
O Muito Boa
O Boa
O Média
OFraca
Muito Fraca

Conteúdo das páginas do curso do Programa Educ@r
O Muito Bom
O Bom
O Médio
O Fraco
O Muito Fraco

Contato com o mentor (prof. distante) no Programa Educ@r
O Muito Bom
O Bom
O Médio
OFraco
O Muito Fraco

Contato com o instrutor (prof. presente) no Programa Educ@r

O Muito Bom O Bom O Médio OFraco O Muito Fraco

5) O que o mentor (prof. distante) poderia fazer para melhor ajudá-lo no curso?

6) O que o instrutor (prof. presente) poderia fazer para melhor ajudá-lo no curso?

7) Você acha que este curso à distância é melhor, igual ou pior que os cursos tradicionais em sala de aula? Por quê?

8) Você usou recursos comunitários (exemplo: Bilbioteca Pública, etc)? Sim ou Não? Se Sim, o que usou? Se Não, por quê? 
9) Você já havia trabalhado com computadores antes?

10) Na sua opinião, o que poderia ser feito para melhorar o curso do Programa Educ@r?

MUITO OBRIGADA POR SEU TEMPO E CONSIDERAÇÃO

Comentários para: monimag@ifqsc.sc.usp.br

Revisado em Março/97 


\section{Programa Educ@r}

Com o envio deste formulário você estará nos ajudando a melhorar este curso. Suas experiências e observações são partes fundamentais neste Programa. Lembre-se que é o Programa Educ@r que está sendo avaliado e não você.

MUITO OBRIGADA POR SUA COLABORAÇÃO

\section{Avaliação final do Curso para o Aluno}
Idade:
Sexo: OM OF
Cidade/Estado:
Escola:

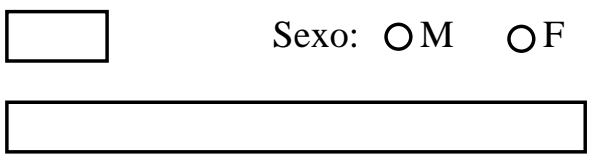
Período:
Série:
Grau:
Curso a ser avaliado:
O Matemática
O Física
O Biologia

\section{1) Como você classificaria os seguintes elementos:}

Apresentação das páginas do curso na Internet
O Muito Boa
O Boa
O Média
O Fraca
O Muito Fraca

Conteúdo das páginas do curso
O Muito Bom
O Bom
O Médio
O Fraco
O Muito Fraco

Contato com o mentor (prof. distante)
O Muito Bom
O Bom
O Médio
O Fraco O Muito Fraco

Contato com o instrutor (prof. presente)
O Muito Bom
O Bom
O Médio
O Fraco
O Muito Fraco

Uso da Internet
O Muito Bom
O Bom
O Médio
O Fraco
O Muito Fraco

Uso da linguagem LOGO
O Muito Bom
O Bom
O Médio
O Fraco
O Muito Fraco

Experimentos práticos usando o Puck
O Muito Bom
O Bom
O Médio
O Fraco
O Muito Fraco

2) Qual a parte do curso do Programa Educ@r que você mais gostou? 
3) Qual a parte do curso do Programa Educ@r que você menos gostou?

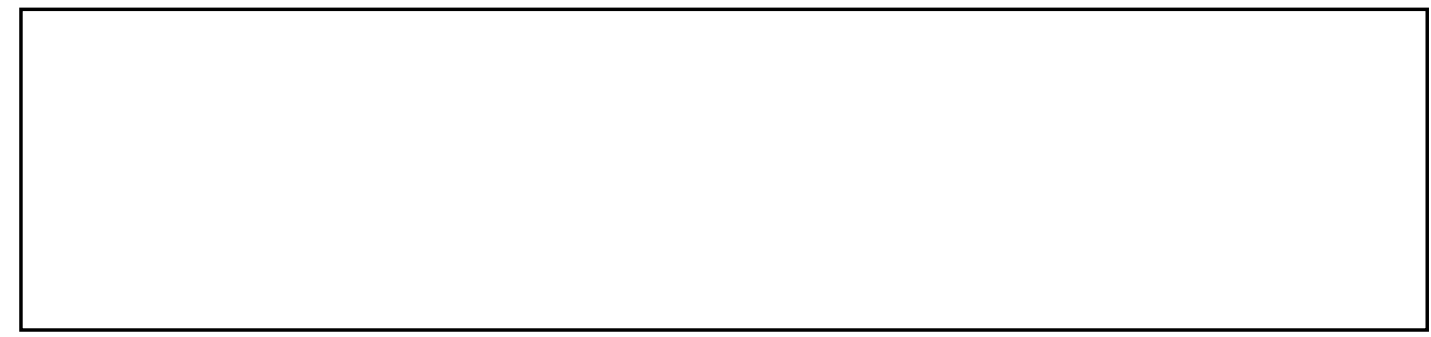

4) Na sua opinião, o que poderia ser feito para melhorar o curso do Programa Educ@r?

\section{MUITO OBRIGADA POR SEU TEMPO E CONSIDERAÇÃO}

Comentários para: monimag@ifqsc.sc.usp.br

Revisado em Março/97 


\section{Programa Educ@r}

Com o envio deste formulário você estará nos ajudando a melhorar este curso. Suas experiências e observações são partes fundamentais neste Programa. Lembre-se que é o Programa Educ@r que está sendo avaliado e não você.

$$
\text { MUITO OBRIGADA POR SUA COLABORAÇÃO }
$$

\section{Avaliação Formativa do Curso para o Instrutor}

Nome:

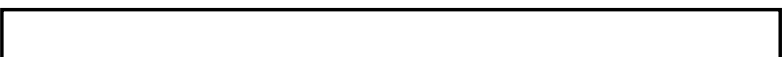

Escola:

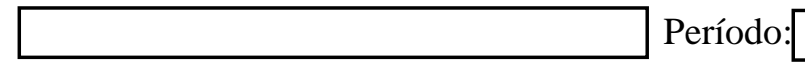

Cidade/Estado:

Curso a ser avaliado:

O Matemática

O Física

Cidade/Estado:

OMatemática

1) Quais as responsabilidades principais do instrutor (prof. presente) e quanto tempo se dedica para cada atividade?

a) Orientação

b) Dúvidas

c) Motivação

d) e outros... 
2) Você sente que possui tempo apropriado para instruir seus alunos ativamente? (Sim ou Não, se Não, por favor explique:)

3) Quais os pontos fortes e quais os críticos no relacionamento entre instrutor (prof. presente) e mentor (prof. distante)?

a) Pontos Fortes

b) Pontos Críticos

4) Como é o relacionamento entre instrutor (prof. presente) e mentor (prof. distante) para ajudar a aumentar o aprendizado?
O Muito Bom
O Bom
O Médio
O Fraco
O Muito Fraco

5) Qual a eficácia das seguintes tecnologias:

Uso da Internet
O Muito Bom
O Bom
O Médio
O Fraco
O Muito Fraco

Uso da linguagem LOGO
O Muito Bom
O Bom
O Médio
O Fraco
O Muito Fraco

Experimentos usando o Puck
O Muito Bom
O Bom
O Médio
O Fraco
O Muito Fraco

6) Como você classificaria as páginas do Programa Educ@r, com relação à:

Apresentação

O Muito Boa O Boa O Média OFraca O Muito Fraca

Conteúdo

O Muito Bom O Bom O Médio OFraco O Muito Fraco 
7) Qual a eficácia dos seguintes serviços de suporte:

Treinamento do instrutor (prof. presente)
O Muito Bom
O Bom
O Médio
O Fraco
O Muito Fraco

Apoio contínuo ao instrutor - prof. presente - (com relação às dificuldades)
O Muito Bom
O Bom
O Médio
O Fraco
O Muito Fraco

Apoio Tecnológico (com relação ao computador)
O Muito Bom
O Bom
O Médio
O Fraco
O Muito Fraco

8) Na sua opinião, quais os aspectos bem sucedidos no curso do Programa Educ@r?

9) Na sua opinião, quais os aspectos mal sucedidos no curso do Programa Educ@r?

10) Na sua opinião, quais os aspectos do curso do Programa Educ@r que poderiam ser melhorados?

MUITO OBRIGADA POR SEU TEMPO E CONSIDERAÇÃO

Comentários para: monimag@ifqsc.sc.usp.br

Revisado em Março/97 


\section{Programa Educ@r}

Com o envio deste formulário você estará nos ajudando a melhorar este curso. Suas experiências e observações são partes fundamentais neste Programa. Lembre-se que é o Programa Educ@r que está sendo avaliado e não você.

$$
\text { MUITO OBRIGADA POR SUA COLABORAÇÃO }
$$

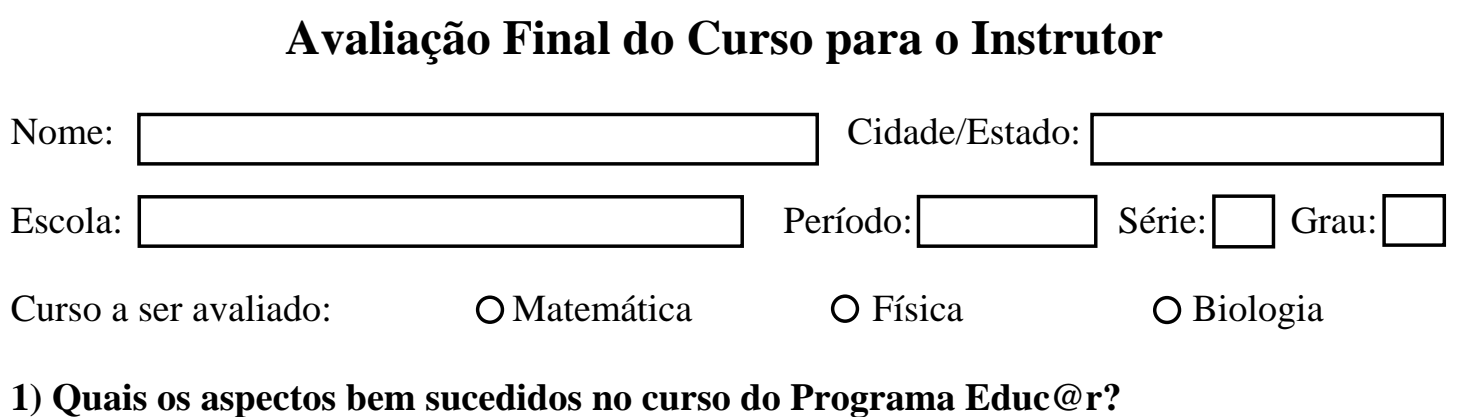

2) Quais os aspectos mal sucedidos no curso do Programa Educ@r?

3) Você tem comentários ou sugestões com relação às tarefas do instrutor durante o curso do Programa Educ@r?

5) Qual a eficácia dos seguintes elementos:

Uso da Internet
O Muito Bom
O Bom
O Médio
O Fraco
O Muito Fraco

Uso da linguagem LOGO

O Muito Bom O Bom

O Médio

O Fraco

O Muito Fraco 
Experimentos usando o Puck
O Muito Bom
O Bom
O Médio
O Fraco
Muito Fraco

Apresentação das páginas do curso
O Muito Boa
O Boa
O Média
O Fraca
O Muito Fraca

Conteúdo das páginas do curso
O Muito Bom
O Bom
O Médio
O Fraco
O Muito Fraco

Treinamento do instrutor (prof. presente)
O Muito Bom
O Bom
O Médio
O Fraco
O Muito Fraco

Apoio contínuo ao instrutor - prof. presente - (com relação às dificuldades)
O Muito Bom
O Bom
O Médio
O Fraco
O Muito Fraco

Apoio Tecnológico (com relação ao computador)
O Muito Bom
O Bom
O Médio
O Fraco
O Muito Fraco

\section{4) $\mathrm{O}$ que você achou da metodologia utilizada nos hipertextos?}
O Muito Boa
O Boa
O Média
O Fraca
O Muito Fraca

5) O que poderia melhorar significativamente a eficácia do Programa Educ@r,com relação à:

a) Educação

b) Tecnologia

c) Participações dos alunos/instrutores(prof. presentes)/mentores(prof. distantes)

MUITO OBRIGADA POR SEU TEMPO E CONSIDERAÇÃO

Comentários para: monimag@ifqsc.sc.usp.br

Revisado em Março/97 


\section{Programa Educ@r}

Com o envio deste formulário você estará nos ajudando a melhorar este curso. Suas experiências e observações são partes fundamentais neste Programa. Lembre-se que é o Programa Educ@r que está sendo avaliado e não você.

$$
\text { MUITO OBRIGADA POR SUA COLABORAÇÃO }
$$

\section{Avaliação Formativa do Curso para o Mentor (prof. distante)}

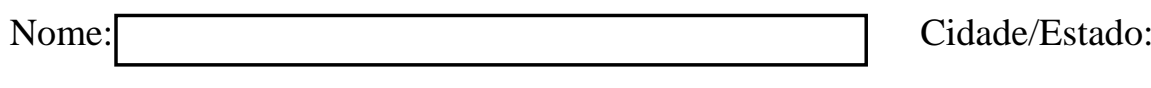

Escola Período: Série: $\square$ Grau: $\square$

Curso a ser avaliado:

O Matemática O Física

O Biologia

1) Quais as responsabilidades principais do mentor (prof. distante) e quanto tempo se dedica para cada atividade?

2) Você sente que possui tempo apropriado para mediar seus alunos ativamente? (Sim ou Não, se Não, por favor explique:)

3) Quais os pontos fortes e quais os críticos no relacionamento entre instrutor (prof. presente) e mentor (prof. distante)?

a) Pontos Fortes 
b) Pontos Críticos

4) Como é o relacionamento entre aluno/instrutor (prof. presente)/mentor (prof. distante) para ajudar a aumentar $\mathrm{o}$ aprendizado?

O Muito Bom O Bom O Médio O Fraco O Muito Fraco

5) Qual a eficácia das seguintes tecnologias:

Uso da Internet

O Muito Bom O Bom O Médio OFraco O Muito Fraco

Uso da linguagem LOGO

O Muito Bom O Bom O Médio OFraco O Muito Fraco

Experimentos usando o Puck
O Muito Bom
O Bom
○ Médio
O Fraco
O Muito Fraco

6) Como você classificaria as páginas do Programa Educ@r, com relação à: Apresentação
O Muito Boa
O Boa
O Média
O Fraca
O Muito Fraca

Conteúdo

O Muito Bom O Bom O Médio O Fraco O Muito Fraco

7) Qual a eficácia dos seguintes serviços de suporte:

Treinamento do mentor (prof. distante)
O Muito Bom
O Bom
O Médio
O Fraco
O Muito Fraco

Apoio contínuo ao mentor - prof. distante - (com relação às dificuldades)
O Muito Bom
O Bom
O Médio
O Fraco
O Muito Fraco

Apoio Tecnológico (com relação ao computador)
O Muito Bom
O Bom
O Médio
O Fraco
O Muito Fraco

8) Na sua opinião, quais os aspectos bem sucedidos no curso do Programa Educ@r? 
9) Na sua opinião, quais os aspectos mal sucedidos no curso do Programa Educ@r?

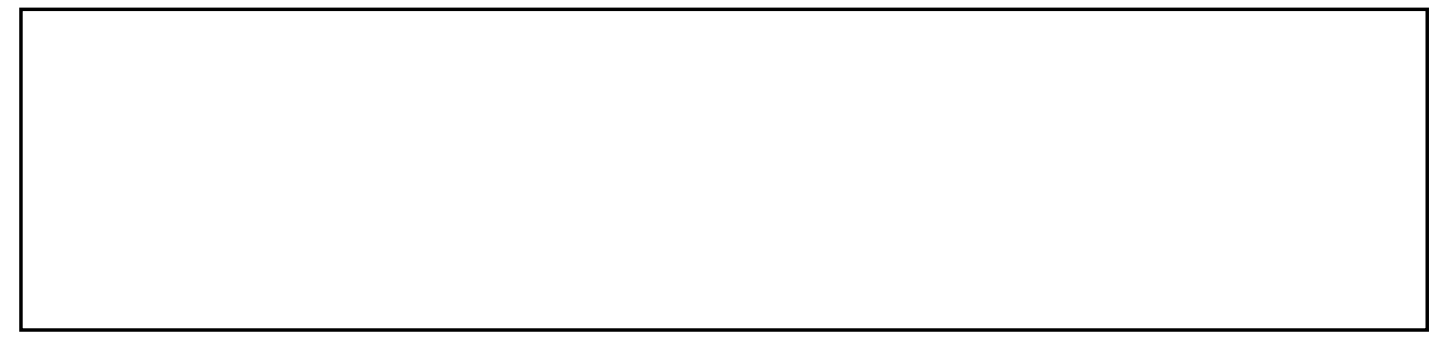

10) Na sua opinião, quais os aspectos do curso do Programa Educ@r que poderiam ser melhorados?

MUITO OBRIGADA POR SEU TEMPO E CONSIDERAÇÃO

Comentários para: monimag@ifqsc.sc.usp.br

Revisado em Março/97 


\section{Programa Educ@r}

Com o envio deste formulário você estará nos ajudando a melhorar este curso. Suas experiências e observações são partes fundamentais neste Programa. Lembre-se que é o Programa Educ@r que está sendo avaliado e não você.

$$
\text { MUITO OBRIGADA POR SUA COLABORAÇÃO }
$$

\section{Avaliação Final do Curso para o Mentor (prof. distante)}

Nome:

Cidade/Estado:

Escola: Período: Série: $\square$ Grau:

Curso a ser avaliado:

O Matemática

O Física

O Biologia

1) Quais os aspectos bem sucedidos no curso do Programa Educ@r?

2) Quais os aspectos mal sucedidos no curso do Programa Educ@r?

3) Se você ministrasse novamente este curso do Programa Educ@r, o que você mudaria? 
4) Há estratégias, sistemas ou tecnologias que poderiam ser integradas ao Programa Educ@r para melhorar o aprendizado independente?

5) Há mudanças na apresentação das páginas da Internet que você gostaria que ocorressem? Quais?

6) Qual a eficácia dos seguintes elementos:

Uso da Internet

O Muito Bom O Bom O Médio OFraco O Muito Fraco

Uso da linguagem LOGO

O Muito Bom O Bom O Médio O Fraco O Muito Fraco

Experimentos usando o Puck
O Muito Bom
O Bom
O Médio
O Fraco
O Muito Fraco

Apresentação das páginas do curso

O Muito Boa O Boa O Média OFraca O Muito Fraca

Conteúdo

O Muito Bom O Bom O Médio OFraco O Muito Fraco

Treinamento do mentor (prof. distante)
O Muito Bom
O Bom
O Médio
O Fraco
O Muito Fraco

Apoio contínuo ao mentor - prof. distante - (com relação às dificuldades)
O Muito Bom
O Bom
O Médio
O Fraco
O Muito Fraco

Apoio Tecnológico (com relação ao computador)
O Muito Bom
O Bom
○ Médio
O Fraco
O Muito Fraco 
7) O que poderia melhorar significativamente a eficácia do Programa Educ@r, com relação à:

a) Educação

b) Tecnologia

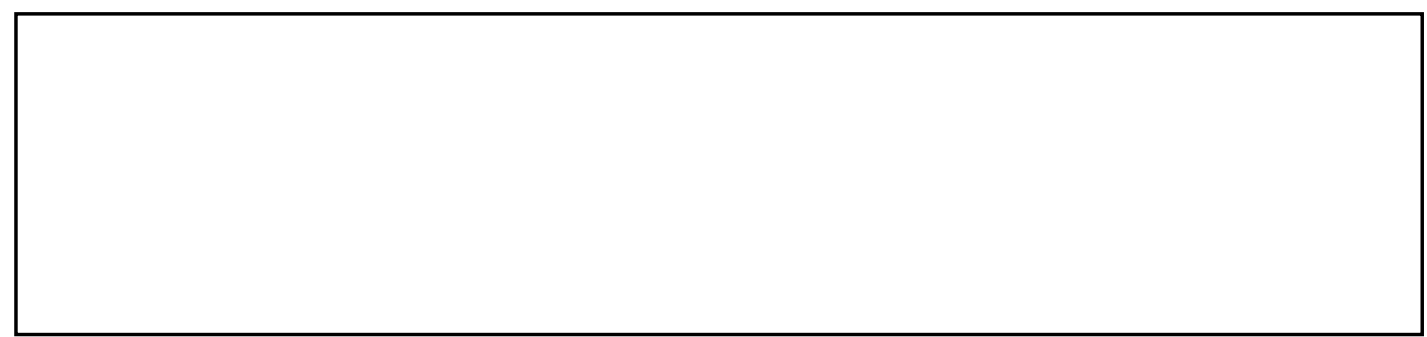

c) Participações dos alunos/instrutores (prof. presentes)/mentores (prof. distantes)

MUITO OBRIGADA POR SEU TEMPO E CONSIDERAÇÃO

Comentários para: monimag@ifqsc.sc.usp.br

Revisado em Março/97 


\section{Programa Educ@r}

Com o envio deste formulário você estará nos ajudando a melhorar este curso. Suas experiências e observações são partes fundamentais neste Programa. Lembre-se que é o Programa Educ@r que está sendo avaliado e não você.

$$
\text { MUITO OBRIGADA POR SUA COLABORAÇÃO }
$$

\section{Curso de Treinamento para Professores}

Nome:

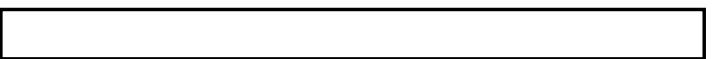

Escola:

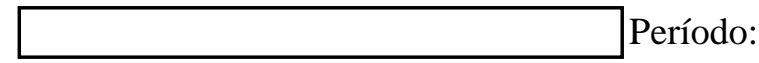

Cidade/Estado:

$\square$ seri

Série: $\square$ Grau:

1) Por que você decidiu fazer este curso de treinamento do Programa Educ@r?

2) Em que partes você teve dificuldades no Programa? Justificar a resposta.

a) LOGO

b) Puck

c) Experimentos 
3) Aonde você teve menos dificuldades no Programa? Justificar a resposta.

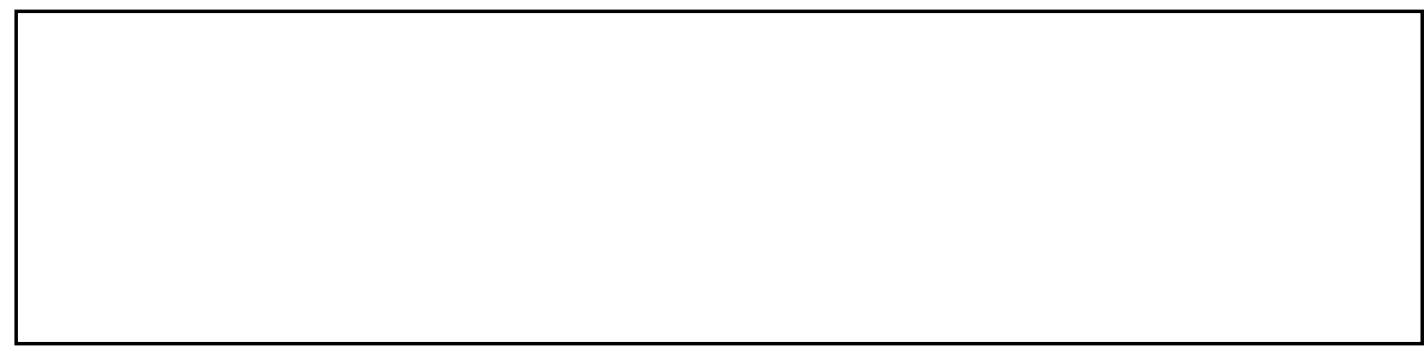

4) Como você classificaria os seguintes elementos:

Uso da Internet como um meio auxiliar ou complementar de suas aulas
O Muito Bom
O Bom
○ Médio
O Fraco
O Muito Fraco

Uso da linguagem LOGO
O Muito Bom
O Bom
O Médio
O Fraco
O Muito Fraco

Experimentos usando o Puck
O Muito Bom
O Bom
O Médio
O Fraco
O Muito Fraco

Apresentação das páginas do curso do Programa Educ@r
O Muito Boa
O Boa
O Média
O Fraca
O Muito Fraca

Conteúdo das páginas do curso do Programa Educ@r
O Muito Bom
O Bom
O Médio
O Fraco
O Muito Fraco

Metodologia das páginas do curso do Programa Educ@r
O Muito Bom
O Bom
O Médio
O Fraco
O Muito Fraco

5) $O$ que o Mentor (prof. distante) poderia fazer para melhor ajudá-lo no curso quando você for aplicá-lo para seus alunos?

6) Você acha que após este curso de treinamento você estará apto a trabalhar com seus alunos usando a Internet? Caso não esteja, justifique. 
7) Como você pretende aplicar este programa para seus alunos?

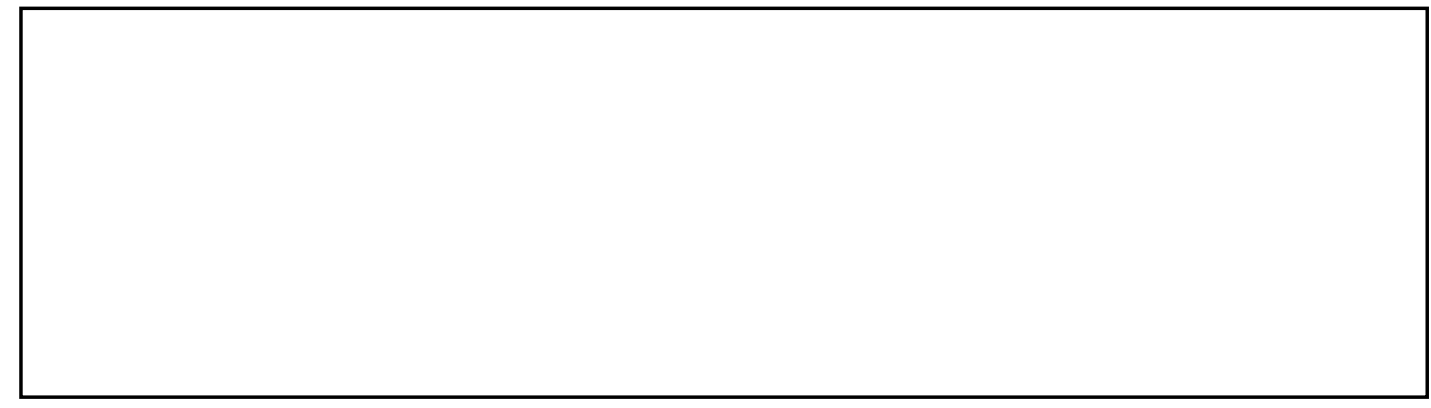

8) O que poderia ser feito para melhorar o curso de treinamento do Programa Educ@r? 


\section{Anexo C}

Dados coletados pelos alunos do $1^{\circ}$ colegial de 1997, enviados através das tabelas interativas do curso de Mecânica Gráfica do Programa Educ@r e as respectivas mensagens do mentor transmitidas por e-mail a cada grupo de alunos. 


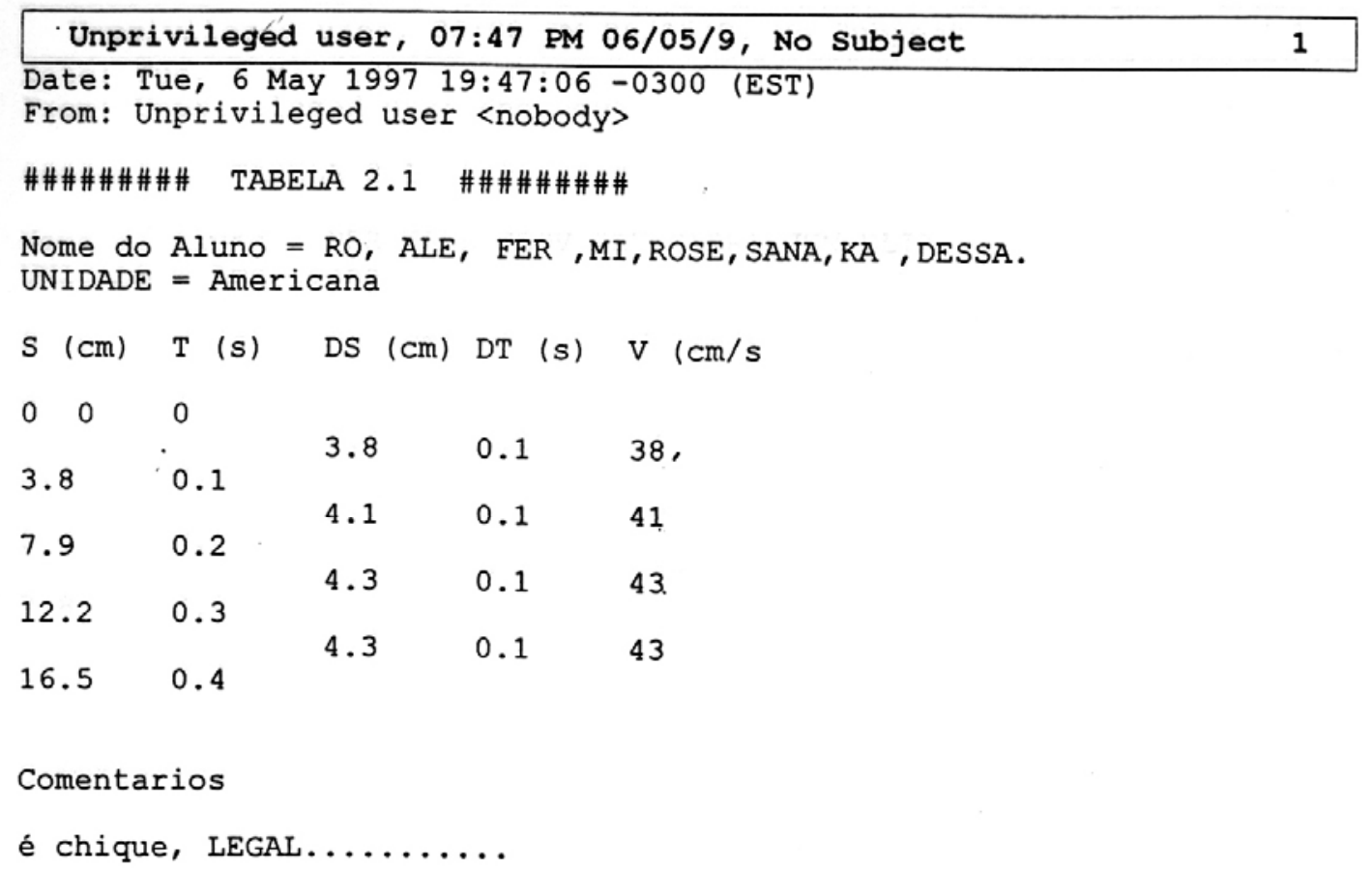

deamspbredglnet.com, 10:58 AM 09/10/9, No Subject 1

To: deamspbredglnet.com.br

From: iria@www.ifqsc.sc.usp.br (Iria Muller Guerrini)

Ola ro e outros!

Os valores encontrados para $\mathrm{V}$ estao bons. Apenas o valor para V 38

$\mathrm{cm} / \mathrm{s}$ esta apresentando um erro maior que $5 \%$ do valor medio mas nao e significativo

Abracos

Iria

Obs Estou enviando novamente porque o primeiro apresentava um erro de digitacao. 
Unprivileged user, 08:08 PM 06/05/9, No Subject

Date: Tue, 6 May 1997 20:08:42 -0300 (EST)

From: Unprivileged user <nobody>

\section{\#\#\#\#\#\#\#\# TABELA 2.1 \#\#\#\#\#\#\#\#\#}

Nome do Aluno = PER WALL GEOV PAU GABRI JUN ELIA

UNIDADE = Americana

$\begin{array}{lllll}\mathrm{S}(\mathrm{cm}) & \mathrm{T}(\mathrm{s}) & \mathrm{DS}(\mathrm{cm}) & \mathrm{DT}(\mathrm{s}) & \mathrm{V}(\mathrm{cm} / \mathrm{s} \\ 0 & 0 & & & \\ 2.4 & 0.1 & 2.4 & 0.1 & 24 \\ 5.0 & 0.2 & 2.6 & 0.1 & 26 \\ 7.8 & 3.0 & 2.8 & 0.1 & 28 \\ 10.2 & 0.4 & 2.4 & 0.1 & 24\end{array}$

Comentarios

dearspbredglnet.com, 11:01 AM 09/10/9, tabela $2.1(06 / 05$ - w

To: deamspbredglnet.com.br

From: iria@www.ifqsc.sc.usp.br (Iria Muller Guerrini)

Subject: tabela 2.1 (06/05 - wallessandra)

Ola per e outros!

Os resultados obtidos para $\mathrm{V}$ estao bons. Apenas o vaor para $\mathrm{V} 28$

difere um pouco do valor medio mas nao e significativo.

Abracos 


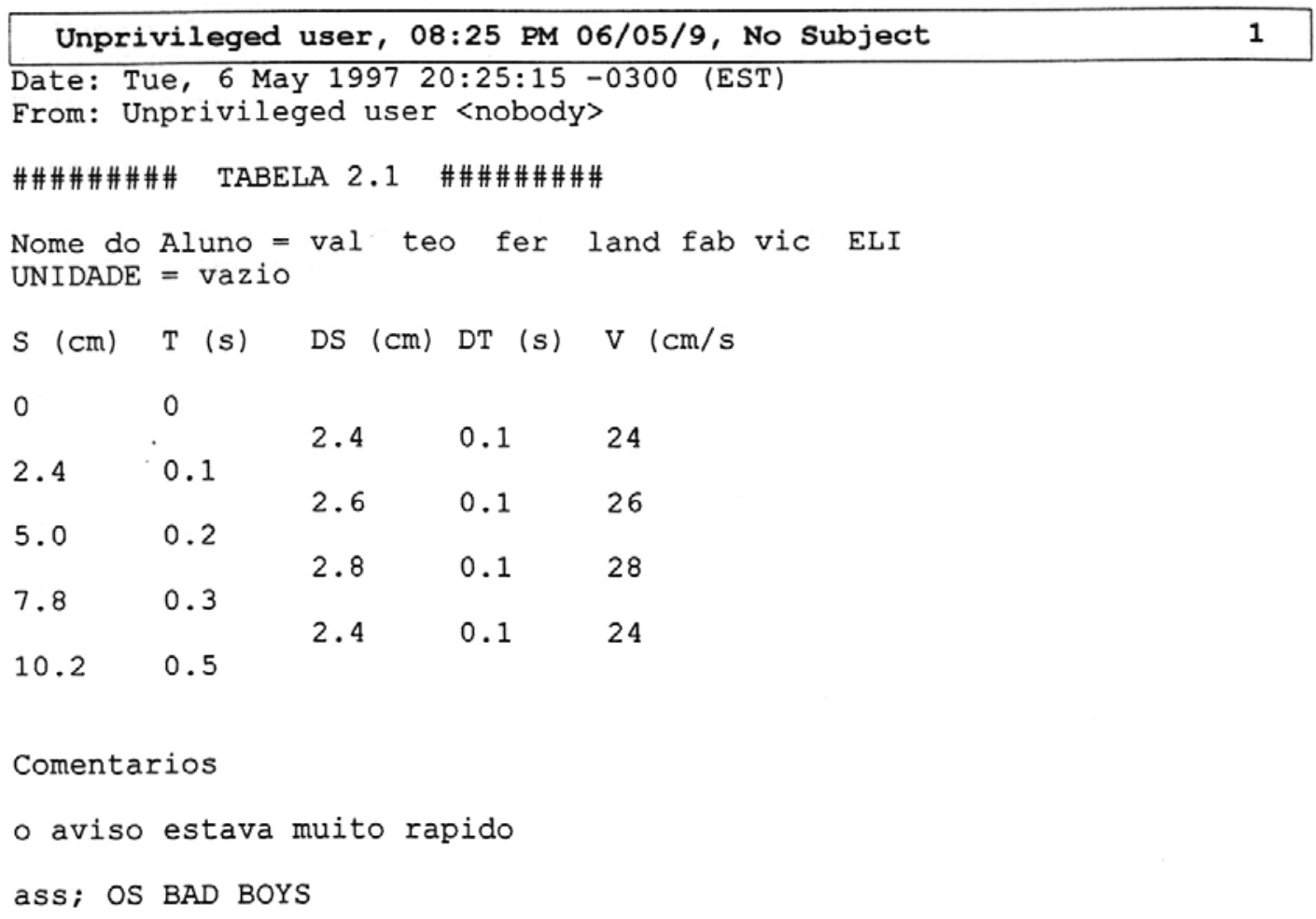

VALDEBERTO LEANDRO FERNANDO JORDAN ELIAS VICENTE FABIO

deamspbredglnet.com, 08:53 AM 04/10/9, tabela 2.1(Wallesandr 1

To: deamspbredglnet.com.br

From: iria@www.ifqsc.sc.usp.br (Iria Muller Guerrini)

Subject: tabela 2.1 (Wallesandra)

Valdeberto e outros

Ola BAD BOYS!

Os valores encontrados estao aproximadamente corretos. O terceiro valor para V $(28 \mathrm{~cm} / \mathrm{s})$ apresenta erro maior do que 5 \% do valor medio da velocidade. Favor verificar as medidas para este valor.

Abracos 


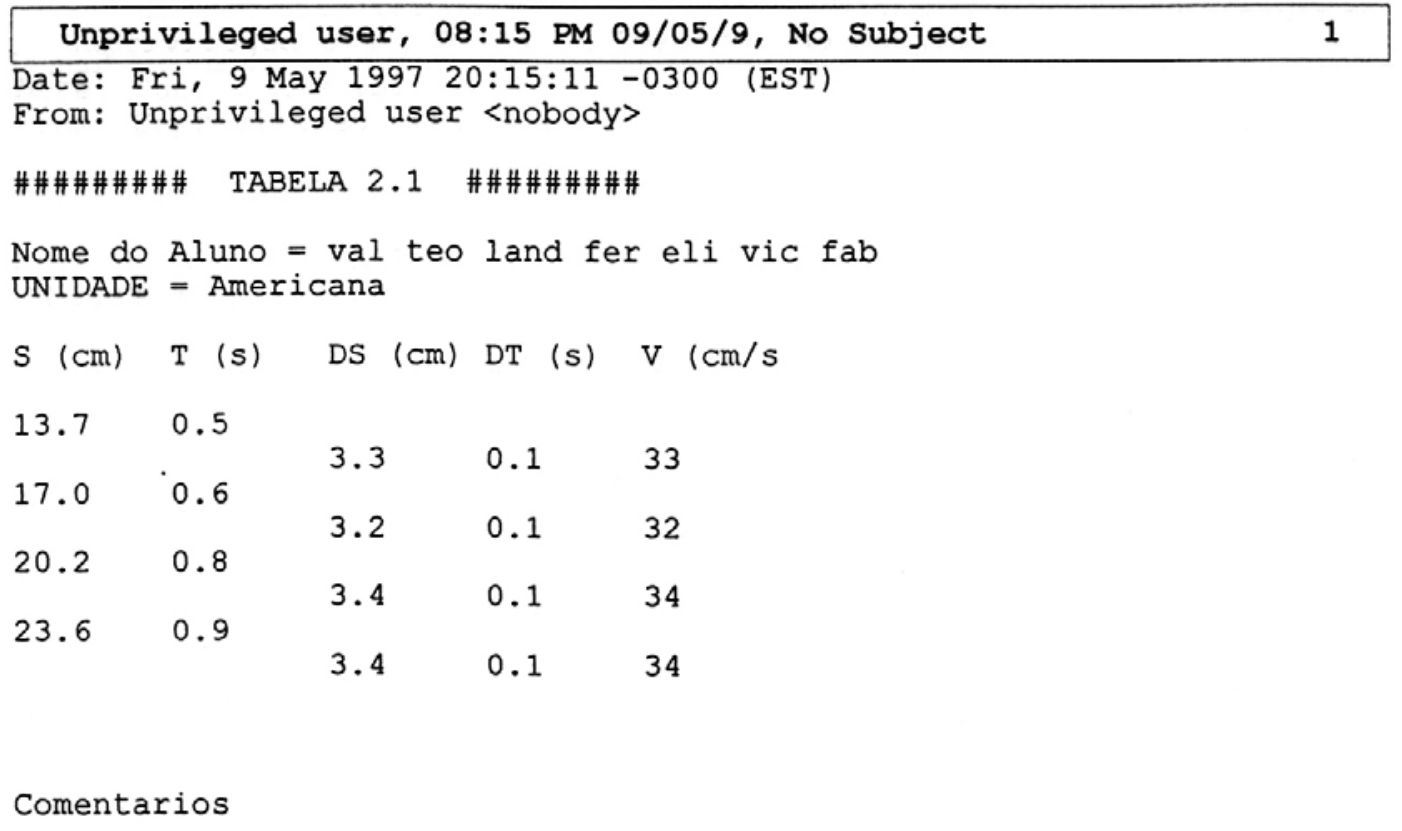

No, Recipient, No Subject

To: deamspbredglnet.com.br

From: iria@www.ifqsc.sc.usp.br (Iria Muller Guerrini)

Subject: tabela 2.1

Ola val e outros!

Os valores encontrados para $\mathrm{V}$ estao excelentes. Parabens!

Abracos 
Unprivileged user, 08:44 PM 06/05/9, No Subject

Date: Tue, 6 May 1997 20:44:55 -0300 (EST)

From: Unprivileged user <nobody>

\#\#\#\#\#\#\#\#\# TABELA 2.1 \#\#\#\#\#\#\#\#\#

Nome do Aluno = DESA MI LU PRI RE DÉIA JACKE

UNIDADE = Americana

$\begin{array}{lllll}\mathrm{S}(\mathrm{cm}) & \mathrm{T}(\mathrm{s}) & \mathrm{DS}(\mathrm{cm}) & \mathrm{DT}(\mathrm{s}) & \mathrm{V}(\mathrm{cm} / \mathrm{s} \\ 0 & 0 & & & \\ 5.3 & 0.1 & 5.3 & 0.1 & 53 \\ 10.3 & 0.2 & 5 & 0.1 & 50 \\ 15.3 & 0.3 & 5 & 0.1 & 50 \\ 20.1 & 0.4 & 4.8 & 0.1 & 48\end{array}$

Comentarios

deidmspbredglnet.com, 08:59 AM 04/10/9, tabela 2.1 (wallessan

To: deamspbredglnet.com.br

From: irialwww.ifqsc.sc.usp.br (Iria Muller Guerrini)

Subject: tabela 2.1 (wallessandra)

Desa e outros

Ola!

Os valores encontrados para $V$ estao bons. Apenas o valor $53 \mathrm{~cm} / \mathrm{s}$ para a velocidade apresenta erro maior do que 5 o que não e muito significativo.

Abracos 
Unprivileged user, 09:08 PM 06/05/9, No Subject

Date: Tue, 6 May 1997 21:08:17 -0300 (EST)

From: Unprivileged user <nobody>

\section{\#\#\#\#\#\#\#\#\# TABELA 2.1 \#\#\#\#\#\#\#\#\#}

Nome do Aluno = OS MALACOS

UNIDADE = Americana

\begin{tabular}{|c|c|c|c|c|}
\hline $\mathrm{S}(\mathrm{cm})$ & $\mathrm{T} \quad(\mathrm{s})$ & DS $(\mathrm{cm})$ & DT (s) & $\mathrm{V}(\mathrm{cm} / \mathrm{s}$ \\
\hline 0 & 0 & 6.2 & 0.1 & 62 \\
\hline 6.2 & 0.1 & 6.8 & 0.1 & 68 \\
\hline 13 & 0.2 & 6.2 & 0.1 & 62 \\
\hline $\begin{array}{l}19.2 \\
25.4\end{array}$ & $\begin{array}{l}0.3 \\
0.4\end{array}$ & 6.2 & 0.1 & 62 \\
\hline
\end{tabular}

Comentarios

deamspbredglnet.com, 09:03 AM 04/10/9, tabela 2.1 (wallessan

To: deamspbredglnet.com.br

From: iria@www.ifqsc.sc.usp.br (Iria Muller Guerrini)

Subject: tabela 2.1 (wallessandra)

Ola malacos!

Os valores estao aproximadamente corretos. O valor de $68 \mathrm{~cm} / \mathrm{s}$ para a velocidade apresenta erro maior que 5 \% do valor medio. Favor verificar as medidas.

Abracos 


\begin{tabular}{|c|c|c|c|c|}
\hline \multicolumn{5}{|c|}{ Unprivileged user, 09:28 PM 06/05/9, } \\
\hline \multicolumn{5}{|c|}{$\begin{array}{l}\text { Date: Tue, } 6 \text { May } 1997 \text { 21:28:59 }-0300 \text { (ES } \\
\text { From: Unprivileged user <nobody> }\end{array}$} \\
\hline \#\#\#\#\#\#\# \# & $\mathrm{TAE}$ & A 2.1 & \#\# \#\#\# \# \# & \\
\hline $\begin{array}{l}\text { Nome do } \\
\text { UNIDADE }\end{array}$ & $\begin{array}{l}\text { Aluno } \\
=\text { Amer }\end{array}$ & cana & OS MAFI & sos \\
\hline $\mathrm{S}(\mathrm{cm})$ & $\mathrm{T}(\mathrm{s})$ & DS $(\mathrm{cm})$ & DT (s) & $\mathrm{V}(\mathrm{cm} / \mathrm{s}$ \\
\hline 0 & 0 & & & \\
\hline 1.8 & 0.1 & 1.8 & 0.1 & 18 \\
\hline & & 2.3 & 0.1 & 23 \\
\hline 4.1 & 0.2 & & & \\
\hline 6.5 & 0.3 & 2.4 & 0.1 & 24 \\
\hline 8.8 & 0.4 & 2.3 & 0.1 & 23 \\
\hline
\end{tabular}

Comentarios

POR NAO TERMOS O CURSO DE LEITURA DINAMICA ACHAMOS QUE

O COMENTARIO ESTA MUITO RAPIDO TORNANDO-SE ATE ILEGIVEL

deamspbredglnet.com, 09:08 AM 04/10/9, tabela 2.1 (wallessan

To: deamspbredglnet.com.br

From: iria@www.ifqsc.sc.usp.br (Iria Muller Guerrini)

Subject: tabela 2.1 (wallessandra)

Ola mafiosos!

Os valores encontrados para $\mathrm{V}$ estao aproximadamente corretos. O valor de $18 \mathrm{~cm} / \mathrm{s}$ apresenta erro maior que 5 \% do valor medio.

Favor verificar as medidas.

Abracos

$$
\text { Iria }
$$




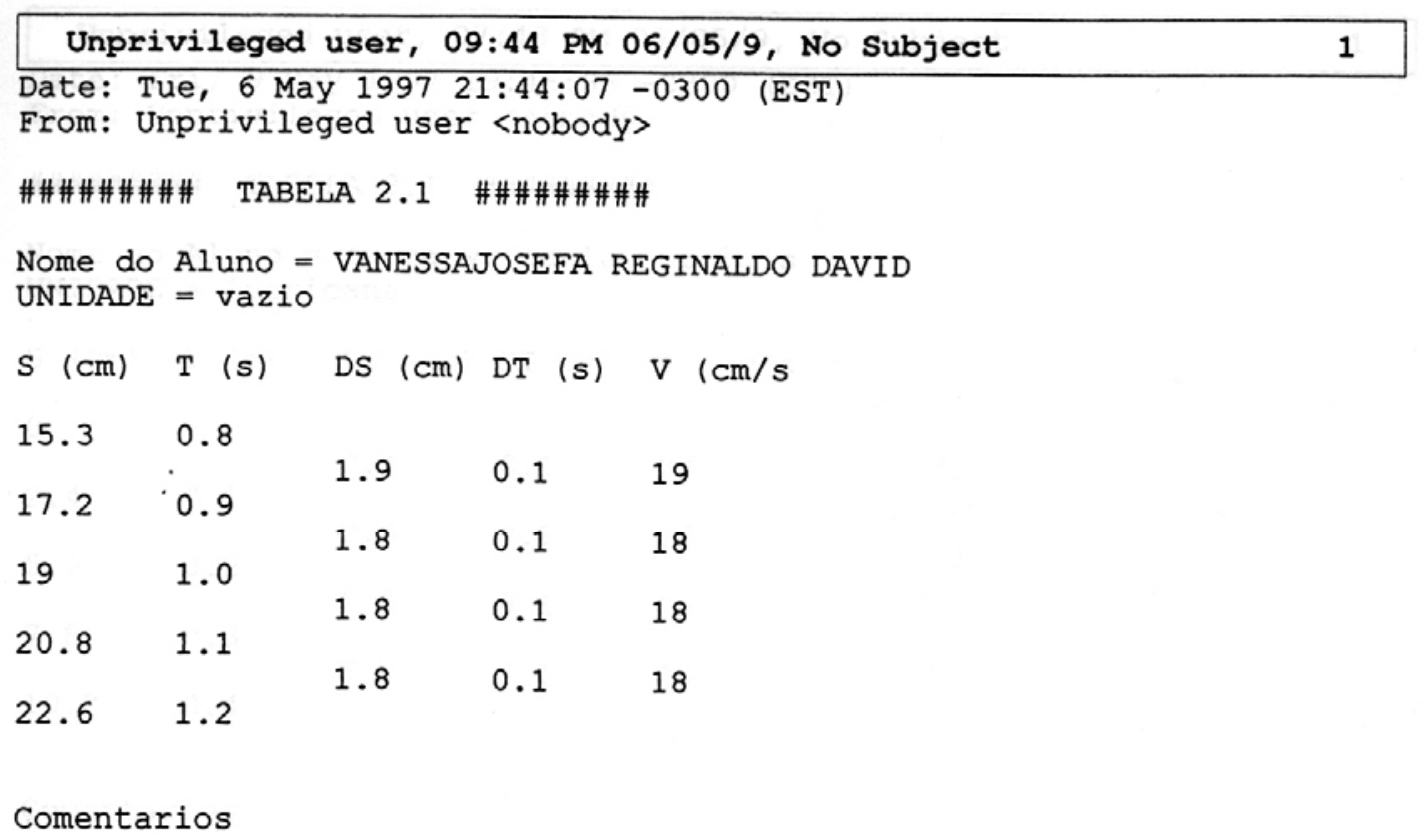

deamspbredglnet.com, 09:10 AM 04/10/9, tabela 2.1 (Wallessan

To: deamspbr@dglnet.com.br

From: iria@www.ifqsc.sc.usp.br (Iria Muller Guerrini)

Subject: tabela 2.1 (Wallessandra)

Vanessa e outros

Ola!

Meus parabens. Os valores encontrados para $\mathrm{V}$ estao excelentes!

Abracos 


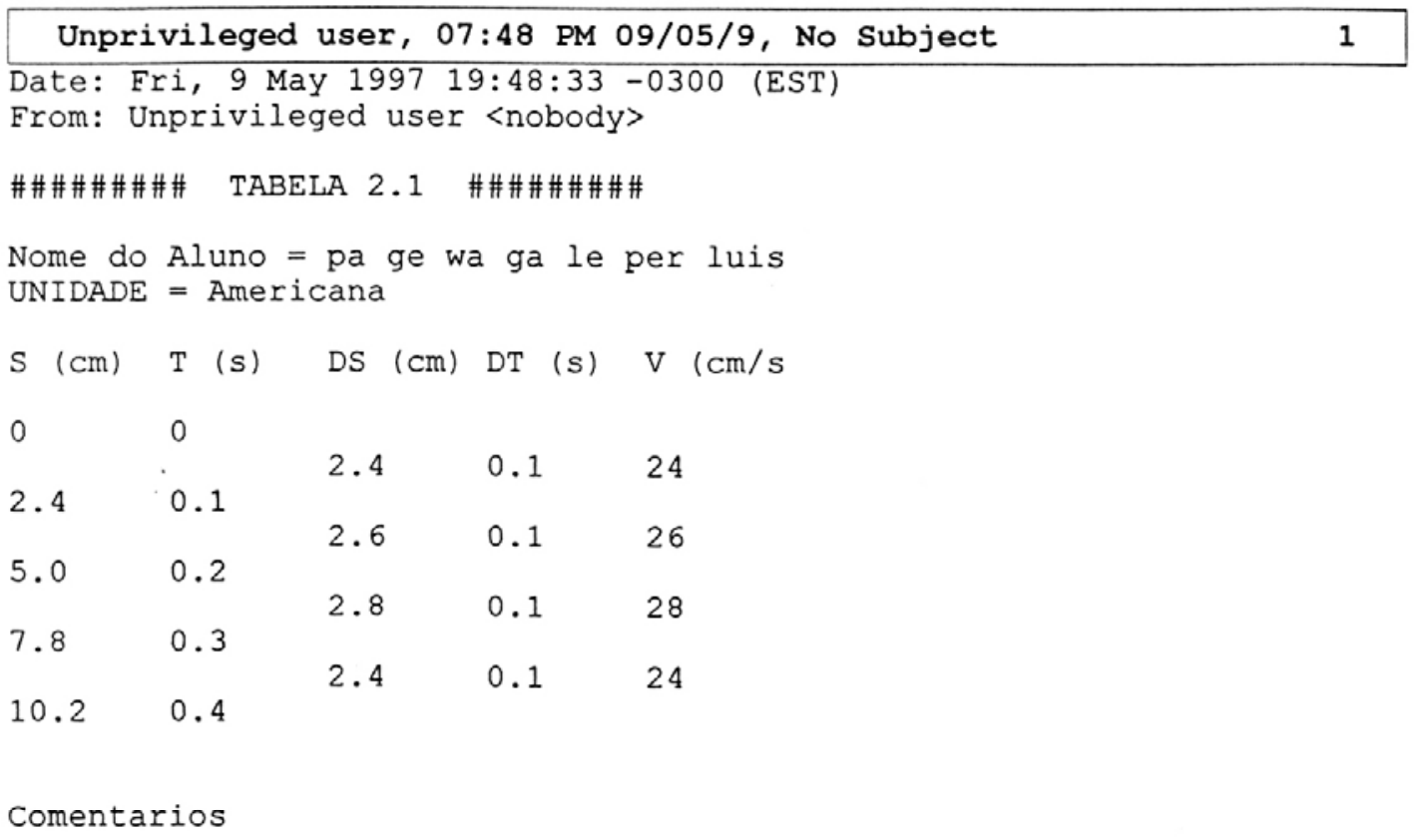

deamspbredglnet.com, 11:18 AM 09/10/9, tabela 2.1 (Wallessan 1

To: deamspbredglnet.com.br

From: iria@www.ifqsc.sc.usp.br (Iria Muller Guerrini)

Subject: tabela 2.1 (Wallessandra)

Ola pa e outros!

Os valores encontrados para $\mathrm{V}$ estao bons. Apenas o valor de $\mathrm{v} 28 \mathrm{~cm} / \mathrm{s}$ apresenta erro maior do $5 \%$ do valor medio mas nao e significativo

Abracos 


\section{Anexo D}

Fotos do curso do $1^{\circ}$ colegial noturno da E. E. P. S. G. João XXIII de Americana, realizado em abril/maio de 1997, sob a orientação da prof ${ }^{a}$ Wallesandra Araújo Silva. 


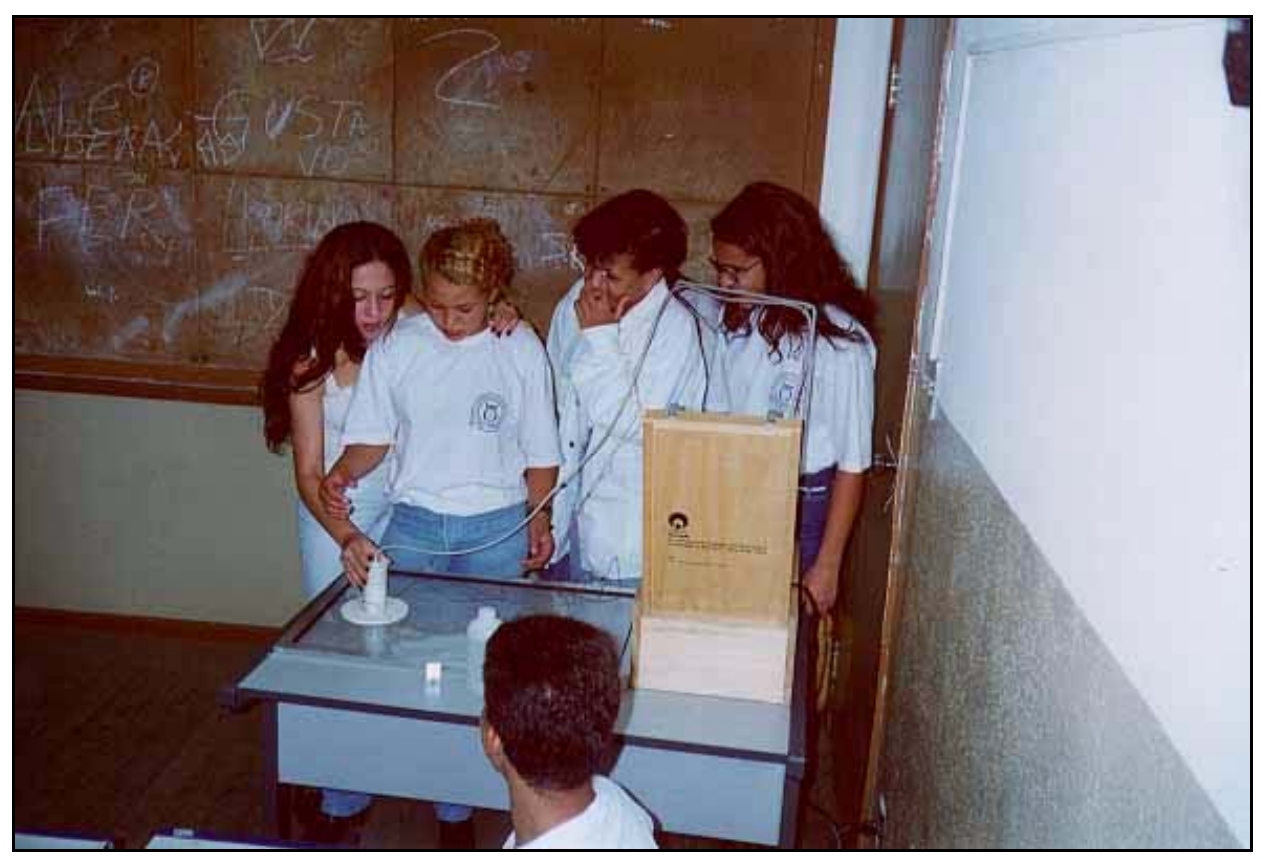

Grupo de alunos utilizando o Puck.

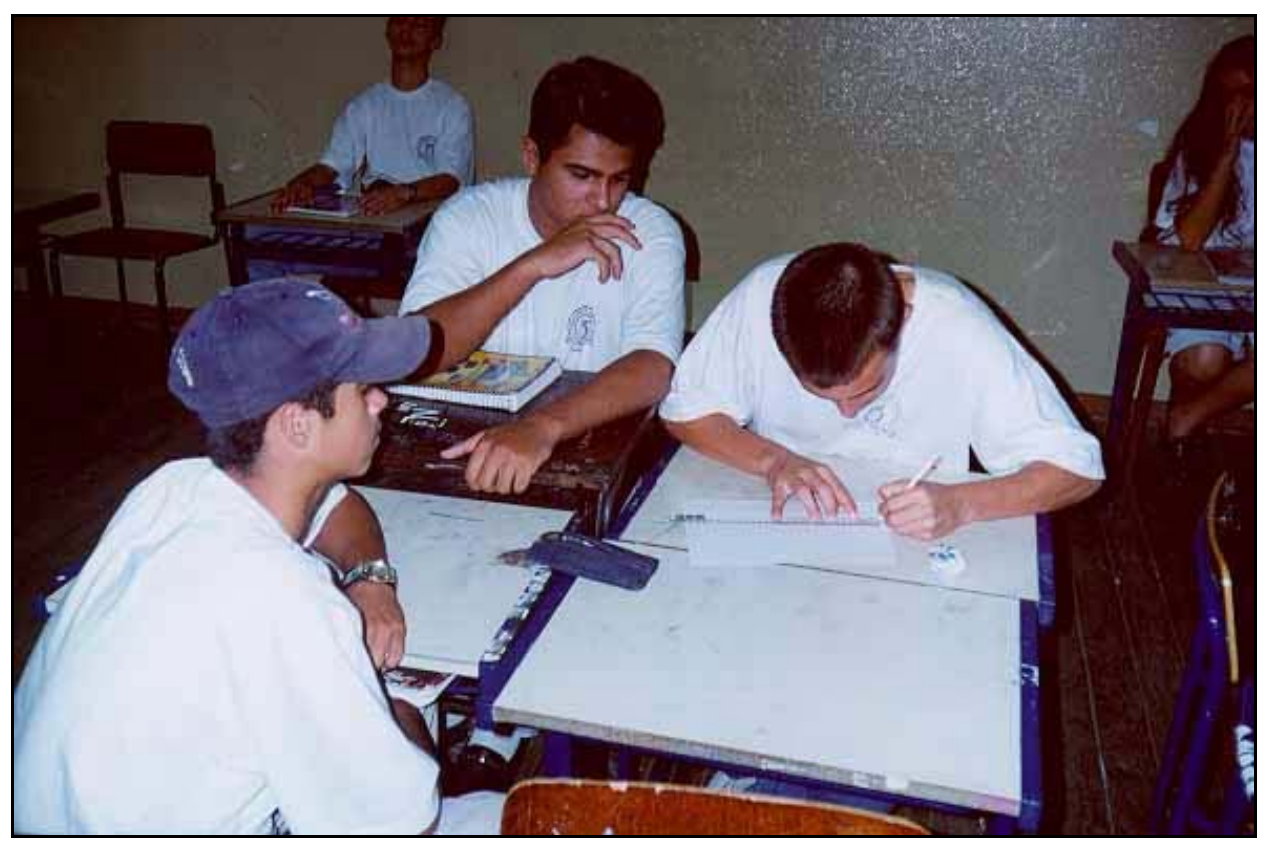

Grupo de alunos obtendo as medidas. 


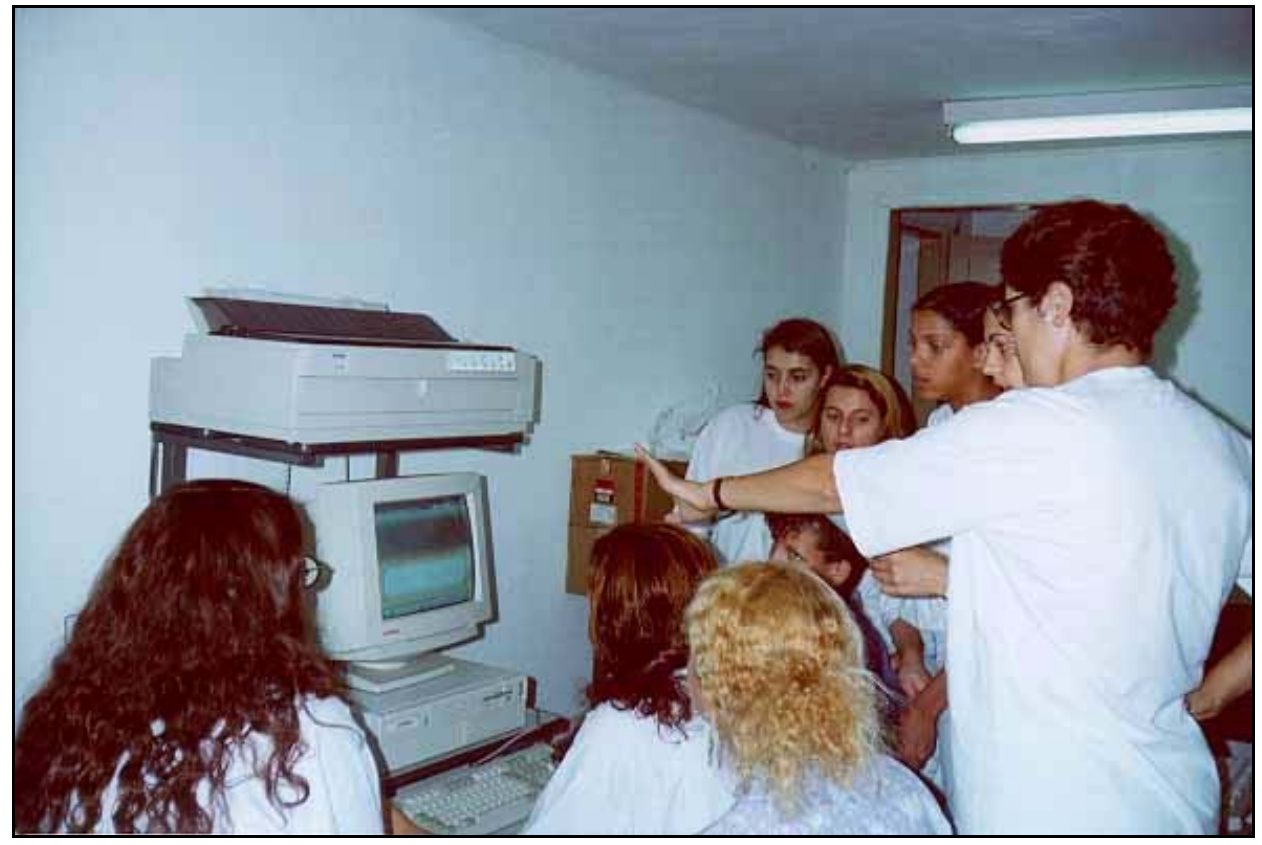

Grupo de alunos utilizando a WWW, orientados pela prof ${ }^{\mathrm{a}}$ Wallesandra.

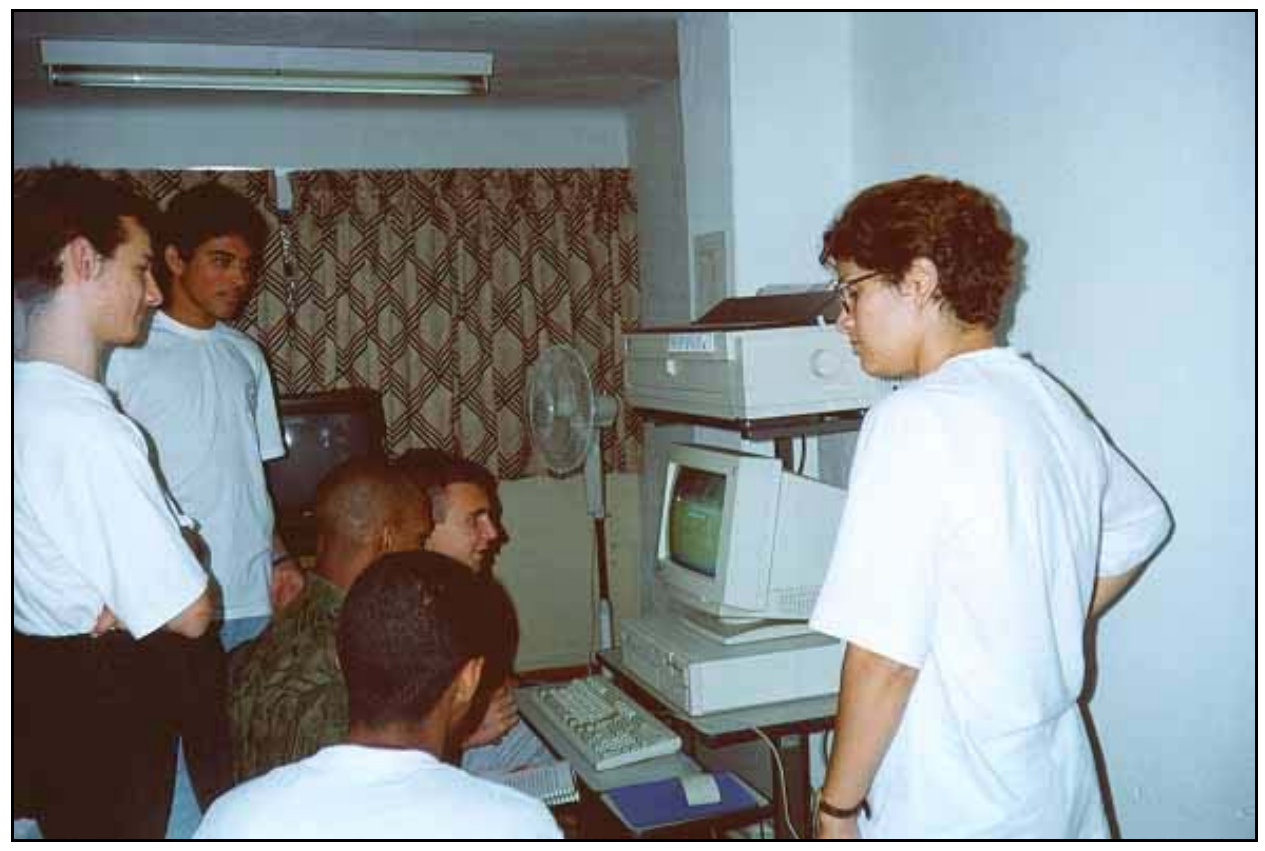

Grupo de alunos preenchendo a tabela interativa via WWW, orientados pela prof ${ }^{\mathrm{a}}$ Wallesandra. 


\section{Anexo E}

Fotos referentes ao curso de treinamento de instrutores realizado em janeiro de 1997 no CDCC/USP São Carlos. 


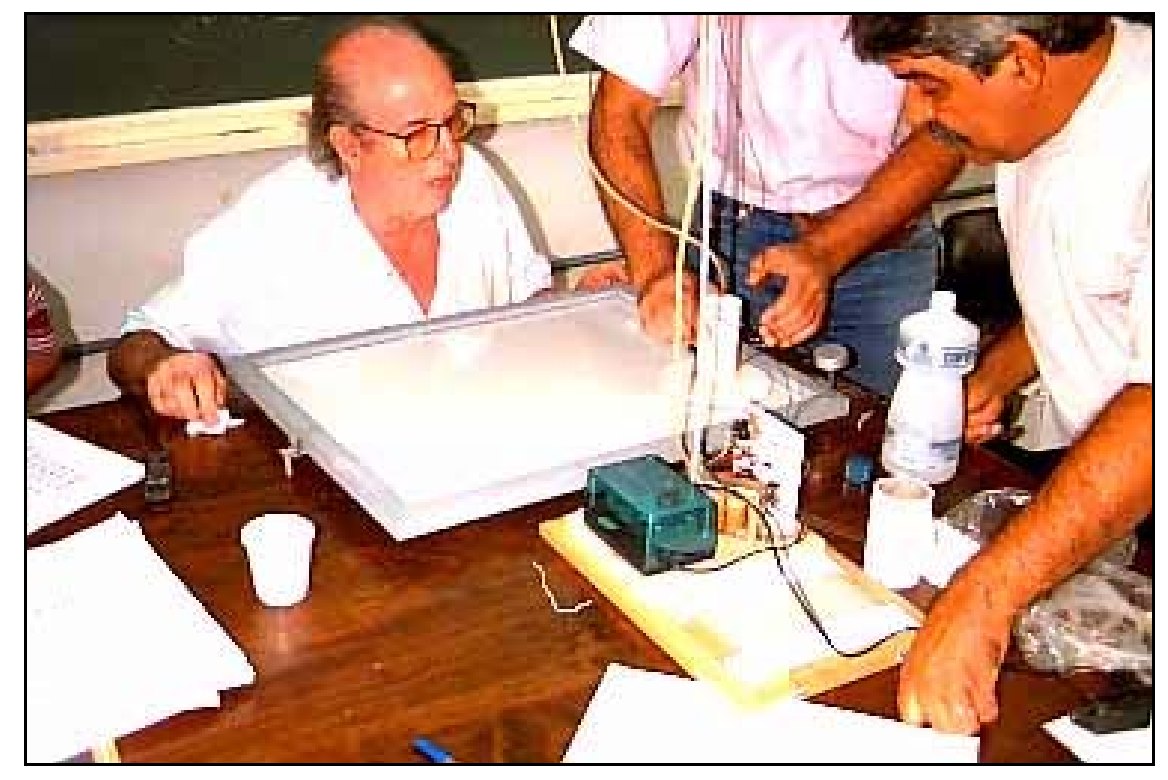

Grupo de professores utilizando o Puck.

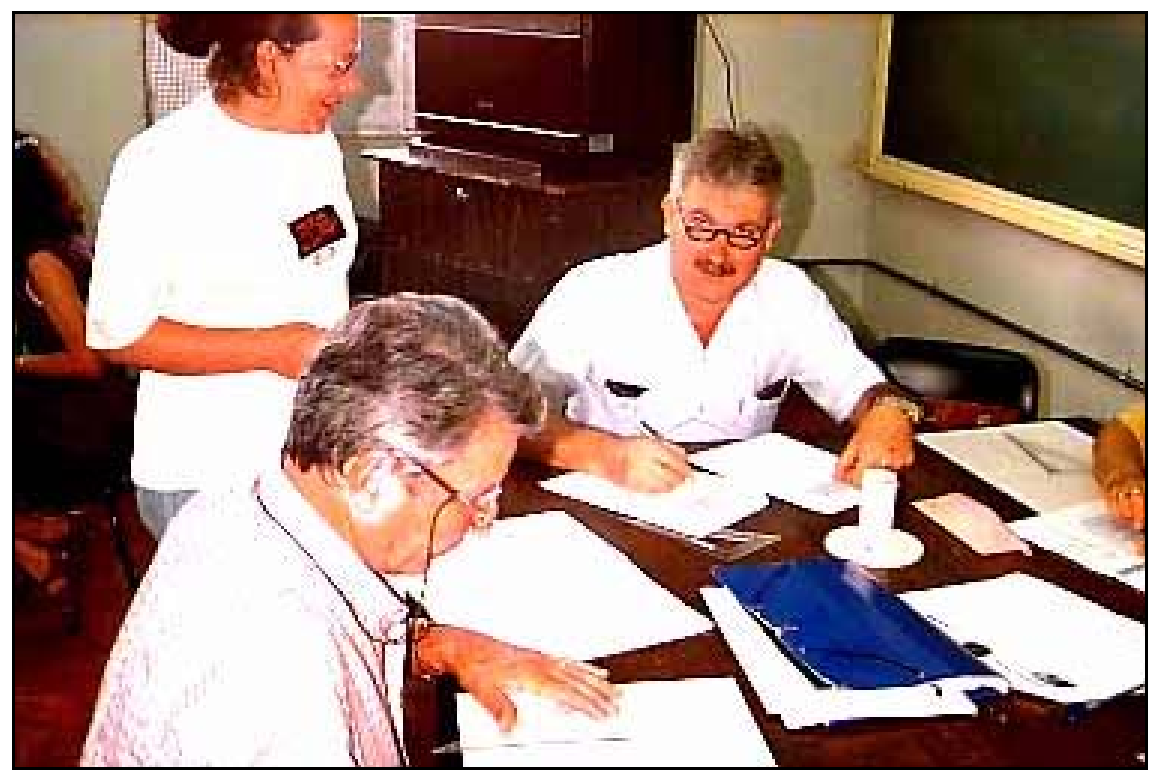

Grupo de professores obtendo as medidas. 


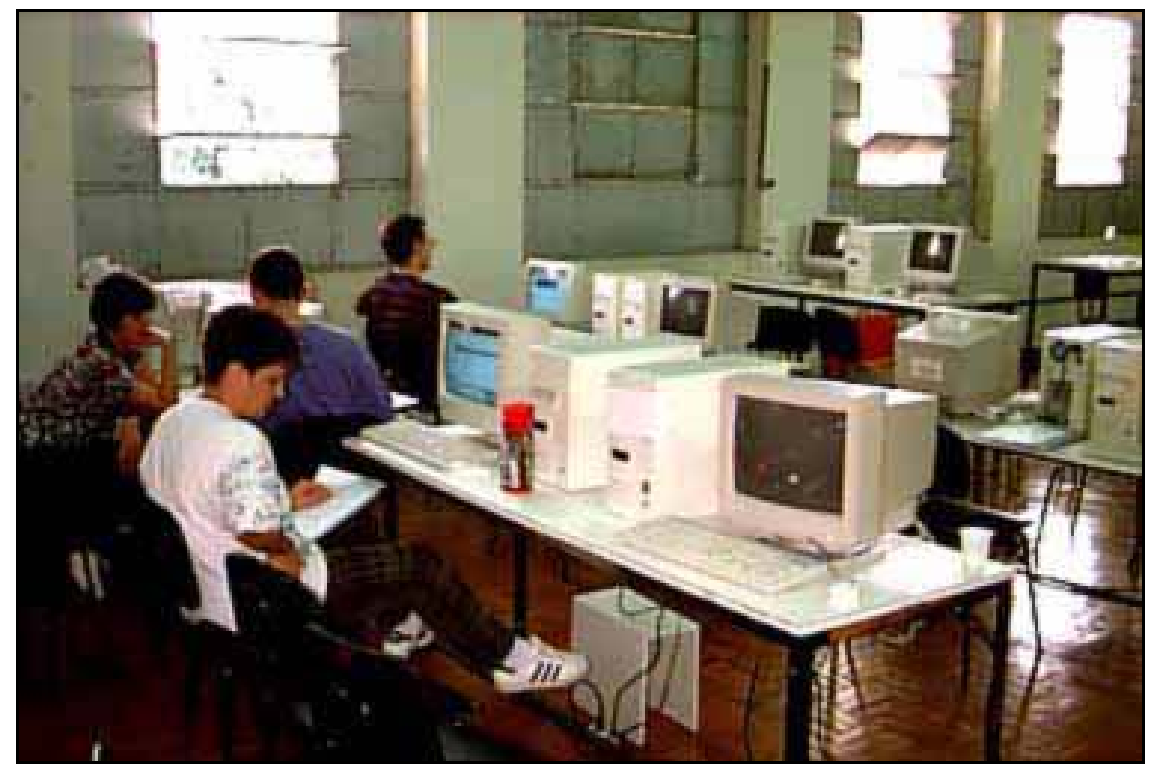

Grupo de professores inserindo os dados na tabela interativa via WWW.

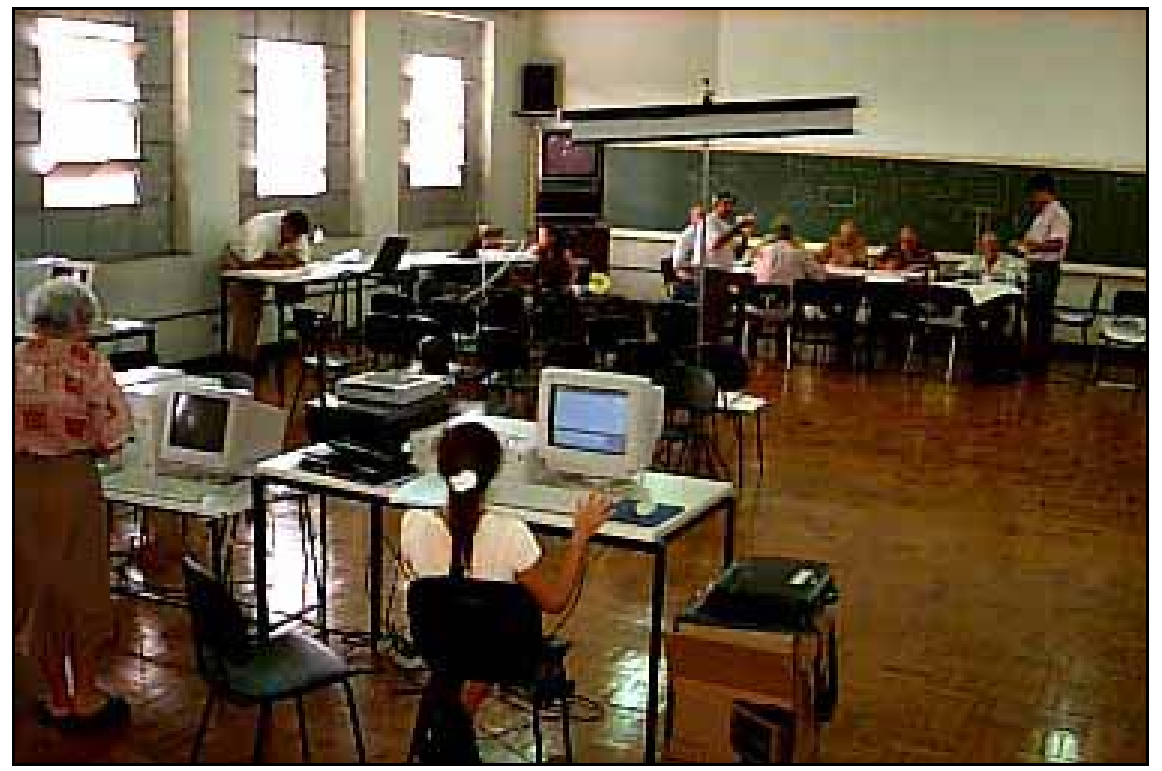

Vista geral do curso. 


\section{Referências Bibliográficas}

ALEXANDER, S. Teaching and learning on the World-Wide Web. In: Australian WorldWideWeb Conference, 1., Australia, April 30 - May 21995.

ALVES, J. R. M. Educação à distância e as novas tecnologias de informação na aprendizagem. In: Teleconferência Engenheiro 2001, 7., p.5-25, São Paulo, 8 outubro, 1996.

ANDRIES, E. O ano em que a Internet decolou no Brasil. Internet World, v.2, n.18, p.66-70, 1997.

BARBROW, E. P., et al. Computer experiences and attitudes of students and preceptors in distance education. Journal of the American Dietetic Association, v.96, n.12, p.1280-1281, Dec. 1996.

BARRIE, J. M. \& PRESTI, D. E. The World Wide Web as an instructional tool. Science, v.274, p.371-372, October 181996.

BARRON, D. D. Distance education in North American library and information science education: applications of technology and commitment. Journal of the American Society for Information Science, v.47, n.11, p.805-810, Nov. 1996.

BEAUDOIN, M. The instructor's changing role in distance education. The American Journal of Distance Education, v.4, n.2, p.21-29, 1990.

BERNERS-LEE, T., et al. The World-Wide Web. Communications of the ACM, v.37, n.8, p.76-82, August 1994.

BINER, P. M., et al. Factors underlying distance learner satisfaction with televised college-level courses. The American Journal of Distance Education, v.8, n.1, p.60-71, 1994.

BLOOM, B., HASTING, J. F. \& MADAUS, G. F. Handbook on formative and summative evaluation of student learning. New York, McGraw-Hill, 1971.

BODZIN, A. M. Incorporating the World Wide Web in the Science classroom. The Electronic Journal of Science Education, v.1, n.3, March 11997.

BRASIL. LDB. Lei no 9.394/96 de 20 de dezembro de 1996. Estabelece as diretrizes e bases da educação nacional. Diário Oficial da União, Brasília, 23 dez. 1996. Seção 1, p.27.834-27.841.

BUSH, V. As we may think. Atlantic Magazine, p.101-108, Jul. 1945. 
CANADA. MINISTRY OF EDUCATION . New Directions in Distance Learning: 1995-96 Mid-term report, a formative evaluation. Canada, Open Learning Agency, 1996. http://olax.ola.bc.ca/schools/nddl/About/Pubs/index.html

CARE, W. D. The transactional approach to distance education. Adult Learning, v.7, n.6, p.11-12, July-August 1996.

CARROLL, G. Virtual U: Students earning degrees on line. Knight-Ridder Newspapers/Tribune News Service, p.514K2030, May 141996.

CARTWRIGTH, G. P. Distance learning: a different time, a different place. Change, v.26, n.4, July/August 1994.

CARVIN, A. More than just hype: the World Wide Web as a tool for education. High School Journal, v.79, n.2, p.76-86, December 1995.

CHARLAB, S. O mundo “on-line”. Internet World, Rio de Janeiro, v.1, n.6, p.26-29, fevereiro 1996.

COMEAUX, P. The impact of an interactive distance learning network on classroom communication. Communication Education, v.44, n.4, p.353-361, Oct. 1995.

CONNORS, P. E. Distance learning: link to a worldwide community. Technical Communication, v.42, n.4, p.646-649, Nov. 1995.

CROTTY, T. Integrating distance learning activities to enhance teacher education the construtivist paradigm of teaching and learning. In: Distance Learning Research Conference Proceedings, 31-37. College Station, TX: Department. of Education and Human Resources Development, Texas A\&M University, /199/.

DELLA-PIANA, C. K. \& DELLA-PIANA, G. M. Findings in search of an issue: preliminary development of a student questionnaire for distance education contexts. In: Annual Meeting of the Western states Communication Association, San Jose, CA, Feb. 1994.

DILLENBOURG, P. \& SCHNEIDER, D. Collaborative learning and the Internet. In: International Conference on Computer Assisted Instruction, Hsinchu, Taiwan, March 7-10 1995.

DRAPER, S. W. Observing, Measuring, or Evaluating Courseware. Department of Psychology, University of Glasgow, 1996.

http://www.psy.gla.ac.uk/ steve/Eval.HE.html

DYRESON, C. E. An experiment in class management using the World-Wide Web. In: Australian WorldWideWeb Conference, 2., Australia, 7-9 July 1996.

EATON, M. Interactive features for HTML-based tutorials in distance learning programs. In: Australian WorldWideWeb Conference, 2., Australia, 7-9 July 1996. 
FLAGG, B. N. Formative evaluation for educational technologies. Hillsdale, NJ: Lawrence, Erlbaum Associates. 1990.

FULTON, J. R. Microcomputers in distance education applications for extension. Journal of Extension, v.30, n.2, Summer 1992.

GARRISON, D. R. \& SHALE, D. An analysis and evaluation of audio teleconferencing to facilitate education at a distance. International Journal of Distance Education, v.1, n.1, p.7-13, 1990.

GEBER, B. Distance education. Training, v.28, n.11, p.57-58, Nov. 1991.

GILCHER, K. IDE evaluation taskforce. Executive summary. Institute for Distance Education, University of Maryland University College, August 1995. (Report IDE). http://www.umuc.edu/ide/eval.html

GONÇALVES, C. T. F. Quem tem medo do ensino a distância. Educação a Distância, INED/IBASE, n.7-8, 1996.

GRIMALDI, C. Dig into distance learning; new research will look at the best uses of DL. Electronic Learning, v.14, n.6, p.12-13, March 1995.

GRONLUND, N. E. Measurement and evaluation in teaching. New York, Macmillan Publishing Co., 1981. p.3-28.

GUBA, E. G. Toward a methodology of naturalistic inquiry in educational evaluation. CSE Monograph Series in Education, 8. Los Angeles, CA, University of California, Center for the Study of Evaluation. 1978. (ED 164 599).

HARRISON, P. J. et al. Development of a distance education assessment instrument. Educational Technology Research and Development, v.39, n.4, p.65-77, 1991.

HEAD, T. \& LOCKEE, B. Forming the future from the past: student-centered evaluation of distance learning at Virginia Tech. In: Annual Conference on Distance Teaching and Learning in Madison, 10., Wisconsin, 10-12 August, 1994.

HESSEL, R. Discos sustentados por colchão de ar, uma nova proposta. Revista Ensino de Física, São Paulo: SBF, v.4, n.3, p. 3-22, dez. 1982.

HUGHES, K. Entering the World-Wide Web: a guide to cyberspace. Honolulu Community College, Hawaii, October, 1993.

http://geosci.uchicago.edu/guide/guide.toc.html

IBRAHIM, B. Distance learning with the World-Wide Web. In: International Conference on "Open and Distance Learning - Critical success Factors", Geneva, 10-12 October, 1994. 
IBRAHIM, B. \& FRANKLIN, S. D. Advanced educational uses of the World-Wide Web. In: International World-Wide Web Conference, 3., Darmstadt, Germany, April 10-14 1995. v.27, p.871-877.

JEFFRIES, M. Research in distance education. Indiana Partnership for Statewide Education, 1995. http://www.ind.net/IPSE/fdhandbook/resrch.html

JOHNSON, D. Evaluating the impact of technology: the less simple answer. From Now On, v.5, n.5, January/February 1996.

JONASSEN, D. H. Applications and limitations of hypertext technology for distance learning. In: Distance Learning Workshop, Armstrong Laboratory, San Antonio, Texas, 1992.

KEARSLEY, G. The nature and value of interaction in distance learning. In: Distance Education Research Symposium, 3., May 18-21, 1995.

KEEGAN, D. The foundations of distance education. London, Croom Helm, 1986.

KEEGAN, D. Reintegration of the teaching acts. In: KEEGAN, D., ed. Theoretical principles of distance education. London \& New York, Routledge, 1993.

KINNAMAN, D. E. The future of distance education. Technology \& Learning, v.15, n.4, p.58, Jan 1995.

KINNAMAN, D. E. A year for debates. Technology \& Learning, v.16, n.8, p.94, May-June 1996.

KNIGHT, P. T. Destined to leapfrog: why a revolution in learning will occur in Brazil, Russia, and South Africa. In: International Conference on Distance Education in Russia, 2., Moscow, 2-5 July 1996.

KULIK J. A., BANGERT, R. L.\& WILLIAMS, G. W. Effect of computer-based teaching on secondary school students. Journal of Educational Psychology, 75, p.19-26, 1983.

LÜDKE, M. \& MENGA, A. Pesquisa em educação: Abordagens qualitativas. São Paulo, EPU, 1986.

MAGAlHÃES, M. G. M. Avaliação de teste piloto do programa de Física. São Carlos, CDCC, dez. 1996. (Relatório Técnico CDCC-USP, 1)

MAGALHÃES, M. G. M. \& SCHIEL, D. Investigação de mecanismos de avaliação de Educação à Distância via WWW. In: Simpósio Interno da Pós-Graduação do IFSC, 3., São Carlos, 1996. Resumos. São Carlos, Instituto de Física de São Carlos/Universidade de São Paulo, 1996. p.46.

MAGALHÃES, M. G. M. \& SCHIEL, D. A method for evaluation of a course delivered via the World Wide Web in Brazil. The American Journal of Distance Education, v.11, n.2, p.64-70, 1997. 
MCISAAC, M. S. \& GUNAWARDENA, C. N. Distance education. In: JONASSEN, D., ed. Handbook for Research on Educational Communications and Technology. Scholastic Press, 1997. /No prelo/

MELTON, R. F. Developing a formative evaluation system for distance teaching. Open Learning, v.10, n.2, June 1995.

MINICH, E. L. Using student feedback to improve distance education. In: Annual TCC-L On-Line Conference "Innovative Instructional Practices”, 1., Kapiolani Community College, Hawaii, April 2-4 1996.

http://leahi.kcc.hawaii.edu/org/tcc_conf96/minich.html

MOORE, M. G. \& KEARSLEY, G. Distance education: a systems view. Belmont, California, Wadsworth Publishing, 1996.

MOORE, M. G. \& THOMPSON, M. M. The effects of distance learning: A summary of the literature. Research Monograph n.2. University Park, PA, The Pennsylvania State University, American Center for the Study of Distance Education, 1990. (ED 330 321).

NETTLES, M. \& KAUfFMAN, S. Assessment. In: The New School 1995 Distance Learning Conference, Nov. 10-11 1995. http://dialnsa.edu/95conf/assesmen.htm

OLIVER, R. Convergence of distance education and on-campus educational strategies. Edith Cowan University, /199 /.

OLIVER, R., HERRINGTON, J. \& OMARI, A. Creating effective instructional materials for the World Wide Web. In: Australian WorldWideWeb Conference, 2., Australia, 7-9 July 1996.

OWSTON, R. D. The World Wide Web: a technology to enhance teaching and learning? Educational Researcher, v.26, n.2, p.27-33, March 1997.

PARKER, A. A distance education how-to manual: recommendations from the field. CSS Journal, v.5, n.2, March/April 1997.

PAYNE, D. Learning any time on any course, anywhere. The European, n.335, p.32, Oct. 101996.

PECK, R. M. \& WALLACE, C. M. Evaluating distance education courses: initiative, methodology, and application. In: NUNAN, T., ed. Distance education futures. Biennial Forum of Australian and South Pacific, 11., Adelaide, Australia, 1993, p.527-538.

PERRATON, H. A theory for distance education. In. SEWART, D., KEEGAN, D. \& HOLMBERG, B., ed. Distance education: International perspectives. New York, Routledge, p.34-45, 1988.

PICARD, D. The future is distance training. Training, v.33, n.11, p.S3-S8, Nov. 1996. 
PORTER, D., FALLICK, A. \& DAGERT, T. NDDL 1993-94: a year in review. Canada, Open Learning Agency, 1994.

http://olax.ola.bc.ca/schools/nddl/About/Pubs/pubarchive.html

PORTER, D. et al. NDDL 1994-1995: phase 2 review. Canada, Open Learning Agency, 1995. http://olax.ola.bc.ca/schools/nddl/About/Pubs/pubarchive.html

PREECE, J. et al. Human-computer interaction. Wokingham, England, AddisonWesley, 1994. p.601-639.

RADCLIFFE, D. Student created Web documents as a design learning environment. In: Australian WorldWideWeb Conference, 2., Australia, 7-9 July 1996.

REGGIANI, L \& SILVESTRE JR., P. F. Navegadores acirram a disputa na rede. Folha de São Paulo, São Paulo, 28 ago. 1996. Informática p.6.

REID, K. A. Student attitudes toward distance learning. AT\&T, 1995. http://www.lucent.com/cedl/stdtatt.html

RICHARDSON, E. C. Internet com louvor. Internet World, v.1, n.7, p.56-61, março 1996.

RINGSTED, M. On-site distance learning: a multimedia full-scale experiment in Denmark. In: EDWARDS, A. D. N. \& HOLLAND, S. Multimedia Interface Design in Education. NATO ASI Series. Springer-Verlag, Berlin, v.F76. 1992. p.45-56.

ROBERTS, J. M. The story of distance education: a practitioners's perspective. Journal of the American Society for Information Science, v.47, n.11, p.811-816, Nov. 1996.

SABA, F. Introduction to distance education. The Distance Educator, v.2, n.3. Fall 1996. http://www.distance-educator.com/intro.htm

SALVADOR, V. L. G. Hipermídia interativa - a educação do futuro, no presente. Tecnologia Educacional, v.22, (123/124), p.22-23, mar.jun. 1995.

SANTAROSA, L. O computador na avaliação formativa. Porto Alegre, 1982. 165p. Tese (Doutorado) - Faculdade de Educação, Universidade Federal do Rio Grande do Sul.

SANTOS, N. Educação à distância e as novas tecnologias de informação na aprendizagem. In: Teleconferência Engenheiro 2001, 7., p.28-38, São Paulo, 8 outubro, 1996.

SCHAMBER, L. Delivery systems for distance education, 1988. (ERIC Document Reproduction Service. $\mathrm{n}^{\circ}$ ED 304 111). 
SCHATZ, B. R. \& HARDIN, J. B. NCSA Mosaic and the World-Wide Web: Global hypermedia protocols for the Internet, Science Magazine, v.265, p.895-901, August 121994.

SCHICK, J. A. Bridging distances between languages and cultures via distance education. Gatherings Newsletter, West Georgia College School of Education, v.9, n.2, April 1996.

SCHIEL, D. Orientações gerais para o professor. Programa Educ@r, São Carlos, CDCC, 1996. http://www.ifqsc.sc.usp.br/educar/fisica/shielrec.html

SCHIEL, D. \& MAGALHÃES, M. G. M. Educação à distância usando a tecnologia WWW. Em Aberto, n.70, outubro 1997. /No prelo/

SCHLOSSER, C. A. \& ANDERSON, M. L. Distance education: Review of the literature. Washington, DC, Association for Educational Communications and Technology. 1994.

SCHNEIDER, D. \& BLOCK, K. The World-Wide Web in education. Andrea Newsletter, v.2, n.5, 12 June 1995.

SCHUTTE, J. G. Virtual teaching in higher education: the new intellectual superhighway or just another traffic jam? California, Northridge, 1996. http://www.csun.edu/sociology/virexp.htm

SELIGMAN, D. The comparative nature of quality: Distance education in the developing world. In: World conference of the International Council for Distance Education, Bangkok, Thailand, Nov 1992.

SHERRY, L. Issues in distance learning. International Journal of Distance Education, v.1, n.4, p.337-365, 1996

SHERRY, L. \& MORSE, R. An assessment of training needs in the use of distance education for instruction. International Journal of Educational Telecommunications, v.1, n.1, p.5-22, 1995.

SORENSEN, C. K. Evaluation of interactive television instruction: assessing attitudes of community college students. DEOSNEWS, v. 5, n.9, 1995.

SPODICK, E. F. The evolution of distance learning. Hong Kong University of Science \& Technology Library, August 1995.

http://sqzm14.ust.hk/distance/evolution-distance-learning.htm

TAKAHASHI, T. Internet Brasil: reflexões sobre 1996. Internet World, v.2, n.18, p.74-76, 1997.

THORPE, M. Evaluating open \& distance learning. 2.ed. London, Longman, 1993.

TODOROV, J. C. A importância da educação a distância. Educação a Distância, INED/IBASE, n.4-5, 1994. 
UPDEGROVE, K. H. Teaching on the Internet. University of Pennsylvania, School of Nursing, 1995. http://pobox.upenn.edu/ kimu/teaching.html

VAUGHAN, M. Summary of quality issues in distance education. Lucent Technologies. 1996. http://www.lucent.com/cedl/sumqual.html

VERDUIN, J. R. \& CLARK, T. A. Distance education: The foundations of effective practice. San Francisco, CA: Jossey-Bass Publishers, 1991.

WARD, E. C. \& LEE, J. E. An instructor's guide to distance learning. Training \& Development, v. 49, n.11, p.40-44, Nov. 1995.

WHITE, R. A. \& THOMAS, P. Ensino à distância: experiências e inovações. In: Comunicação e Educação, São Paulo, Moderna, ano 1, n.3, p.47-53, mai./ago. 1995.

WILLIS, B. Instructional development for distance education. 1992. (ERIC Document Reproduction Service, no. ED 351007).

WILLIS, B. Strategies for teaching at a distance. 1993. (ERIC Document Reproduction Service, no. ED 351008).

WILLIS, B. et al. Guide \#1 Distance education: an overview. In: Distance Education at a Glance. University of Idaho, Engineering Outreach, 1995a.

WILLIS, B. et al. Guide \#4 Evaluation for distance educators. In: Distance Education at a Glance. University of Idaho, Engineering Outreach, 1995b.

WILLIS, B. et al. Guide \#7 Computers in distance education. In: Distance Education at a Glance. University of Idaho, Engineering Outreach, 1995c.

WILLIS, B. et al. Guide \#10 Distance education: research. In: Distance Education at a Glance. University of Idaho, Engineering Outreach, 1995d.

WITHERSPOON, J. P. A “2+2" baccalaureate program using interactive video. DEOSNEWS, v.6, n.6, 1996.

WORKMAN, J. J. \& STENARD, R. A. Student support services for distance education. DEOSNEWS, v.6, n.3, 1996.

YOAKAM, M. Distance learning: an introduction. Indiana Partnership for Statewide Education, 1995. http://www.ind.net/IPSE/fdhandbook/dist_lrn.html 


\section{Bibliografia Complementar}

ARMSTRONG, S. Farming for distant degrees. New Scientist, v.150, n. 2031, p.1415, May 251996.

BARKET, R. T. \& HOLLEY, C. L. Interactive distance learning: perspective and thoughts. Business Communication Quarterly, v.59, n.4, p.88-97, Dec. 1996.

BARRERA, A. Distance Education: the challenge for a multicultural society. NCBE FOCUS: Occasional Papers in Bilingual Education, n.8, Fall 1993.

BAUMGARTNER, P. \& PAYR, S. Learning as action: a social approach to the evaluation of interactive media. CSS Journal, v. 5, n. 2, March/April 1997.

BERNARD, R. M. \& LUNDGREN, K. M. Learner assessment and text design strategies for distance education. Canadian Journal of Educational Communication, v.23, n.2, p.133-152, Summer 1994.

BLUMENSTYK, G. Faculty group calls for caution and curbs on distance education. The Chronicle of Higher Education, v.42, n.20, p.A20, Jan. 26, 1996.

BUTTS, C., et al. WWW and the Globewide Network Academy. In: International WWW Conference, 1., Geneva, May 25-27 1994.

DAVIS, H. J. A review of open and distance learning within management development. Journal of Management Development, v.15, n.14, p.20-34, April 1996.

EKLUND, J. Integrating the Web and the teaching of technology: cases across two universities. In: Australian WorldWideWeb Conference, 2., Australia, 7-9 July 1996.

FETTERMAN, H. E. Videoconferencing training: assessment of applicability. DEOSNEWS, v.6, n.9, 1996.

FILIPCZAK, B. Putting the learning into distance learning. Training, v.32, n.10, p.111-117, Oct. 1995.

FILIPCZAK, B. Think locally, train globally: distance learning across cultures. Training, v.34, n.1, p.40-45, Jan. 1997.

HARRIS, D. A. \& DIPAOLO, A. Advancing asynchronous distance education using high-speed networks. IEEE Transactions on Education, v.39, n.3, p.444-449, August 1996.

HECHT, J. Classroom chaos on the information highway. New Scientist, v.145, n.1962, p.52-53, Jan. 28, 1995. 
HILTZ, S. R. Teaching in a virtual classroom ${ }^{\mathrm{TM}}$. In: International Conference on Computer Assisted Instruction, Hsinchu, Taiwan, March 7-10 1995.

JONES-DELCORDE, D. H. Distance education: promoting a continuous learning culture. Canadian Manager, v.20, n.1, p.27-28, Spring 1995.

KANTOR, A., NEUBARTH, M. \& LOEB, L. Dos gráficos para o mundo: a Internet em 1996. Internet World, v.2, n.18, p.57-64, 1997.

MARTINS, O. B. A educação superior a distância, uma modalidade de educação permanente para a UFPR. Educação a Distância, INED/IBASE, n.4-5, 1994.

MOSKOWITZ, R. Universidade por um fio. Internet World, v.1, n.3, p.127-128, nov. 1995.

NELSON, C. J. In search of theoretical and practical information on distance education for distance learning teachers: an annotated bibliography. Summer 1996. http://www.cudenver.edu/public/education/edschool/dlannbib.html

OMARI, A. \& BROGAN, M. New directions in courseware delivery: multimedia, CDROM and the Internet. In: Australian WorldWideWeb Conference, 1., Australia, 30 April - 02 May 1995.

POCOROBBA, J. S. How to plan for distance learning. School and College, v.34, n.4, p.24-28, April 1995.

RUTHERFORD, P. Annotations: the key to collaborative teaching and learning on the Internet. . In: Australian WorldWideWeb Conference, 2., Australia, 7-9 July 1996.

SHERIDAN, D. Can adults learn at a distance? And how well? Training, v.33, n.11, pS12-S19, Nov. 1996.

SMITH, C. R. Taking the distance out of distance learning. Training \& Development, v.50, n.5, p.87-89, May 1996.

SMITH, R. D. Distributed professional education and the Internet. In: InterService/Industry Training, Simulation, and Education Conference Proceedings, 17., November 1995.

STAHLMAN, M. Prisoners to technology? Information Week, n.609, p.126, Dec. 9 1996.

SUEN, H. K. \& STEVENS, R. J. Analytic considerations in distance education research. The American Journal of Distance Education, v.7, n.3, p.61-69, 1993.

THACH, E. C. \& MURPHY, K. L. Training via distance learning. Training \& Development, v.49, n.12, p.44-46, Dec. 1995. 
TORRES, C. A. A Universidade Aberta de Brasília. Educação a Distância, INED/IBASE, n.4-5, p.33-34, 1994. 


\section{Apêndice}

\section{Breve Guia de Periódicos de Educação à Distância}

\section{THE AMERICAN JOURNAL OF DISTANCE EDUCATION}

(AJDE). ISSN 0892-3647. Primeira publicação em 1987. 3 edições por ano. Informações para assinaturas em AJDE, The Pennsylvania State University, 110 Rackley Building, University Park, PA 16802-3202, USA. Primeira edição em 1987. Foi criado para disseminar a informação e agir como um fórum para críticas e debates sobre pesquisa e prática da educação à distância nas Américas.

Editor: Michael Grahame Moore, American Centre for the Study of Distance Education, College of Education, The Pennsylvania State University, 403 South Allen Street, Suite 206, University Park, PA 16801-5202, USA

2. DISTANCE EDUCATION. ISSN 0158-7919. Primeira publicação em 1980. 2 edições por ano, em maio e outubro. Periódico publicado pela Open and Distance Learning Association of Australia. Tem como objetivo disseminar informação sobre teoria, pesquisa e prática na educação à distância incluindo estudo por correspondência, estudos externos, aprendizado individualizado, open learning, tecnologia educacional, rádio e TV educacional e outra mídia educacional.

\footnotetext{
** Baseado em Harry (1994), Moore \& Kearsley (1996), Darling (1997) e The International Centre for Distance Learning (ICDL) Database.
} 
Distance Education Centre,

University College of Southern Queensland,

PO Darling Heights,

Toowoomba, Queensland 4350

AUSTRALIA

3. JOURNAL OF DISTANCE EDUCATION. ISSN 0830-0445.

Primeira publicação em 1986. Publicado 2 vezes por ano, em novembro e maio. É uma publicação internacional do Canadian Association for Distance Education (CADE). Seu objetivo é promover e ajudar o trabalho escolar de uma natureza teórica e empírica que relata a educação à distância no Canadá.

CADE Secretariat

205-1 Stewart Street,

Ottawa, Ontario, K1N 6H7

CANADA

4. OPEN LEARNING. ISSN 0268-0513. Publicado 3 vezes por ano, em fevereiro, junho e novembro. Primeira publicação em 1986, como sucessor do TEACHING AT A DISTANCE, 26 edições publicadas pela Open University entre 1974 e 1985. O periódico inclui duas seções: a primeira inclui artigos longos com referências; a segunda inclui edições para debate, observações, notas de pesquisa, relatórios e revisões de conferências. O público do periódico é aquele envolvido em educação universitária, treinadores nos setores públicos e privados do Reino Unido e o mais substancial é na educação à distância por todo o mundo.

Longman Group UK Ltd,

Subscriptions (Journals) Department

P.O. Box 77

Harlow, Essex CM19 5BQ, U.K.

5. A publicação internacional ABOUT DISTANCE EDUCATION teve sua primeira publicação em 1974, pelo International Extension College; foi incorporada pelo NEWS ABOUT IEC, publicado 2 vezes por ano (primeira edição 
em 1988) e disponível no IEC, Dale's Brewery, Gwydir Street, Cambridge, CB1 2LJ, United Kingdom. NEWS ABOUT IEC foi renomeado para IEC NEWS, cuja primeira edição foi em setembro de 1991.

6. THE DISTANCE EDUCATOR. Periódico quadrimestral. Informações para assinatura e formulário disponível on-line em http://www.distanceeducator.com.

Editor: Farhad Saba.saba@cts.com

\section{EPISTOLODIDAKTIKA: THE EUROPEAN JOURNAL OF} DISTANCE EDUCATION. Informações para assinaturas em The Rapid Results College, Tuition House, London, SW19 4DS, United Kingdom. 2 edições por ano, sendo que a primeira edição foi publicada em 1963. O periódico da Association of European Correspondence Schools, nem sempre está restrito à Europa, nem mesmo aos interesses específicos das escolas por correspondência.

8. INDIAN JOURNAL OF OPEN LEARNING. ISSN 0971-2690. Primeira publicação em 1992. 2 edições por ano, em janeiro e julho. Objetivos: 1) disseminar informação sobre teoria, pesquisa e prática na área de educação aberta e à distância, incluindo educação por correspondência e multimídia, tecnologia educacional e comunicação, aprendizado experimental e independente e outras formas inovadoras de educação; 2) fornecer um fórum para debates sobre essas áreas de interesse, particularmente para a Índia, permitindo um espaço razoável para contribuições de outros países.

Indira Gandhi National Open University, Maidan Garhi

New Delhi 110 068, INDIA

9. ISTRUZIONE A DISTANZA (IAD). Primeira publicação em 1989. Quadrimestral. O periódico é italiano mas tem cobertura internacional. Istruzione a Distanza, Piazza San Carlo III, 42 I-80137 Napoli, ITALY 
10. THE JOURNAL OF DISTANCE LEARNING. Primeira publicação em 1994. Um periódico da Distance Education Association of New Zealand. Dr. Terry Hearn, TJHEARN@rivendell.otago.ac.nz 7 Tui Street, St Leonards, Dunedin, NZ, Fax +64-3-4677522 Book reviews editor: Dr. Ken Stevens, Ken.Stevens@vuw.ac.nz Department of Education, Victoria University of Wellington PO Box 600, Wellington, NZ, Fax +64-4-471-5349

\section{OPEN FORUM: DISTANCE EDUCATION AND OPEN}

LEARNING. Primeira publicação em 1991. Grátis. O periódico fornece um veículo para comunicação da teoria, pesquisa e prática relatada para ensino e aprendizado através da educação à distância e sistemas de open learning.

Distance Education Centre, University of Southern Queensland Post Office Darling Heights, Toowoomba QLD 4350, AUSTRALIA

12. OPEN LEARNING UPDATE. ISSN 1324-7654. Publicado quatro vezes por ano: em fevereiro, maio, agosto e novembro. O periódico foi projetado para fornecer aos administradores de educação e treinamento, informações e análises de desenvolvimentos em open learning e educação à distância. Esta publicação também está disponível on-line.

Open Learning Technology Corporation Ltd

Science Park, Laffer Drive, Bedford Park

South Australia 5042, AUSTRALIA

13. OPEN PRAXIS. ISSN 0264-0210. Duas publicações por ano, em abril/maio e setembro/outubro. Primeira publicação em 1993 como sucessor do ICDE Bulletin. São bem-vindos artigos, itens novos, cartas, cartoons e cópias de publicações para revisão dos membros institucionais e individuais do ICDE.

The Permanent Secretariat, ICDE

Gjerdrums vei 12

N-0486 Oslo 4, NORWAY 
14. REVISTA DE EDUCACIÓN A DISTANCIA. ISSN 1131-8783. Primeira publicação em 1991. 3 publicações por ano. O periódico é em espanhol, mas são incluídas contribuições de outros países. Edições incluem seções de informe dirigido, estúdios, novas tecnologias, informação e documentação.

RED, CIDEAD

C/Argumosa, No 43, Pabellon 6

28012 Madrid, SPAIN

15. REVISTA IBEROAMERICANA DE EDUCACIÓN SUPERIOR A DISTANCIA. ISSN 0214-3992. 3 publicações por ano, em outubro, fevereiro e junho. Primeira publicação em 1988 para substituir o AIESAD's Boletin Informativo, o qual foi lançado em 1983. O periódico da Asociacion Iberoamericana de Educacion Superior a Distancia, traz artigos, informações e revisões dos membros das instituições.

Secretaria Permanente de AIESAD UNED

Apartado de Correos 50.487, 28080 Madrid, SPAIN

As seguintes publicações regionais e nacionais, algumas das quais são periódicos de circulação restrita, são inestimáveis recursos de informação corrente nas atividades de ensino à distância e em tópicos de interesse especial para os países ou regiões onde são produzidos.

16. CIFFAD (Consortium International Francophone de Formation a Distance) BULLETIN D'INFORMATION. Primeira publicação em março de 1991. Secretariat du CIFFAD, Direction General de l'Education et de la Formation, Agence de Cooperation Culturelle et Technique, 13 Quai Andre Citroen, 75015 Paris, France. Grátis.

17. COMLEARN: novas publicações do Commonwealth of Learning. Primeira edição publicada em 1990. Publicada pela Commonwealth of Learning, P.O. Box 10428, Pacific Centre, 1700-777 Dunsmuir Street, Vancouver, B.C. 
CANADA, V7Y 1K4. Grátis.

18. COMMUNIQUÉ. 6 edições por ano. O periódico da Canadian Association for Distance Education (CADE) fornece partes com notícias e informações do Canada e de outros países. Informações para Canadian Association for Distance Education, 151 Slater, Ottawa, Ontario, Canada, K1P 5N1.

19. DEANZ Bulletin. Uma publicação da Distance Education Association of New Zealand; traz artigos que não foram publicados na DEANZ Conference Proceedings. Contatar o DEANZ Secretary Alison Rowland, Centre for University Extra Mural Studies, Massey University, Private Bag, Palmerston North, NEW ZEALAND

20. DEH (Distance Education in Health) NEWS. Periódico publicado 2 vezes por ano pela Distance Education Unit of AMREF, a African Medical and Research Foundation. Grátis. Tem como subtítulo - "Um fórum para troca de notícias e visões entre os trabalhadores da saúde na educação à distância”. A Editora, DEH News, AMREF, Distance Education Unit, PO Box 30125, Nairobi, KENYA

21. DEOSNEWS. Um periódico on-line publicado pelo Distance Education Online Symposium, The Pennsylvania State University, College of Education, 403 South Allen Street, Suite 206, University Park, PA 16801-5202, USA. Publica artigos na área da educação à distância, dos EUA e outros países. Para assiná-lo, enviar o seguinte comando para LISTSERV@PSUVM ou LISTSERV@PSUVM.PSU.EDU, escrevendo SUBSCRIBE DEOSNEWS; deixe um espaço e escreva seu primeiro nome e sobrenome.

22. DERUN (Distance Education Research Update Newsletter). Teve sua primeira publicação em janeiro de 1997 pela Division for Distance and Continuing Education (DDCE) na Central Queensland University na Austrália. Será publicado duas vezes por ano, em janeiro e julho, e tem tipicamente 10 páginas. DERUN fornece resumos do trabalho de pesquisa e desenvolvimento do staff do 
DDCE, breve revisões dos artigos de jornais selecionados, comentários, pequenos relatórios de conferências e perfil do pesquisador. Para receber uma cópia grátis contatar o editor Dr Colin Macpherson pelo e-mail c.macpherson@cqu.edu.au

\section{DISTANCE EDUCATION AND TRAINING NETWORK}

NEWSLETTER. Primeira publicação em 1987. 4 edições por ano, para membros da Distance Education and Training Network of the National Society for Performance and Instruction (NSPI). Informações com Bob Spencer, DETN Vice Presidente Finance, Athabasca University, Box 10,000, Athabasca, Alberta, CANADA, T0G 2R0.

24. DISTANCE EDUCATION AND TECHNOLOGY NEWSLETTER. Cobre questões e eventos na educação à distância e tecnologia educacional dos Estados Unidos e do mundo. Informações com Joan E Connick, Distance Education Publications, RRD \#2, Box 7290, no.3, Winthrop, ME 04364, USA.

25. DISTANCE EDUCATION NEWS AND VIEWS. ISSN 0794-540X. Irregularmente publicado; última edição recebida pelo ICDL até março de 1997, foi o vol.III, no.1 \& 2, December, 1986. Primeira publicação em 1983. Informações para assinatura com B.C. Marumo, Dept of Non-Formal Education, Ministry of Education, P.M.B. 0043, Gaborone, BOTSWANA.

26. DLA Newsletter. Desde a edição de março de 1993 que é noticiada que a Distance Learning Association (DLA) of Southern Africa está para se tornar Distance Education Association of Southern Africa (DEASA). O Editor, DLA Newsletter, DLA of Southern Africa, c/o PO Box 11350, Johannesburg 2000, SOUTH AFRICA

27. EADTU News. Periódico da European Association of Distance Teaching Universities. Primeira publicação em 1989. É publicada irregularmente. Disponível da EADTU Secretariat, P.O. Box 2960, 6401 DL Heerlen, NETHERLANDS. 
28. EDEN Newsletter. Grátis. Periódico da European Distance Education Network. Kerry Mann, Secretária Executiva, EDEN, PO Box 92, Milton Keynes, MK7 6DX, UK.

29. EUROSTEP COURIER. Publicação mensal. Para assinar, contatar a EUROSTEP, PO Box 11112, 2301, EC Leiden, THE NETHERLANDS.

30. INDIAN JOURNAL OF DISTANCE EDUCATION. Uma publicação por ano, planejado para duas por ano. Primeira publicação em 1988. Informações para assinaturas com Professor S. Bhatnagar, Director, Correspondence Courses, Panjab University, Chandigarh, INDIA. Última edição recebida no ICDL até março de 1997, foi vol.III, em Maio 1990.

31. KAKATIYA JOURNAL OF DISTANCE EDUCATION. Publicado 2 vezes por ano. Primeira publicação em janeiro de 1992. Informações para assinatura com o Director, School of Distance Learning and Continuing Education, Kakatiya University, Warangal, 506 009, INDIA.

Editor: Professor K. Murali Manohar,

Director, School of Distance Learning and Continuing Education, Kakatiya University, Warangal, 506 009, INDIA.

\section{MEDIA AND TECHNOLOGY FOR HUMAN RESOURCE} DEVELOPMENT. Publicado 4 vezes por ano. Informações para assinaturas com $\mathrm{Dr}$ (Mrs) Kailash Khanna, Lady Irwin College, Sikandra Road, New Delhi 110 001, INDIA.

Editor Chefe: Professor M. Mukhopadhyay , Media and Technology for Human Resource Development, NIEPA, New Delhi 110 016, INDIA.

33. NEVER TOO FAR. Primeira publicação em 1983. Publicado irregularmente. Editado pela Sukhothai Thammathirat Open University em 
cooperação com o Unesco Regional Office for Edcuation in Asia and the Pacific. Disponível da Never Too Far, Sukhothai Thammathirat Open University, Pakkred, Nonthaburi 11120, THAILAND. Grátis.

34. ODLAA Times. ISSN 1320-7954. Substituiu o ASPESA NEWS em 1993 quando a Australian and South Pacific External Studies Association se tornou a Open and Distance Learning Association of Australia. ODLAA também publica o periódico internacional DISTANCE EDUCATION.

Open Learning Unit

Queensland University of Technology, Kelvin Grove Campus

Locked Bag No.2, Red Hill, Queensland 4059, AUSTRALIA

\section{ONLINE CHRONICLE OF DISTANCE EDUCATION AND} COMMUNICATION. Publicado on-line duas vezes por ano. Co-editado e publicado pela Nova Southeastern University, USA. Procura compartilhar informações relatadas para educação à distância e comunicação, e ajudar a criar uma "living network" de recursos pessoais na educação à distância. Para assinar, enviar o seguinte comando para LISTPROC@PULSAR.ACAST.NOVA.EDU:

SUB DISTED seu_nome_completo

para ajuda, contatar chron@fcae.nova.edu

36. ON PIRADE. Primeira publicação em 1994 como periódico da Pacific Islands Regional Association for Distance Education. Informações com Christiana Garo c/o DEC, Solomon Islands College of Higher Education, PO Box G23, Honiara, SOLOMON ISLANDS.

37. OLS (OPEN LEARNING SYSTEMS) NEWS. 4 publicações por ano, com edições em junho, setembro dezembro e março. Informações para assinatura, com NCET, OLS News, Sir William Lyons Road, Science Park, Coventry, CV4 7EZ, UK.

38. OPEN LEARNING TODAY. Periódico da British Association for 
Open Learning. . Primeira publicação em 1989. 4 publicações por ano. Standard House, 15 High Street, Baldock, Herts, SG7 6AZ, UK.

39. PAKISTAN JOURNAL OF DISTANCE EDUCATION. 2 edições por ano. Última edição recebida pelo ICDL até março de 1997, foi o vol.III, no.1, 1986. Informações para assinatura com Dr Ahmed Noor Khan, Research and Statistical Centre, Allama Iqbal Open University, Sector H-8, Islamabad, PAKISTAN.

40. RADIO Y EDUCACION DE ADULTOS. Grátis. Tem o subtítulo de Boletin Cuatrimestral ECCA, mas contém informações de todo o mundo, particularmente da Espanha. Radio ECCA, Apartado 994, 35080 Las Palmas de Gran Canaria, SPAIN.

41. SATURNOVA. Primeira publicação em 1987. 4 edições por ano. SATURN Head Office Keizergracht 756, 1017 EZ Amsterdam, THE NETHERLANDS. Grátis. O periódico da SATURN Community: Europe's Open Learning Network (a Instituição européia para relacionamento entre indústria e instituições de treinamento e educação à distância.

\section{USING TELEMATICS IN EDUCATION AND TRAINING.}

Publicado 10 vezes por ano. Tem o subtítulo de “The European Newsletter”, contém informações correntes sobre educação baseada na tecnologia. pjb Associates, 10 Green Acres, Stevenage, Herts, SG2 8ND, UK. 


\section{Referências do Apêndice}

DARLING, Charles. Journals \& Newsletters for Distance Education. March 19 1997. cdarling@commnet.edu

http://webster.commnet.edu/hp/pages/darling/journals.htm

HARRY, K. A Rough Guide to Distance Education Journals and Newsletters. Open Praxis. v.1, 1994.

MOORE, M. G. \& KEARSLEY, G. Distance education: a systems view. Belmont, California, Wadsworth Publishing, 1996.

The International Centre for Distance Learning (ICDL) Database. U. K. Open University. Telnet: acsvax.open.ac.uk URL: http://www-icdl.open.ac.uk 


\section{Glossário*}

Alunos off-campus - alunos que estão participando de um curso à distância fora do local em que está sendo ministrado.

Alunos on-campus - alunos que estão participando de um curso no mesmo local em que está sendo oferecido.

Âncora - tipo de ligação hipertexto em documentos da WWW. Ao "clicar" sobre uma âncora, o usuário “salta” para outro ponto do mesmo documento ou para qualquer outro documento que esteja disponível na WWW.

BBS (Bulletin Board System - Sistema de Quadro de Avisos) - serviço eletrônico que oferece recursos, como: correio eletrônico (e-mail), acesso a outros computadores e serviços remotos, meios de oferecer e receber arquivos. Nos BBS's privados, o usuário paga uma taxa mensal para ter direito a acessar o sistema de troca de arquivos, participação em grupos de discussão ou de diálogo on-line, etc.

Bitnet (Because It's Time Network - Porque é tempo de rede) - nome de uma rede acadêmica e de pesquisa iniciada em 1981 e operada pela Educom.

Bps (bits per second - bits por segundo) - é uma unidade usada para medir a velocidade de transmissão de dados digitais. Por exemplo, um modem cuja velocidade é 28.800 bps, transmite 28.800 bits a cada segundo.

Browser (navegador) - programa utilizado para visualizar as páginas na WWW. Com o endereço de um site, o browser recebe as informações disponíveis no site e as

\footnotetext{
* Palavras grifadas estão em verbete próprio.
} 
interpreta, exibindo na tela do computador do usuário imagens, textos, sons, animações, etc.

Caminho do documento (path) - diretório onde se encontra um documento.

CD-ROM (Compact Disc Read Only Memory) - Disco óptico com alta capacidade de armazenamento de arquivos.

CGI (Common Gateway Interface) - é uma interface definida de maneira a possibilitar a execução de programas (cgi-bins) sob um servidor de informações. Exemplos de aplicação de CGI incluem: •processamento de dados submetidos através de formulários - consulta a banco de dados, cadastramento em listas, livros de visita, pesquisas de opinião; •criação de documentos personalizados; •gerenciamento de contadores de acesso; •processamento de mapas.

Cgi-bins - são programas ou scripts que recebem requisições de informação, retornando um documento com os resultados correspondentes. Esse documento pode existir previamente, ou pode ser gerado pelo script especialmente para atender à requisição. Tais scripts podem ser escritos em qualquer linguagem de programação: a) C, Perl, ou shell de UNIX, em redes de ambiente UNIX, b) C, Perl, ou VB Script, em ambiente Windows.

Chat - permite que vários usuários se comuniquem em tempo real através da Internet.

Chaveamento de pacotes - é um esquema para transmissão em rede de computadores no qual as informações são subdivididas em pequenos pacotes que contêm trechos dos dados, o endereço do destinatário e informações que permitam a remontagem da mensagem original.

Client/Server, Cliente/Servidor - arquitetura de interconexão de computadores, na qual existe um computador central (o servidor) que libera (ou não) acesso a computadores a ele ligados (os clientes).

Documento - na Internet, é um arquivo HTML ou página da WWW. 
Domínio (Domain) - O domínio identifica o computador e a organização onde o documento se encontra. As partes do domínio separadas por "pontos” representam “subdomínios”. Por exemplo: caviar.igce.unesp.br significa: computador de nome “caviar” localizado no IGCE - Instituto de Geociências e Ciências Exatas da UNESP - Universidade Estadual Paulista, Brasil.

Download - processo no qual o usuário, conectado a uma rede, transfere arquivos dela para seu computador através de modem e programa específico.

Editor ou ferramenta de edição - programa usado para criar, editar e gravar documentos quaisquer (textos, imagens, vídeos, sons).

E-mail (eletronic mail - correio eletrônico) - é um serviço da Internet que permite a troca de mensagens escritas, às quais podem ser anexadas imagens, vídeos, documentos ou qualquer outro tipo de arquivo.

Endereço IP - número especialmente desenvolvido para acessar um computador na Internet.

Frames/s. (quadros por segundo) - medida de transmissão de vídeo.

FTP (File Transfer Protocol) - é um dos protocolos mais populares, pois funciona como padrão para a transferência de arquivos na Internet;

Gif (Graphics Interchange Format) - formato compactado de codificação de imagens. Desenvolvido pela CompuServe para transmissão de imagens por linhas discadas. As imagens (ícones, ilustrações, dentre outras apresentadas nas páginas WWW) que seguem este formato são armazenadas em arquivos de extensão gif. $O$ termo "gifs animados” é atribuído a uma seqüência destas imagens, as quais podem formar uma animação.

Gopher - sistema não-gráfico de navegação na Internet, no qual o usuário vê menus que indicam arquivos disponíveis em diferentes computadores da rede.

Hipermídia - é a união das propriedades do hipertexto às da multimídia. São aplicações multimídia que possuem ligações de hipertexto entre as diversas mídias, 
como textos, gráficos, figuras, sons, vídeos e animações. Estas mídias relacionam-se via links.

Hipertexto - é uma estrutura não linear de ligação de várias informações (textos, imagens), possibilitando o usuário seguir diferentes caminhos de leitura de documentos. Os documentos são apresentados com palavras em destaque; estas palavras representam as ligações com outros documentos.

Home page - página de apresentação. A primeira página que o usuário vê ao entrar em determinado endereço na WWW.

Hytelnet - banco de dados sempre atualizado, que fornece informações sobre localidades Telnet específicas e ajuda a conectá-las.

Interface - elo de comunicação e interação entre computador e o usuário.

Java - Linguagem de programação utilizada para criar interatividade em páginas disponíveis na WWW. Permite a criação de programas independentes de plataformas, ou seja, podem ser executados em qualquer computador ou sistema operacional.

Layout - forma como textos, imagens e títulos são dispostos visualmente em uma página.

Link (elo de ligação) - ponto de ligação entre partes diferentes de um hipertexto ou entre hipertextos. Ponto de um texto ou imagem, através do qual o usuário "salta” para outra fonte de informação relacionada (texto, imagem, animação). É a ferramenta essencial de navegação entre documentos.

Modem (MOdulador/DEModulador) - é um dispositivo que converte os sinais digitais gerados pelo computador em sinais analógicos e vice-versa. Permite a transmissão de informações entre computadores através de linhas telefônicas. Os modems comerciais de hoje permitem velocidades de até 33.600 bps ou 33,6 Kbps (quilobits por segundo) 
Newsgroup ou grupo de discussão - área da Usenet dedicada à troca de mensagens sobre um assunto determinado. O grupo pode ou não ter um moderador (pessoa encarregada de mediar as mensagens). O mecanismo básico é: qualquer integrante do grupo pode mandar mensagens para o centro e todas elas são despachadas periodicamente para todos os integrantes do grupo. Quando há um moderador, este lê todas as mensagens enviadas para o centro, filtra as mais apropriadas e as despacha para os integrantes.

On-line - termo designado ao estado de um computador quando este está conectado a uma rede, seja via modem, seja via placa de rede.

Plataforma - é a combinação de um sistema operacional mais o equipamento, ou o hardware no qual esse sistema é executado.

PPP (Point to Point Protocol) - é um protocolo usado na comunicação entre dois computadores via modem e linha telefônica.

Protocolo - conjunto de regras e procedimentos para transmissão de dados entre dispositivos ligados em rede.

Provedor de acesso - uma empresa que presta serviço de acesso à Internet e cobra uma assinatura mensal. Junto com assinatura, o usuário recebe seu endereço na rede, sua senha de acesso e geralmente um pacote de softwares com as instruções de instalação e manuais.

Realidade Virtual - simulação digital de um ambiente real.

Script - descrição de uma tarefa complexa ou de uma série de tarefas usando uma determinada linguagem. O script permite que o procedimento nele descrito seja executado automaticamente.

Server, Servidor - termo genérico que designa o computador considerado central em algum processo. Portanto, existem os servidores de impressão (computadores que gerenciam a impressão em uma rede), servidores de mensagens (que gerenciam as mensagens enviadas e recebidas por componentes da rede), etc. 
Site (localidade) - é qualquer endereço na Internet. Por exemplo, o site do Instituto de Física da USP de São Carlos tem o endereço http://www.ifqsc.sc.usp.br

SLIP (Serial Line Internet Protocol) - outro protocolo utilizado na conexão entre dois computadores via modem e linha telefônica.

Software de domínio público - software que pode ser usado por qualquer um, sem necessidade de remuneração ao autor.

Tags (marcações ou marcadores) - códigos de formatação de texto usados em documentos HTML da WWW.

TCP/IP (Transmission Control Protocol/Internet Protocol) - protocolos básicos de comunicação da Internet, para interconectar redes cujos componentes usam sistemas operacionais distintos. Foram desenvolvidos nos EUA no final dos anos 70. O TCP controla a transferência de dados e o IP propor1ciona o roteamento (processo pelo qual um sistema em rede determina qual o caminho mais conveniente para um pacote de dados transitar entre computadores).

Telnet - protocolo usado na Internet para permitir que um computador acesse outro e nele execute programas.

URL (Uniform Resource Locator) - padronização da localização ou dos detalhes de endereçamento dos recursos da Internet.

Usenet (USEr NETwork ou rede de usuários) - grupo de sistemas de acesso público na Internet que permitem troca de mensagens, estruturação de grupos de discussão, etc.

UUCP (Unix-to-Unix CoPy) - pacote de programas para transferir arquivos através de serial line, escalonar estas transferências e iniciar a execução de programas em sites remotos.

VRML (Virtual Reality Modelling Language) - linguagem de programação que estende a capacidade do HTML, permitindo construir ambientes 3D interativos na WWW. 
WAIS (Wide Area Information Service) - sistema utilizado para localização de informações em bancos de dados disponíveis na Internet.

\section{Referências do Glossário}

HELP! INFORMÁTICA, Klick Editora, O Estado de S. Paulo, 1996.

INFORMÁTICA EXAME, v.10, n.116, p.82, novembro 1995.

INTERNET WORLD, v.1, n.2, p.109, outubro 1995.

INTERNET WORLD, v.1, n.8, p.104-108, abril 1996.

NOVO DICIONÁRIO FOLHA WEBSTER’S, São Paulo, 1996 